\title{
ESSAYS IN POLICY EVALUATION AND
}

LABOR ECONOMICS

A Dissertation
presented to
the Faculty of the Graduate School
at the University of Missouri-Columbia
In Partial Fulfillment
of the Requirements for the Degree
Doctor of Philosophy
Dr. Peter Mueser, Dissertation Supervisor

MAY 2021 
The undersigned, appointed by the dean of the Graduate School, have examined the dissertation entitled

ESSAYS IN POLICY EVALUATION AND LABOR ECONOMICS

presented by Zhiyang You

a candidate for the degree of doctor of philosophy

and hereby certify that, in their opinion, it is worthy of acceptance.

Professor Peter Mueser

Professor Cory Koedel

Professor David Kaplan

Professor Jonathan Krieckhaus 


\section{ACKNOWLEDGEMENTS}

I would like to thank my academic advisor, Dr. Peter Mueser, for being the most inspiring and kind person that I have ever met. I would like to thank my

committee members, Dr. Cory Koedel, Dr. David Kaplan, and Dr. Jonathan Krieckhaus for their great support for my dissertation. I would also like to thank Mr. David Black and Dr. Peter Williams for enlightening me with the joy of Economics. 


\section{TABLE OF CONTENTS}

ACKNOWLEDGEMENTS .ii

List of Tables vi

List of Figures ..vii

Abstract Error! Bookmark not defined.

Chapter 1 1

1.1 Introduction 1

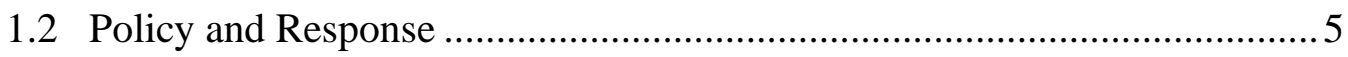

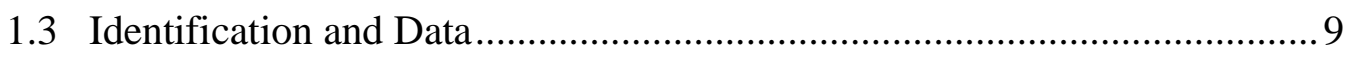

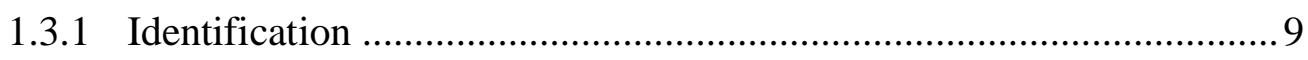

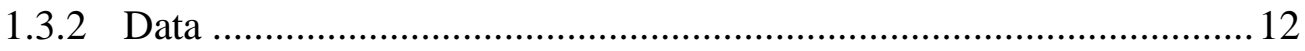

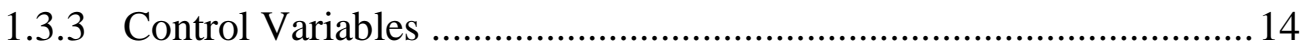

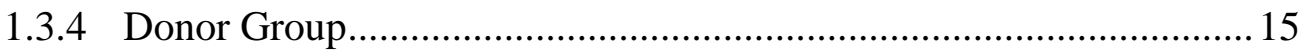

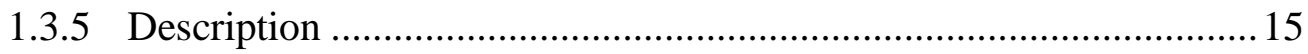

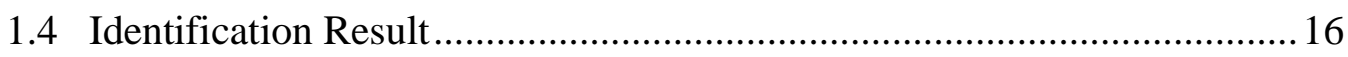

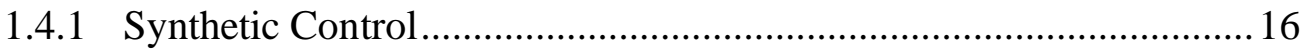

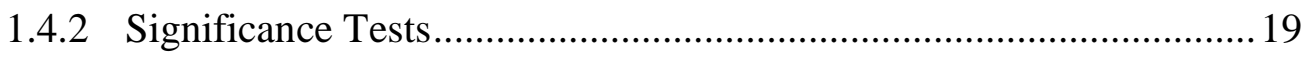

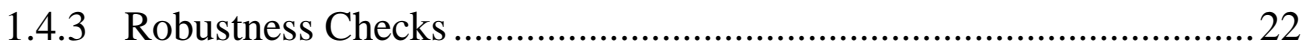

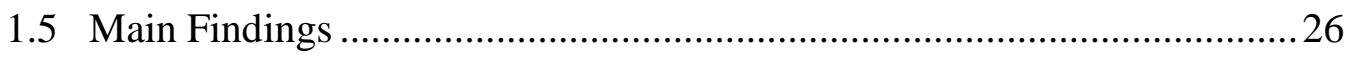

1.5.1 Similar Legislation in Connecticut and Maryland...........................2 27

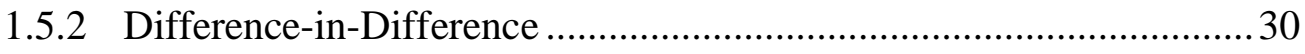

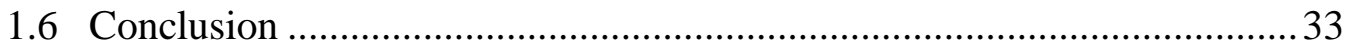




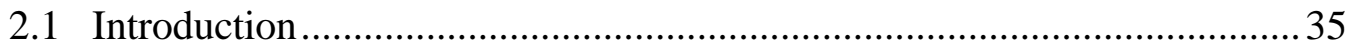

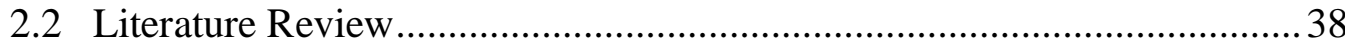

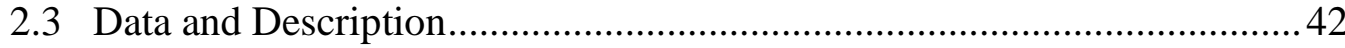

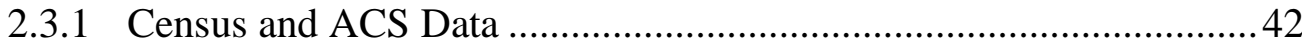

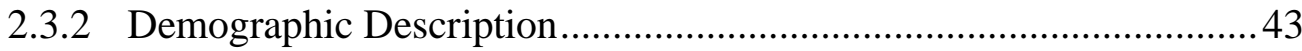

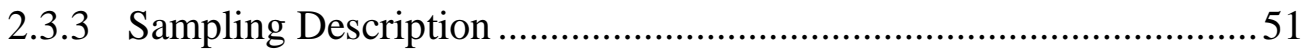

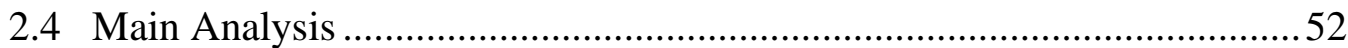

2.4.1 Conventional Regression Model Using Cross-Sectional Data ...........52

2.4.2 Estimating Assimilation with Panel Data.........................................55

2.4.3 Controlling for Observed Characteristics ......................................57

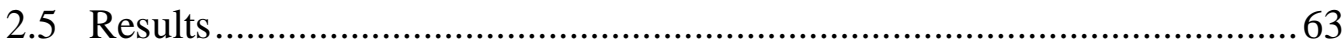

2.5.1 Conventional Estimates of Assimilation .........................................63

2.5.2 The Nonparametric Method Controlling for Observed Characteristics 65

2.5.3 Revisiting Conventional Model........................................................ 74

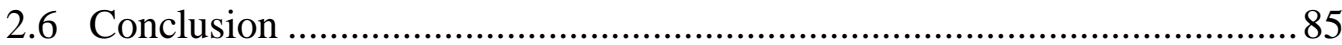

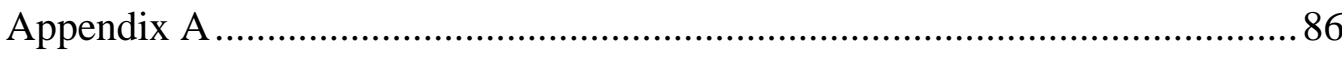

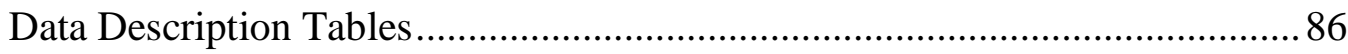

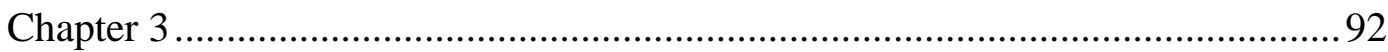

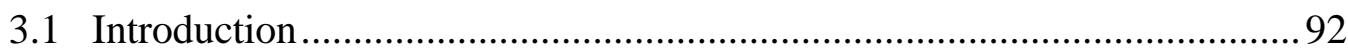

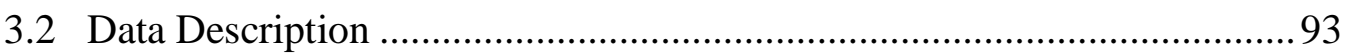




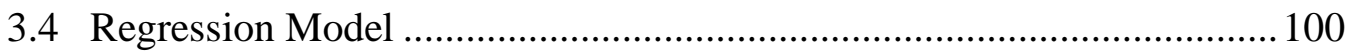

3.5 Testing Hypotheses Behind the 10-year Puzzle...................................... 105

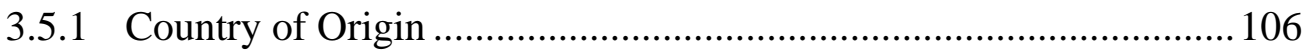

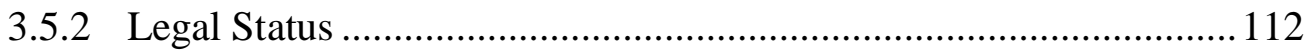

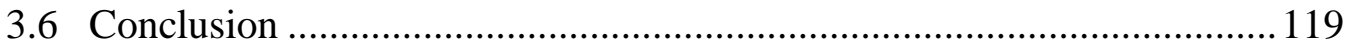

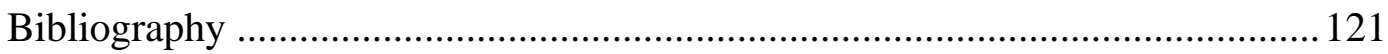

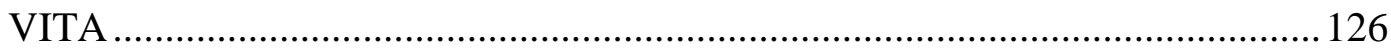




\section{List of Tables}

Table 1-1 Synthetic Control Weight 16

Table 1-2 Control Variable Difference Between Synthetic Unit, California, and

Other Control Groups

Table 1-3 Background Check Rank Statistics .................................................23

Table 1-4 Weight Selection from Multiple Method ….........................................25

Table 1-5 Difference-in-Difference Result with Trend Tests ............................... 32

Table 2-1 Population Size of Each Cohort by Year (in millions) ...........................45

Table 2-2 Selected Race Composition of Each Cohort by Year...........................4 47

Table 2-3 Education Composition by Cohort and Year...................................... 48

Table 2-4 Age Composition of Natives and Immigrants by Cohort and Year ......51

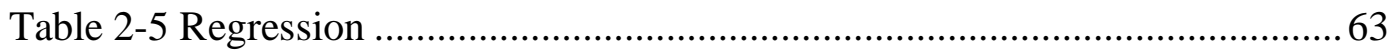

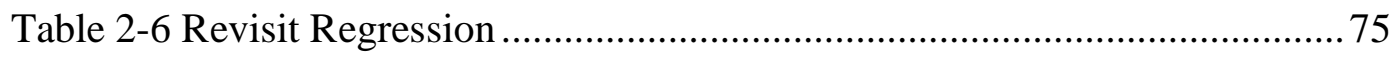

Table 2-7 Estimated Assimilation by Age of Arrival ....................................... 80

Table 2-8 Assimilation by Country of Origin ................................................. 84

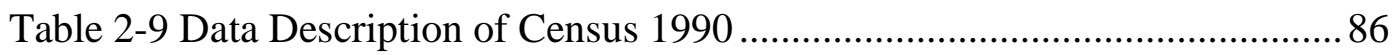

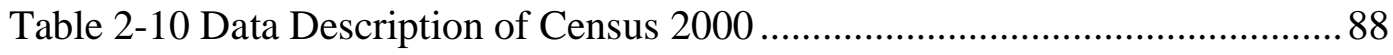

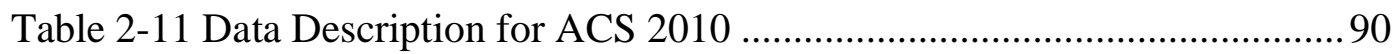

Table 3-1 Population Estimates Decomposition ................................................96

Table 3-2 Linear Regression of Cohort Size Trend ........................................ 101

Table 3-3 Cohort Size by Year Since Migration ............................................ 104

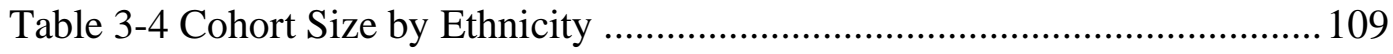

Table 3-5 The 10-Year Puzzle by Hispanic Group............................................. 112

Table 3-6 Cohort Size by Immigration Status .............................................. 117

Table 3-7 Cohort Size of Naturalized Immigrants ............................................ 119 


\section{List of Figures}

Figure 1-1 Background Check of California from 2006 to 2017. 8

Figure 1-2 Background Check of California, Synthetic Unit, Donor States Average

and U.S. Average

Figure 1-3 Causal Effect of the Bullet Button Ban....

Figure 1-4 Placebo Tests by Mean Square Prediction Error. 21

Figure 1-5 Post-Treatment to Pre-Treatment MSPE Ratio 22

Figure 1-6 Difference between the Background Checks of California and Synthetic

California

Figure 1-7 Synthetic Control for Connecticut and Maryland

Figure 2-1 Earnings Distribution by Immigrant Cohorts Compared to Natives.... 67

Figure 2-2 Difference in Earnings Distribution Between Immigrant Cohorts and Natives 68

Figure 2-3 Difference in Earnings distribution Between Immigrant Cohorts and Natives After Modification 69

Figure 2-4 Adding Control Variables to Distribution Adjustment Method..... 71

Figure 2-5 Adjusted Earning Distribution by Cohort in Different Years .73

Figure 2-6 Estimated Assimilation using Different Models .76

Figure 2-7 Estimated Assimilation by Age of Arrival. 81

Figure 2-8 Estimated Assimilation by Country of Origin 82

Figure 3-1 Cohort Population Estimation using ACS and IPUMS. 96

Figure 3-2 Cohort Size by Year Since Migration .98

Figure 3-3 Component Plus Residual Graph 102

Figure 3-4 Estimated Year Since Migration Fixed Effect with Confidence Interval 
Figure 3-5 Population Estimates Program Immigrants Group for Emigration

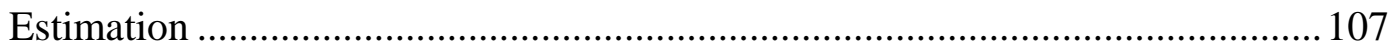

Figure 3-6 Year Since Migration Fixed Effect by Race Group ......................... 111

Figure 3-7 The $10^{\text {th }}$ Year Population Growth with Population Arrived with Green Cards by Year of Arrival.................................................................................... 116 


\title{
ESSAYS IN POLICY EVALUATION \\ AND LABOR ECONOMICS \\ Zhiyang You \\ Dr. Peter Mueser, Dissertation Supervisor
}

\begin{abstract}
This dissertation contains three chapters. The first chapter evaluates the effect of a gun control act in California. State legislators in the U.S. are striving to curb gun violence. A common approach is to extend the existing firearms ban list. This paper examines the effect of legislation restricting sales of selected firearms in California using the synthetic control method. This case study method forms a synthetic unit using a linear combination of other states in the U.S. as the control group. The results show substantial increases in firearm sales in California from the point of passage until the law becomes effective. After the surge ends when the law becomes effective, the sale of firearms is only moderately affected thereafter. This paper also creates robustness checks to confirm that the synthetic control method is working properly with low firearm density in California, which calls into question some of the assumptions underlying the synthetic control method. The Differencein-Difference regression reaches the same conclusion.
\end{abstract}

The second chapter focuses on immigrant assimilation in the U.S. Assimilation is the process in which immigrants improve earnings as they become more adapted to the host country society. Cross-sectional studies show that immigrants have lower earnings upon arrival and faster earnings growth compared to natives. Longitudinal studies conclude that estimates based on cross-sectional data are positively biased due to decreasing cohort quality and negatively selected outmigration. I reproduce such estimates with recent U.S. data. The estimates would 
appear to show "bias," as inclusion of cohort fixed effects alter estimates. However, in contrast to expectations based on the current literature, decreasing cohort quality and outmigration do not explain the difference. Next, I apply a non-parametric method to make the wage distributions visually comparable across cohorts and time. I find that the linear specification of assimilation is misleading. Finally, I revisit the classic model with a quadratic assimilation term and expand it to explore the assimilation process's heterogeneity. I find that the "bias" disappears with a quadratic assimilation effect. The assimilation effect is sensitive to age at arrival and country of origin.

The third chapter considers an unexplained puzzle in one of the most widely used public datasets in the U.S. The American Community Survey (ACS) replaced the Decennial Census as the primary data source for identifying immigrants' socioeconomic characteristics. This paper focuses on cohort analysis, in which a cohort combines immigrants arriving in a given year from surveys in multiple years. Tracking the sizes of cohorts from 2006 to 2019 using the ACS, we observe an abnormal increase in cohort size in the $10^{\text {th }}$ and $20^{\text {th }}$ years since arrival. Two hypotheses are tested, population estimate structural break and the renewal of green card. Neither appears to explain the puzzle. 


\section{Chapter 1}

\section{Gun Control News Effect on Firearm Sales}

\subsection{Introduction}

The Second Amendment to the U.S. Constitution protects "the right of the people to keep and bear arms." Throughout the history of the U.S., the interpretation of the Second Amendment remains controversial. Both federal- and state-level legislators have attempted to address gun violence with laws and regulations, and to clarify the boundary of gun rights. Unfortunately, despite extensive media coverage of gun violence and related legislation, few economists have studied these policies. As a result, many policies are neither data-based nor empirically verified.

Among the limited number of studies, economists, social scientists, and policymakers are interested in the effect of gun control on social benefits in the U.S. Cook and Ludwig $(2000,2001,2006)$ find that interpersonal gun violence is responsible for annual losses of $\$ 100$ billion in the 1990s. They observe that gun violence declined from the mid-1990s to the 2000s.

There have been some studies attempting to determine if gun control legislation was responsible for the reduction in gun violence, many exploiting the variance of the "stringency" of gun control regulations across different states or counties. For example, Raissian (2016) uses variation in court interpretations of the Gun Control Act (GCA) expansion in different states and under different circuits to identify the effect of firearm restrictions in a difference-in-difference analysis. She finds the expansion of the federal GCA, which prohibited those convicted of felonies and violent misdemeanors from possessing and purchasing firearms, reduces homicides of their female intimate partners and children. 
Knight (2013) uses two indexes to measure the stringency of gun control in a state. Both indexes are built upon a checklist of restrictions enforced by a state. The results show a flow of guns from states with weak gun control laws to states with stringent laws, indicating cross-state externalities. However, the arbitrarily chosen checklist may be questioned, as it is not clear whether stringencies of gun laws are equivalent between two states when their index scores are equal.

Some studies debate whether firearm ownership is beneficial to the society. John Lott (1998), in his book, More Guns, Less Crime, states that an armed public deters crime. He argues that the stock of firearms held by the public has deterrent value by raising the potential cost of crime. Gun controls will weaken the deterrence effect by limiting the number of firearms in the market. In his research, Lott exploits the variance of adopting right-to-carry laws, by which individuals are permitted to carry concealed handguns. He finds that rates of multiple violent crimes decrease following the passage of the law. He also finds that non-violent crimes, such as auto theft and larceny, occur more often when people become more likely to carry handguns. In contrast, Duggan (2001) finds no statistically significant effect of right-to-carry laws on the frequency of violent crimes in his book, More Guns, More Crime. Ayres and Donohue (2002) demurs Lott's findings by merging Lott's estimation models into a hybrid model. Both Ayres and Donohue (2003) and Plassmann and Whitley (2003) find that there is not enough evidence to conclude that there is a deterrence effect when using corrected and extended data. Both Black and Nagin (1998) and Plassmann and Tideman (2001) expand the analysis to the state level. Only a few states have experienced declines in crime rates following the adoption of right-to-carry laws. Most state-level estimates are not statistically significant. The National Research Council (2005) conducts a critical review on Lott's research by replicating the analysis with 
Lott's revised data and with more recent data. The replication successfully reproduced most of Lott's results. The question remains open.

Those who study firearm legislation often assume strict gun control has negative effects on the number of firearms in the market. Fewer firearms then lead to positive, negative, or mixed effect on crime rates. The assumption appears to be reasonable but is never tested. Knight's research (2013) shows the demand may still be fulfilled through illegal firearm trafficking across states when gun control is tight in one state but not in surrounding states.

This paper questions the assumption that more stringent gun control legislation always reduces the number of firearms in the market. Customers may buy more firearms, when given a legal grace period prior to implementation of an upcoming restriction. My results agree with Knight's findings by indicating ways in which limitations applied to firearm transactions may be evaded.

Cook and Ludwig (2006) separate gun control policies into two categories. Demand-side policies focus on deterring firearm owners from misusing their weapons by increasing the punishment for using firearms in criminal assaults. For example, committing the same type of crime with or without firearms leads to different consequences. The supply-side policies restrict transactions, possessions, and carrying of certain kinds of firearms. For example, many universities prohibit people from carrying weapons on campus; some states keep assault weapon lists identifying prohibited weapons. Cook and Ludwig find that supply-side policies are more effective in reducing the homicide rate.

As Cunha, Heckman and Navarro (2005) stated, "Although economic policy analysis should be grounded in data, it is important to recognize that those policies that 
can be evaluated empirically are only a small subset of the policies that might be tried." Fortunately, data regarding the willingness of people to purchase new firearms are available because of the Brady Handgun Violence Prevention Act (enacted November 30, 1993), which led to the implementation of the mandated background checks on firearm purchasers in the U.S.

The empirical justification for the existence and the extension of the assault weapon ban is based on Zimring's studies (Zimring 1968, 1972), in which he finds the weapon type had an important effect on the extent of the damage inflicted for a particular incident. In particular, he found that the shooting speed, reloading speed, magazine capacity, and many other characteristics can affect the extent of causalities in criminal cases. A recent article in the Washington Post (Berkowitz and Alcantara 2020) summarizes mass shootings since 1966 . The deadliest shootings are more common in recent years. The article argues that shooters learned from earlier attackers' experience and planned their attacks with more powerful weapons, larger crowds, and even use strategies that prevented victims from evacuating. Banning selected firearms is intended to limit the damage criminals can cause.

There is an important limitation to state-level firearm sales injunctions. People can buy and sell second-hand firearms through the secondary market. In fact, 30 to 40 percent of all firearm transfers do not involve licensed dealers (Cook, Molliconi and Cole 1995), and these transactions account for most firearms used in crimes (Cook and Ludwig 2006). An important source of firearms used for crimes is stolen firearms sold in the secondary market. Over 500,000 firearms are stolen each year in the U.S. (Cook and Ludwig 1997, Hess, Blairy and Kleck 1997) There is a close connection between the primary and secondary firearm market as mentioned by Cook and Leitzel (1996) "If regulation or enforcement could reduce the flow of guns from primary to secondary 
market, standard economic analysis suggests that the resulting decline in supply would increase the price of guns in secondary markets. Diverting high-risk buyers from the primary to the secondary market would further increase prices in the latter by increasing demand." As a result, it is crucial to evaluate how legislation affects the firearm market because an increase in firearms flow today could produce a supply shock in the secondary market in the future.

This paper estimates on the direct effect of the news about expanding California's firearms-ban list on the sales of firearms using the synthetic control method. I find that there is an increase in firearm sales during the grace period between the passage and the effective date of a firearm restriction. Leaving a grace period substantially weakens the law's power to limit the number of firearms in the market. The result is further verified by considering two other states (Connecticut and Maryland) that passed similar regulations - one with a grace period and one without a grace period. The result is robust across alternative models using difference-in-difference methods. The analysis of Connecticut shows that if there is no grace period, there is no increase in firearm sales. Although it may limit the types of weapons in the market, the law does not appear to affect the overall sales of firearms after the effective date.

\subsection{Policy and Response}

The Second Amendment of the U.S. Constitution says,

"A well regulated Militia, being necessary to the security of a free State, the right of the people to keep and bear Arms, shall not be infringed."

This amendment was adopted on December 15, 1791 in the Bill of Rights. The interpretation of the Second Amendment has never been coherent in the U.S., sparking 
many lawsuits. ${ }^{1}$ While few advocate abolishing the right to own firearms, most Americans believe in the need for limitations.

The Second Amendment does not indicate what kinds of restrictions are acceptable and what types of weapons are protected. Seven states maintain lists of prohibited firearms that parallel the Federal Assault Weapon Ban, which prohibited the manufacture, transfer, or possession of assault weapons. The federal injunction, which was in effect from 1994 to 2004, was not renewed when it expired under a sunset provision, whereas state-level legislation remained active. Some states extended their ban lists in response to catastrophic attacks. Firearm sellers, conservatives, and firearm organizations often argue their rights have been violated when more models become illegal. They challenge these gun control acts as unconstitutional. A series of Supreme Court rulings have affirmed both the jurisdiction of a state to implement gun control within its boundaries, and the individual's right to own firearms. In 1989, California passed the Roberti-Roos Assault Weapons Control Act (AWCA), which banned the ownership and the transfer of over fifty brands of semi-automatic firearms classified as assault weapons.

The AWCA was associated with an immediate decrease in sales of many rifles, for example, the famous AK-47 and the Colt AR-15. To recover from the revenue loss, firearm manufacturers redesigned prohibited rifles to satisfy new rules. At the same time, manufacturers strived to maintain functions of banned models. For example, firearms banned by the AWCA had magazines that could be easily detached by pushing a button. Lawmakers argued this design should be banned on powerful weapons since it allowed shooters to reload quickly in the shooting position, but provided minimal

\footnotetext{
${ }^{1}$ For example, U.S. vs. Miller (1939), District of Columbia vs. Heller (2008), McDonald vs.
} Chicago (2010). 
benefits in legal activities, such as recreational range shooting, hunting, or self-defense. Firearm manufacturers redesigned the magazine release button in 2007 so that the magazine would not release without a thin, hard object pushing a button hidden in a small hole. This design was called a bullet button, since a bullet was the most common tool used to release the magazine. In common with other states with similar bans, California permitted sales of rifles with bullet buttons, even though these rifles remained the same in other respects.

The introduction of the bullet button boosted the sales of rifles by bringing popular models back to California's firearm market. Shooters continued to use semiautomatic weapons in attacks, since the bullet button design only weakened these firearms mildly. Firearms like AR-15s were used as primary weapons in mass shootings like the 2015 San Bernardino attack resulting in 16 deaths. In some cases, police found that weapons used in these attacks were illegally modified with bullet buttons uninstalled or bypassed. After the San Bernardino attack, California lawmakers proposed to expand the weapon ban list to include semi-automatic rifles with the bullet button. The bullet button ban was passed on July 1st, 2016 and took effect on January 1st, 2017 with a six-month grace period. During this grace period, people could purchase, trade, or transfer semi-automatic rifles without any new restrictions. All affected weapons were required to be registered before the ban became effective. Any sale or transfer within the state of California became illegal after the effective date.

After passing the law in July 2016, California background checks increased rapidly to its historical high that December. This paper uses the number of background checks to proxy the number of firearm transactions. Figure 1-1 shows the monthly background check applications for long gun purchases increased to more than 2.3 applications per 1,000 people in California in December 2016 (about 90,275 requests 
for buying one or more firearms that month). The numbers of background checks in each month in 2016 after passage of the law were greater than in prior years.

Figure 1-1 Background Check of California from 2006 to 2017

Long Gun Background Check for California from 2006-2017

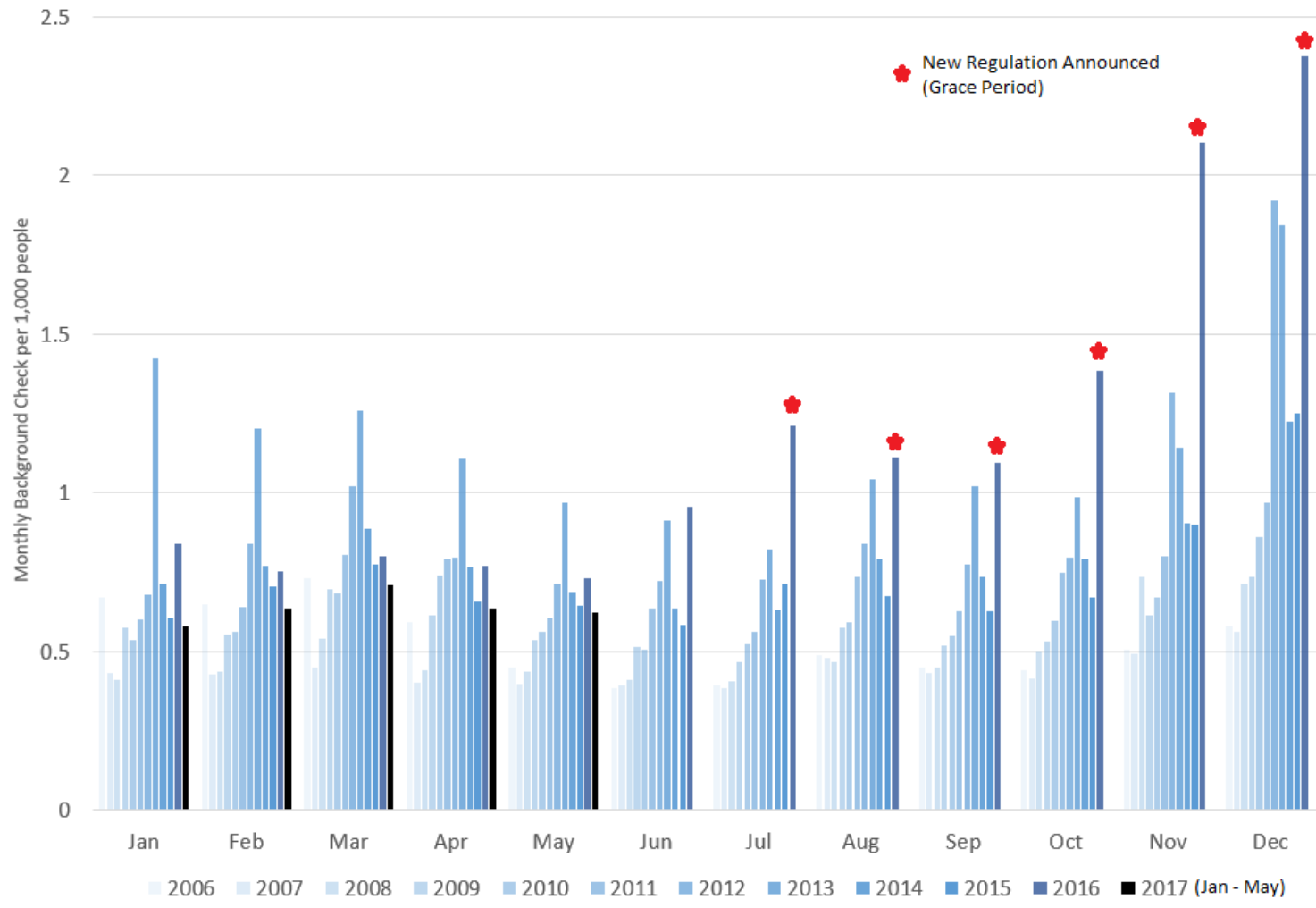

Nonetheless, the effects of the ban are not clear from Figure 1-1 since there is a long-term increasing trend in gun sales in the decade prior to passage of this legislation and a seasonal increase in gun sales at the end of each year. Figure 1-2 shows that there are similar surges nationally, whereas no other states pass similar legislation in the same period. I am going to identify the proportion of the increase that is caused by the legislation. If people do respond by buying more semi-automatic rifles, many buyers of these rifles may not be planning to use them in activities like hunting or range shooting. Their responses simply reflect the value of keeping the option of using a semi-automatic rifle available. When the realized value of having a firearm is not as high as expected, these buyers may sell their rifles sometime in the future. Since the bullet button ban forbids future trade of these weapons within California, the resale is more likely to be 
off the radar. Harlow (2002) finds that about $80 \%$ of firearms used by criminals are obtained from private transactions. As a result, selling weapons to people who are unlikely to use them may be problematic in the long run if those firearms ultimately find their ways to black or grey markets.

Figure 1-2 Background Check of California, Synthetic Unit, Donor States Average and U.S. Average

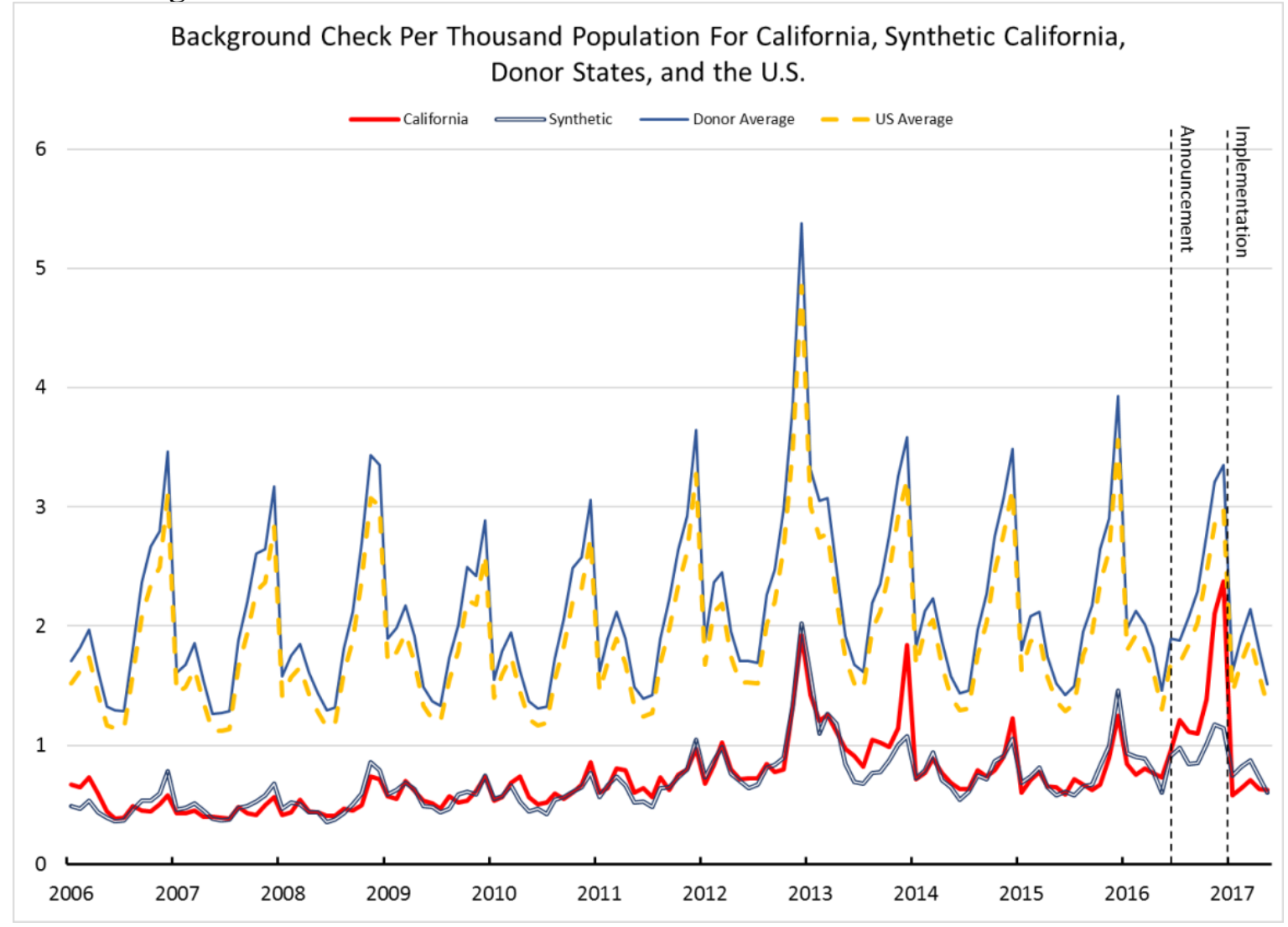

\subsection{Identification and Data}

\subsubsection{Identification}

The primary goal of this paper is to estimate the effect of California's bullet button ban on firearm sales. The effect is separated into two sub-effects by time - the news effect during the grace period, and the implementation effect after the ban is in place. As the treatment applies to a single state, I use synthetic control method, which is designed to handle a single treated unit with aggregate data. 
The synthetic control method is a case study method developed by Abadie, Diamond and Hainmueller (2010). In their research about a tobacco control program in California, they use a linear combination of control states to match the per capita tobacco consumption in California before the treatment is implemented The combination, known as the synthetic unit, predicts what would have happened in the absence of the program.

Comparative research often deals with aggregated data. Forming a good comparison unit with large-sample quantitative methods is important for policy evaluation. The synthetic control method provides a compelling and data-driven way to choose the comparison unit for comparative studies with extensive pre-treatment data.

The underlying model follows from Abadie, Diamond and Hainmueller (2010). Suppose there are $J+1$ observable states, the treated group is state 1 , and states $i=$ $2, \ldots, J+1$ form the donor pool. The donor pool is the set of states that are available for forming the control group for the treated state. States in the donor pool cannot receive any treatment that is similar to what the treated state implements at $T_{0}$ through the entire time span, $t=1, \ldots, T$. The pre-treatment periods are from $t=1, \ldots, T_{0}$, and post-treatment periods are from $t=T_{0}+1, \ldots, T$. Let $Y_{i t}^{N}$ be the outcome variable of state $i$ at time $t$ without treatment. $Y_{i t}^{I}$ is the outcome for state $i$ at time $t$ with the treatment.

The effect of interest is $\alpha_{1 t}=Y_{i t}^{I}-Y_{i t}^{N}, t>T_{0}$ which is the difference between the treated outcome and the untreated outcome of state 1 . Since only one of the outcomes can be observed at any $t$, the counter-factual, $Y_{i t}^{N}$ for $t>T_{0}$, must be estimated. An underlying factor model is assumed as,

$$
Y_{i t}^{N}=\delta_{t}+\boldsymbol{\theta}_{t} \boldsymbol{Z}_{i}+\boldsymbol{\lambda}_{t} \boldsymbol{\mu}_{\boldsymbol{i}}+\epsilon_{i t}
$$


where $\delta_{t}$ is an unknown common factor for all units, $\boldsymbol{Z}_{\boldsymbol{i}}$ is a $(r \times 1)$ vector of observable control variable not depending on time. $\boldsymbol{\theta}_{\boldsymbol{t}}$ is a $(1 \times r)$ vector of unknown parameters and $\lambda_{t}$ is a $(1 \times m)$ vector of the unobserved factors, both of which vary by time only. $\boldsymbol{\mu}_{\boldsymbol{i}}$ is a $(m \times 1)$ vector of unmeasured factors that vary by state. $\epsilon_{i t}$ is a mean zero individual transitory shock.

Consider assigning weights to states in the donor group, $\boldsymbol{W}=\left(w_{2}, \ldots, w_{J+1}\right)^{\prime}$ such that $w_{j} \geq 0$ for $j=2, \ldots, J+1$ and $w_{2}+\cdots+w_{J+1}=1$. Thus,

$$
\sum_{j=2}^{J+1} w_{j} Y_{j t}=\delta_{t}+\boldsymbol{\theta}_{\boldsymbol{t}} \sum_{j=2}^{J+1} w_{j} \boldsymbol{Z}_{\boldsymbol{i}}+\boldsymbol{\lambda}_{\boldsymbol{t}} \sum_{j=2}^{J+1} w_{j} \boldsymbol{\mu}_{\boldsymbol{i}}+\sum_{j=2}^{J+1} w_{j} \epsilon_{i t}
$$

Assume there exists $\boldsymbol{W}^{*}=\left(w_{2}^{*}, \ldots, w_{J+1}^{*}\right)$ that makes following equations hold,

$$
\sum_{j=2}^{J+1} w_{j}^{*} Y_{j t}=Y_{1 t} \text { for } t=1, \ldots, T_{0} \text { and } \sum_{j=2}^{J+1} w_{j}^{*} Z_{j}=Z_{1}
$$

Notice equation (1.2)| shows a linear combination of donors that is able to replicate the treated unit in the pre-treatment period. This combination is the synthetic unit. The treated unit can be compared with its synthetic unit in the post-treatment period,

$$
\hat{\alpha}_{i t}=Y_{1 t}-\sum_{j=2}^{J+1} w_{j}^{*} Y_{j t}, \text { when } t>T_{0}
$$

In practice, a set of weights that makes equation (1.2) holds often does not exist. We consider the set of weights that minimizes the difference between the treated unit and the control unit. To get this set of weights, let $\boldsymbol{X}_{1}$ be a $(k \times 1)$ vector that contains characteristics of the treated unit in the pre-treatment period, and let $\boldsymbol{X}_{\mathbf{0}}$ be a $(k \times J)$ matrix that contains characteristics of the donor group units in the pre-treatment period. 
The standard way to select $\boldsymbol{X}$ is to combine $\boldsymbol{Y}$ and $\boldsymbol{Z}, \boldsymbol{X}=[\boldsymbol{Y} ; \boldsymbol{Z}]^{2}, k=T_{0}+r$. Abadie et al. (2010) suggests using some linear combinations of $\boldsymbol{Y}$ when forming $\boldsymbol{X}$ to save calculation time (e.g., using annual averages rather than monthly values). Solving for $J$ weights with estimator $\boldsymbol{X}$ involves two layers of minimization problem. First, $\boldsymbol{W}^{*}=$ $\left(w_{2}^{*}, \ldots, w_{J+1}^{*}\right)$ is selected in the first layer by minimize $\left\|\boldsymbol{X}_{1}-\boldsymbol{X}_{\mathbf{0}} \boldsymbol{W}\right\| \boldsymbol{v}$ where $\boldsymbol{V}=\boldsymbol{v}^{\prime} \boldsymbol{v}$ is a given diagonal matrix with $\operatorname{trace}(\boldsymbol{V})$ normalized to be 1 . The selection of weights is subject to $0 \leq w_{j} \leq 1$ for $j=2, \ldots, J+1$ and $w_{2}+\cdots+w_{J+1}=1$. The second layer updates $\boldsymbol{V}$ to get a better result. I choose $\boldsymbol{V}$ that minimizes the mean square prediction error (MSPE), $\sqrt{\left(\boldsymbol{Y}_{\mathbf{1}}-\boldsymbol{Y}_{\mathbf{0}} \boldsymbol{W}(\boldsymbol{V})\right)^{\prime}\left(\boldsymbol{Y}_{\mathbf{1}}-\boldsymbol{Y}_{\mathbf{0}} \boldsymbol{W}(\boldsymbol{V})\right)}$, between the treated unit outcome variable and the synthetic control unit outcome variable in the pre-treatment period. With the optimal weight, $\boldsymbol{W}^{*}$, I apply the same set of weights to construct a proxy,

$$
\hat{Y}_{i t}^{N}=\sum_{j=2}^{J+1} w_{j}^{*} Y_{j t}, \text { when } t>T_{0}
$$

for the treated state in the post-treatment period.

The linear combination of the donor group with the obtained weight is a synthetic unit (or synthetic control). Notice, the underlying model is not explicitly estimated. The detailed statement of assumptions and proofs are available in Abadie, Diamond and Hainmueller (2010).

\subsubsection{Data}

The outcome variable is the monthly number of background checks performed for long gun transactions per 1,000 people in each state from January 2006 to May 2017. Data are from the National Instant Criminal Background Check System (NICS). Founded in 1996, NICS is a U.S. federal on-line checking system that determines

\footnotetext{
${ }^{2}[A ; B]$ is the matrix formed by concatenating matrix $A$ with matrix $B$.
} 
whether prospective buyers are eligible to purchase firearms based on their criminal and mental health records. The Brady Handgun Violence Prevention Act of 1993 (Brady Act), which mandates a background check on firearm buyers, led to the implementation of NICS. NICS stores information about individual criminal convictions, mental illness, immigration status, and other information that would prohibit an individual from purchasing firearms. All sellers with federal firearms licenses are required to perform background checks on buyers under the Brady Act. Firearm trades through non-licensed sellers are private transfers and are not covered.

Background checks reflect firearm sales with reliable accuracy. When buyers and sellers agree upon a purchase (can involve one or multiple firearms in a single transaction), buyers must complete a Firearm Transaction Record (Form 4473) and submit it to the NICS. The number of NICS applications per month by states is available in the FBI NICS database. The background check application data evaluates people's willingness to buy firearms. This paper uses the number of background check applications for long gun sales, including both shotguns and rifles. Other background checks regarding transactions about handguns, permits for concealed carry, other guns, and multiple types of guns are excluded from the outcome variable as less relevant to rifle sales. Another advantage of using long gun application is that I can capture the substitution effect when potential buyers buy other long firearms as substitution. The number of background checks has a close relationship to firearm sales since the denial rate is stable around 1.6 percent.

However, this count of background checks is an imperfect measure of semiautomatic rifle sales for two reasons. First, the number of background checks is reported 
for long guns, defined as the combination of "rifles"” and "shotguns" substitution between types of long guns. For example, people who planned to purchase a shotgun may change their minds knowing semi-auto rifles are being banned. Insofar as this occurs, any increase in the purchases of semi-automatic rifles will be underestimated. We posit that this bias is small.

Another weakness of using background checks for long guns as measures for semi-automatic rifle sales is that buyers with Carry Concealed Weapon (CCW) permit can buy semi-automatic rifles without a background check. Also, a purchase order can include multiple firearms with only one background check required. This issue suggests that estimates of effects based on background checks are only a lower-bound for changes in semi-automatic rifle sales. On the other hand, even though the background checks may underestimate the sale of semi-auto rifles, new buyers are the major concern of this injunction.

\subsubsection{Control Variables}

To make synthetic control more precise, I add some control variables other than the dependent variable. Kalesan, et al. (2016) show, "a typical American gun owner is white, married or divorced, high income, and over 55 years old." We have chosen $\boldsymbol{Z}$ to includes measures of income, age, education level, and political spectrum for the state. These four measures depict general characteristics of each state that we expect to be related to firearm purchases. The rationale is to find a synthetic control not only by fitting the background checks but also fitting other factors that may affect the firearm market. These factors need to be time invariant, so we average all the factors across the

${ }^{3}$ Fully automatic rifles are not included since they were banned by The Firearm Owners' Protection Act of 1986. Automatic weapons that were manufactured before 1986 can be traded, although restrictions apply. 
pre-treatment period. The natural logarithm of GDP per capita reflects the state's economy; age and education distributions provide demographic information; political support is the proportion of votes for Democratic candidates in all three presidential elections in the pre-treatment period.

\subsubsection{Donor Group}

The donor group is the group of untreated states used to estimate the number of background checks for firearm sales in California that would have occurred in the absence of the treatment. It is crucial that donors, as potential control group members, are not affected by any major idiosyncratic shock within the time span. Since Connecticut, Washington D.C., Hawaii, Maryland, Massachusetts, New Jersey, and New York banned semi-automatic rifles within the window of this analysis (20062017), these states are excluded from the donor group. I also exclude Illinois due to a major gun law revision affecting gun sales in the post-treatment period.

\subsubsection{Description}

Figure 1-2 presents background checks for long gun sales per 1,000 population in California from January 2006 to May 2017. The background-checks-to-population ratio is much lower in California than the U.S. average in all periods. This difference reflects the fact that people living in metropolitan areas do not acquire as many firearms as those in rural areas. 97\% of Californians live in metropolitan areas. Based on CPS data, the average of the rest states in the U.S. is $81.6 \%$. The U.S. average consists of forty-nine states (excluding California). Including California and the donor group, background check rates of all three groups are moving in the same direction most of the time, indicating state firearm markets react similarly to national shocks. For example, background check rates reach their all-time high prior to 2016 after the Sandy 
Hook Elementary School shooting on December 14, 2012. The two vertical dash lines on the right end of the graph are the passage date and the effective date of the bullet button act. The passage date is July 2016 when the bullet button ban is officially signed by the governor. The effective date is January 2017 when the bullet button ban takes effect. Background checks in California increased after passing the injunction. However, whether this increase is due to the news about the bullet button ban is uncertain since other states experience increases in firearm sales as well. Moreover, the outcome variable shows seasonal cycles, with lower sales in the first half of year and higher sales in the second half. The movements of California and the rest of the U.S. state averages are similar. Synthetic control can help to isolate the effect of the bullet button ban.

\subsection{Identification Result}

\subsubsection{Synthetic Control}

Table 1-1 presents the weight assigned to states in the synthetic group. A synthetic group contains states from the donor group with assigned weight that are greater than zero. In this case, the synthetic group includes Arizona, Delaware, and Rhode Island, although most weight goes to Rhode Island.

Table 1-1 Synthetic Control Weight

\begin{tabular}{cc}
\hline States & Weights \\
\hline Arizona & 0.187 \\
Delaware & 0.017 \\
Rhode Island & 0.796 \\
Other States & - \\
\hline
\end{tabular}

Notes: The synthetic unit is constructed with the monthly background checks with these weights.

Table 1-2 presents values for eight measures for California, its synthetic unit, the U.S., and the donor group. These measures form the regressor $\boldsymbol{X}$ as described in section III.A, including four control variables along with annual averages for outcome 
variables in 2006, 2009, 2012, and 2015. California is a stable blue state, with an average of $61 \%$ of votes for Democratic presidential candidates in the elections of 2008 , 2012, and 2016. California also has higher income than the average for the U.S. and for the donor group. California has a large share of its people within the adult range, so a larger share of the population qualifies to make firearm purchases. The California population is also more educated. Moreover, California has extremely low gun density. The synthetic control successfully constructed a control unit that is similar to the treated unit in all eight measures.

Table 1-2 Control Variable Difference Between Synthetic Unit, California, and Other Control Groups

\begin{tabular}{cccccc}
\hline Variables & California & $\begin{array}{c}\text { Synthetic } \\
\text { California }\end{array}$ & $\begin{array}{c}\text { Rest of } \\
\text { U.S. }\end{array}$ & $\begin{array}{c}\text { Donor } \\
\text { Group }\end{array}$ & V-Matrix \\
\hline In(RGDPPC) & 10.90 & 10.72 & 10.76 & 10.71 & 0.000 \\
Age 18-64 (\%) & 63.6 & 63.6 & 63.0 & 62.7 & 0.112 \\
Bachelor or & 29.23 & 28.88 & 27.33 & 25.99 & 0.000 \\
$\quad \begin{array}{l}\text { Higher } \\
\text { Vote For Dem. }\end{array}$ & 0.61 & 0.57 & 0.48 & 0.45 & 0.000 \\
BGC Annual & & & & & \\
AVG & & & & & \\
2006 & 0.528 & 0.497 & 1.780 & 2.048 & 0.005 \\
2009 & 0.578 & 0.578 & 1.766 & 2.017 & 0.868 \\
2012 & 0.928 & 0.938 & 2.290 & 2.606 & 0.020 \\
2015 & 0.955 & 0.845 & 1.937 & 2.259 & 0.000 \\
\hline
\end{tabular}

Notes: The rest of U.S. includes all fifty states except California. Donor group consists of 42 states, excluding CA, CT, DC, HI, IL, MA, MD, NJ, and NY.

Source: National Instant Criminal Background Check System, from January 2006 to May 2017. Real GDP data are from Bureau of Economic Analysis. Age proposition uses Census 2010. Education proposition uses American Community Survey.

* $\ln$ (RGDPPC) stands for the natural logarithm of real GDP per capita.

Figure 1-2 and Figure 1-3 compare California with its synthetic unit, along with the U.S. and the donor group average, in different periods. During the pre-treatment period (in Figure 1-2), the background check rates of California and synthetic California are similar, while the U.S. and donor group have both higher mean and greater volatility. Notice, synthetic California deviates from California in an important way only once in the pre-treatment period, during 2013. The reason for this deviation will be discussed 
in section V. In general, synthetic California provides a good replication of California's firearm background checks in the pre-treatment period, making it a promising counterfactual after the treatment. Figure 1-3 provides detail for the most recent three years. Background checks increased after the law was passed, while background checks in synthetic California also increased because of the sale season. California background checks grew substantially more than synthetic California, showing the news effect on firearm sales. After the effective date, all transactions of semi-automatic rifles became illegal and the surge in the background check rate also ended with the rate of background checks dropping to slightly below that of synthetic California. This small reduction occurs for four months after the effective date.

The bullet button ban has two unexpected consequences. First, it boosts the firearm market in the grace period. Second, it does not reduce firearm sales when it is in place. Both results are not in accord with legislators' intentions and researchers' assumptions. The estimates are discussed in greater detail in section V. 
Figure 1-3 Causal Effect of the Bullet Button Ban

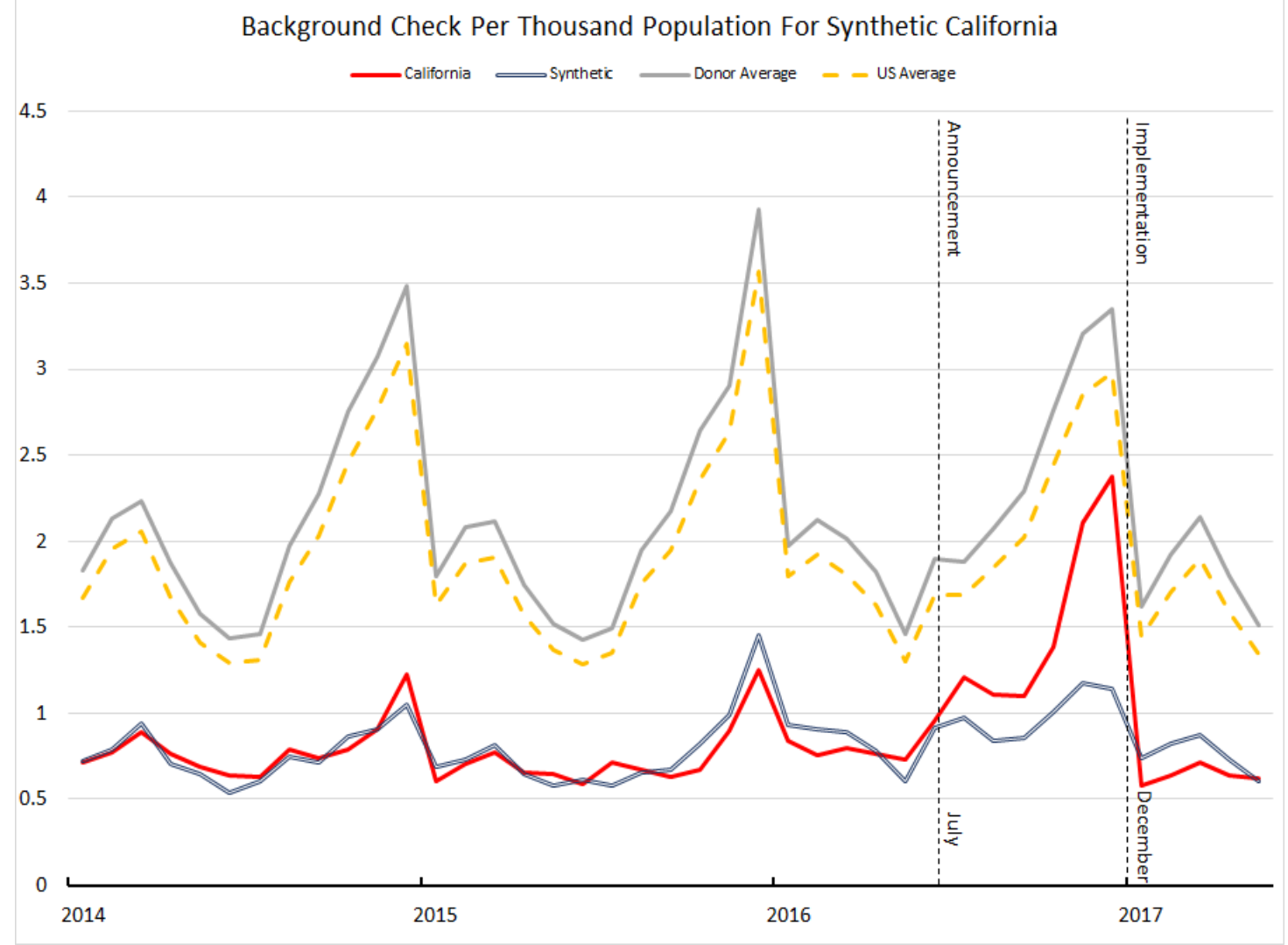

\subsubsection{Significance Tests}

Following procedures developed by Abadie et al. (2010) we us a placebo test to infer the significance of estimates based on the synthetic control method. In the placebo test, I will run the synthetic control 42 times. In these analyses, each state from the donor group becomes the "treated unit" in turns. The optimal set of weights in each analysis is found among the remainder of the donor group units plus California. The purpose is to identify the distribution of estimated background checks in the absence of treatment. By comparing the effect estimates of California with those of states with no treatment, one can identify the probability that California's estimates after treatment is due to random variation.

In Figure 1-4, the top graph shows the result of the placebo test. The result is chaotic as some states have much higher variance than the others. Synthetic control 
does not work for all states because the synthetic control must be formed with positive weights that sum to one. To make this test meaningful, states that cannot be replicated well in the pre-treatment must be dropped.

The bottom graph excludes any unit that has a pre-treatment MSPE that is two times larger than California's to omit states with poorly performing synthetic controls. For the remaining 22 states, variation is more consistent in the pre-treatment period. Moreover, in each of the last five months of the grace period, California's background check gaps are higher than all the other 22 units, implying a significance level at 0.045.

The effect of the act drops below zero after the effective date and is not statistically significant except for the first month. The news effect of the bullet button ban is completely at odds with the law's intention in the short-run, which is to decrease the number of assault-style firearms. The passage of the ban dramatically increases purchases until the law's effective date. The ban also fails to reduce firearm sales substantially after its effective date.

Since the MSPE reflects how well the synthetic unit follows the real data, I can assume the MSPE is stable across time when there is no treatment. Figure 1-5 is the histogram of post/pre-treatment MSPE ratio for all 41 states in the donor group plus California. A state with similar MSPE before and after the treatment time should has a ratio close to one. The larger this ratio is the higher the probability that there is a structural change at the treatment period. California's post-treatment MSPE is 4.4 times that of its pre-treatment MSPE, indicating structural change in its firearm market. This ratio is significantly larger than any that of the other 41 states in the donor group. The interpretation of this result is that, if there were no treatment, the possibility of getting a ratio as large as California's is 0.024 . 
Figure 1-4 Placebo Tests by Mean Square Prediction Error

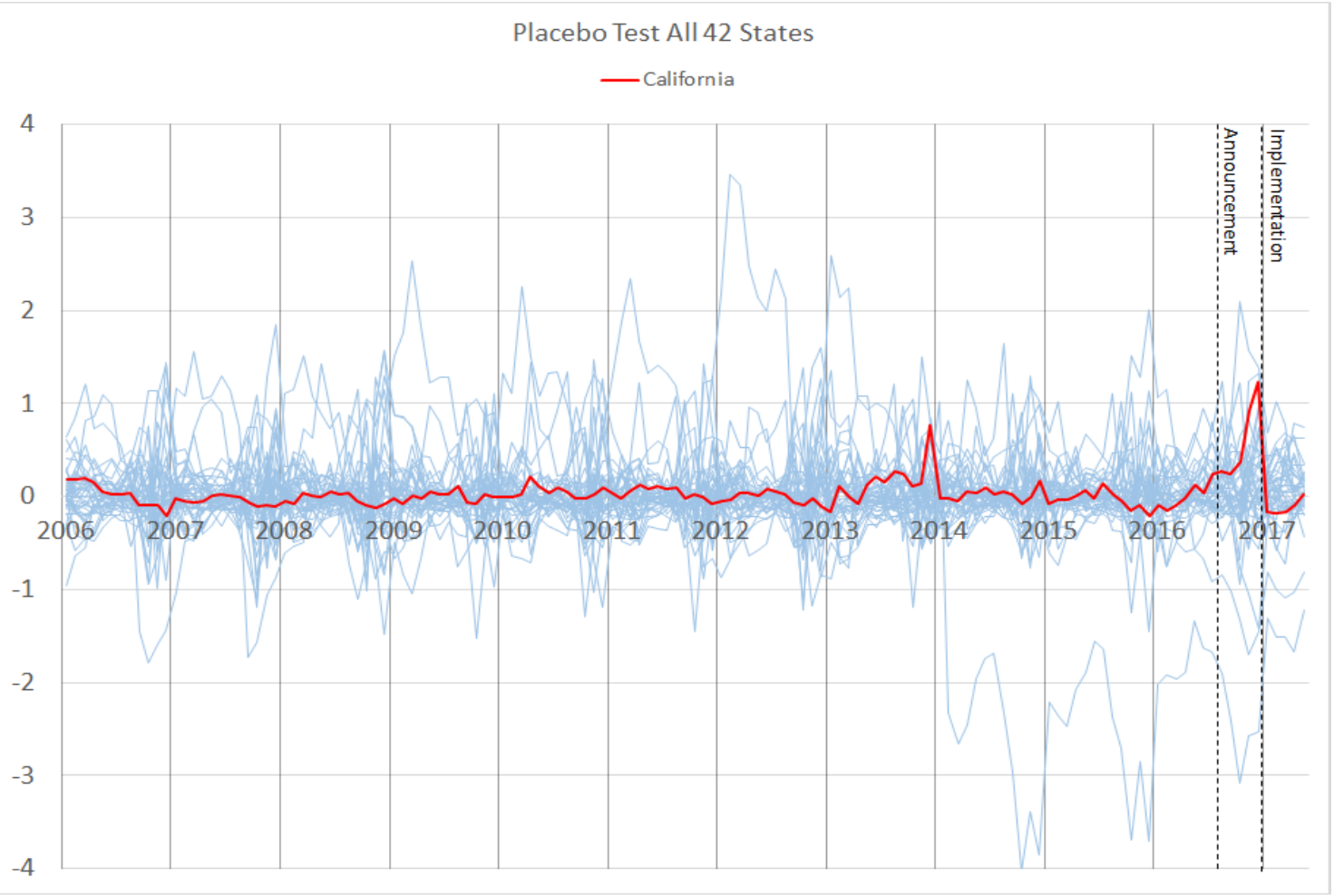

Placebo Test Less Than 2 Times of CA MSPE - 22 States

- California

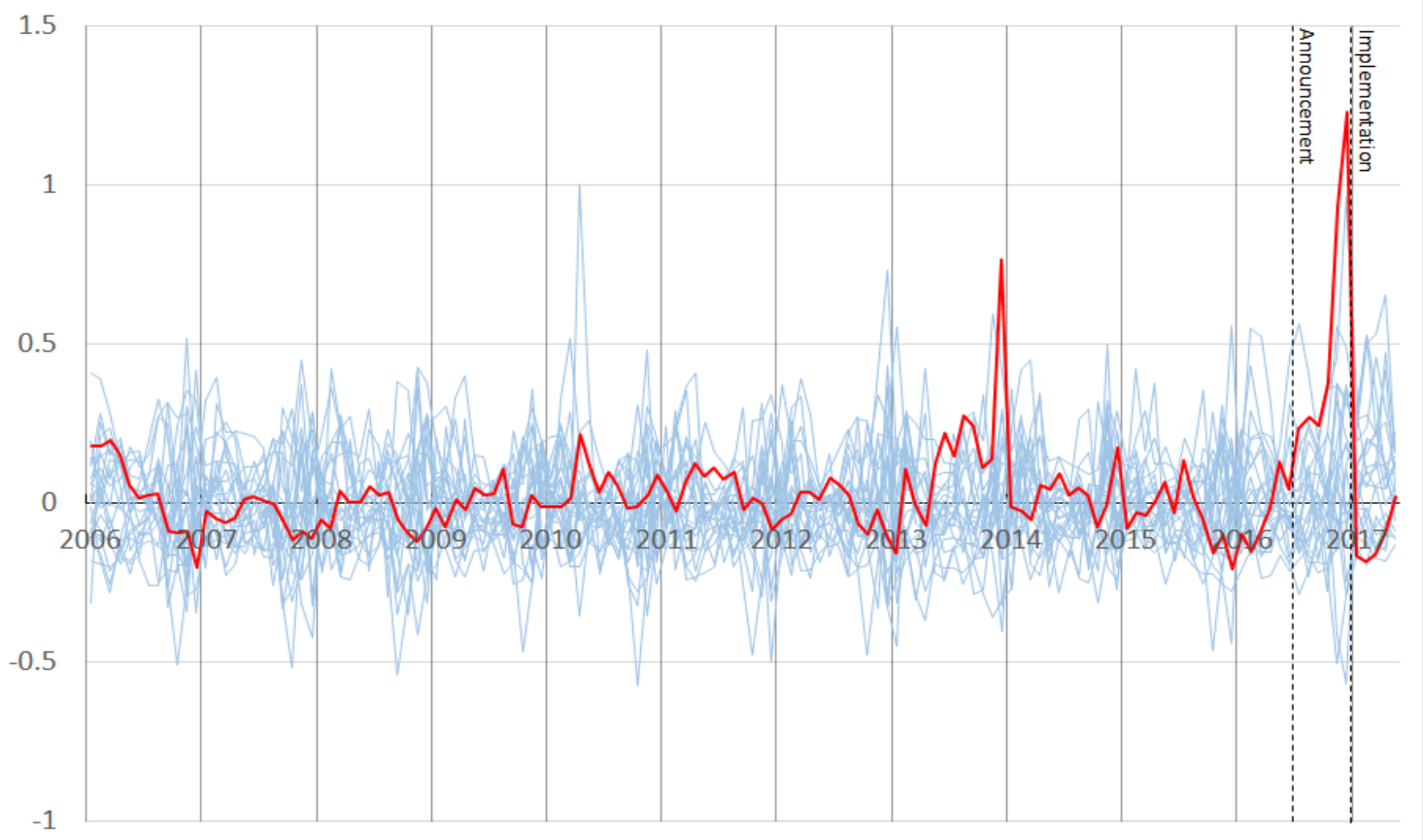


Figure 1-5 Post-Treatment to Pre-Treatment MSPE Ratio

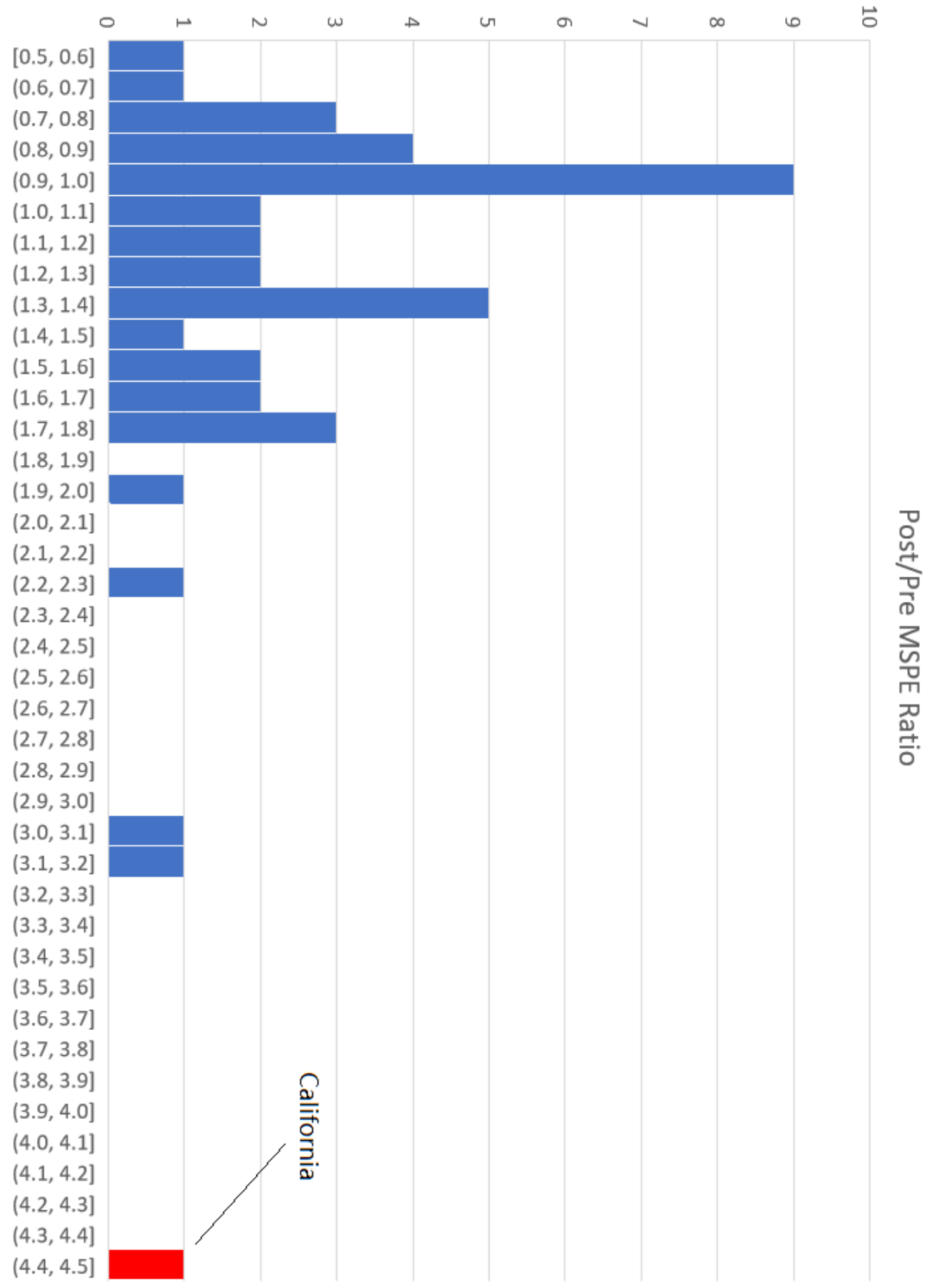

\subsubsection{Robustness Checks}

A common concern of having a treated unit with extreme observations is that there may not be a linear combination of donor group units that can match the treated unit's value. In this case, there may be few options in constructing a group of states for synthetic California, since background checks in California are lower than any other 
states except Rhode Island. When negative weights cannot be used and weights must sum to one, synthetic control has to select states that have low levels even if they do not match the behavior of the treated state.

Table 1-3 presents the summary statistics of monthly ranks of the outcome variables for Rhode Island, Arizona, Delaware, and California. The rank is determined by the background checks per 1,000 people in each month from the highest to the lowest. For example, California's rank is 43 in a month meaning all other states have higher background checks densities than California. Four states mentioned above ranked at the bottom in terms of per capita background checks in the donor group. Other states in the donor group could not get positive weights even if they replicate the time pattern of background checks of California. Selecting a synthetic state with high per capita firearm sales will increase the mean square prediction error in every period. In other words, synthetic control must choose greater weights for states that have similar means rather than similar time patterns when the treated group has outcome values that are too small or too large.

Table 1-3 Background Check Rank Statistics

\begin{tabular}{cccccccc}
\hline \multicolumn{2}{c}{ California } & \multicolumn{2}{c}{ Rhode Island } & \multicolumn{2}{c}{ Arizona } & \multicolumn{2}{c}{ Delaware } \\
\hline Mean & 40.95 & Mean & 42.67 & Mean & 35.32 & Mean & 39.48 \\
Std. Dev. & 2.21 & Std. Dev. & 0.73 & Std. Dev. & 2.74 & Std. Dev. & 2.63 \\
Skewness & -2.29 & Skewness & -2.53 & Skewness & 0.03 & Skewness & -5.40 \\
Min & 31 & Min & 39 & Min & 30 & Min & 16 \\
Max & 43 & Max & 43 & Max & 41 & Max & 42 \\
\hline
\end{tabular}

Notes: This is the monthly rank based on background check density. The density is measured as number of background checks conducted out of 1000 people in a one month. There are 43 states in total.

Indeed, all three states with significant weights have low gun densities. The result is surprising, since the background check rate of California, the third largest state in the U.S. (and the largest by population), is predicted by a synthetic control that weights one of the smallest states very heavily. The question is, "is the choice of states 
primarily a reflection of California's low gun density rather than a reflection of patterns over time?" Doudchenko and Imbens (2016) propose using synthetic control with extrapolation to relax the restriction on weight. Since our result in Table 1-2 has a reasonable MSPE, I consider an alternative strategy.

This paper proposes two ways, multiplier test and demeaning data, to test if the set of optimal weights from synthetic control relies too much on the level of the outcome variable when the outcome variable is extreme. The idea of both robustness tests is to examine the result's consistency by reducing the impact of outcome level in weight selection. If the weight selection change is modest, the primary synthetic control result is valid. The first test applies a multiplier, $\gamma$, to background checks of California, in order that the value for California corresponds more closely to that of the donor pool. California background checks are increased by $(\gamma-1) \times 100$ percent. This approach allows a different set of states from the donor group to match California's background check numbers in the pre-treatment period. Notice the variance of the outcome variable increases when applying the multiplier to the original data. As a result, the MSPE changes from $\sqrt{\left(\boldsymbol{Y}_{\mathbf{1}}-\boldsymbol{Y}_{\mathbf{0}} \boldsymbol{W}(\boldsymbol{V})\right)^{\prime}\left(\boldsymbol{Y}_{\mathbf{1}}-\boldsymbol{Y}_{\mathbf{0}} \boldsymbol{W}(\boldsymbol{V})\right)}$ to $\sqrt{\left(\gamma \boldsymbol{Y}_{\mathbf{1}}-\boldsymbol{Y}_{\mathbf{0}} \boldsymbol{W}(\boldsymbol{V})\right)^{\prime}\left(\gamma \boldsymbol{Y}_{\mathbf{1}}-\boldsymbol{Y}_{\mathbf{0}} \boldsymbol{W}(\boldsymbol{V})\right)}$, which increases as $\gamma$ increases. To compensate for the increase, I define $\sqrt{\left(\gamma \boldsymbol{Y}_{\mathbf{1}}-\boldsymbol{Y}_{\mathbf{0}} \boldsymbol{W}(\boldsymbol{V})\right)^{\prime}\left(\gamma \boldsymbol{Y}_{\mathbf{1}}-\boldsymbol{Y}_{\mathbf{0}} \boldsymbol{W}(\boldsymbol{V})\right)} / \gamma$ as the adjusted MSPE used for optimization in this approach. With grid a search, a new layer of optimization is added to the synthetic control. The process looks for the optimal multiplier, $\gamma^{*}$, that minimizes the adjusted $\mathrm{MSPE}^{4}$.

\footnotetext{
${ }^{4}$ The search range is from $\left(1, \gamma^{\max }\right)$, where $\gamma^{\max }$ makes California's outcome variable the highest among all 43 states.
} 
Another method to check the robustness of the primary result is to demean all data before applying synthetic control, so that every state has a mean zero outcome variable in the pre-treatment period. This method completely removes the difference between gun densities across different states in the optimization. Synthetic California only includes states that have similar responses to national shocks.

Table 1-4 shows three sets of weights, one from the original synthetic control and two based on the robustness tests described above. Column 2 displays weights that the multiplier method applies to the synthetic group. The optimal multiplier is 1.13 and the alternative synthetic California assigns only a slightly different set of weights, with $3.8 \%$ to New Hampshire. The remaining weights distribute similarly within the original set of synthetic states. Column 3 shows weights selected using demeaned data. Like the multiplier method, this approach moves a minor share of weights away to a new state, Vermont, while most of the weight is still assigned to the original set with a slightly different distribution. Rhode Island consistently receives between $69 \%$ and $80 \%$ of the weight in all three methods, which indicates that its background check rates are indeed similar to California's in both level and movement. Both robustness tests show that California's low firearm-sale density is not dominating the weight selection. The standard synthetic control is robust. As expected, when I use these alternative approaches to replicate the analysis presented above, results are similar to the original.

Table 1-4 Weight Selection from Multiple Method

\begin{tabular}{cccc}
\hline States & Original & Multiplier & Demeaned \\
\hline Arizona & 0.187 & 0.247 & - \\
Delaware & 0.017 & 0.026 & 0.203 \\
New Hampshire & - & 0.038 & - \\
Rhode Island & 0.796 & 0.689 & 0.766 \\
Vermont & - & - & 0.031 \\
Other States & - & - & - \\
\hline
\end{tabular}




\subsection{Main Findings}

In most pre-treatment periods, the gap between California and its synthetic unit is between -0.2 and 0.2 background checks per month per 1,000 people with mean difference at 0.075 (the variance of California background check rate is 0.26), indicating synthetic California successfully predicts California ${ }^{5}$. In July 2016, the gap increased immediately after the bullet button ban was passed and remained positive and increasing until the act became effective in January 2017. The negative implementation effect of the act on gun sales after the effective date appears to be weak and temporary. Figure 1-6 displays the gap from January 2014 to May 2017. The darker shaded area after May 2016 is the news effect measured by the increase of background checks due to the bullet button ban. The accumulated increase in background checks during the grace period is about 3.46 per 1000 people in California, which is equivalent to about 136,000 background checks for buying long guns. Using the fact that the passing rate for background checks is above $98 \%$, this implies there are approximately 133,000 more semi-automatic rifles sold in the firearm market, not considering each background check may associate with multiple semi-automatic rifles sales. The average monthly background check rate for long guns in California is 0.7 per 1000 people in the last decade. The regulation boosts firearm sales during the grace period by the equivalent of five months of sales. This estimate is conservative since we have attributed the increase in background checks to semi-automatic rifle transactions, so any substitution from other kinds of long guns is missed. Also, since permit holders can buy firearm without conducting background checks, as mentioned above, any purchases by permit

${ }^{5}$ There is only one substantial deviation, occurring in October 2013. This was caused by the passage of California Senate Bill 374, an act similar to the bullet button ban, at the senate- and the assembly- level. The market responded quickly with more applications to buy firearms. This shock ended immediately when the governor of California vetoed the act on October 11th of the year. 
holders are excluded. The result reveals how destructive this policy can be in the shortrun. The increase does not appear to be compensated for by the reduction in sales following the implementation of the ban, as the decrease in background check rate after the effective date is negligible.

Figure 1-6 Difference between the Background Checks of California and Synthetic California

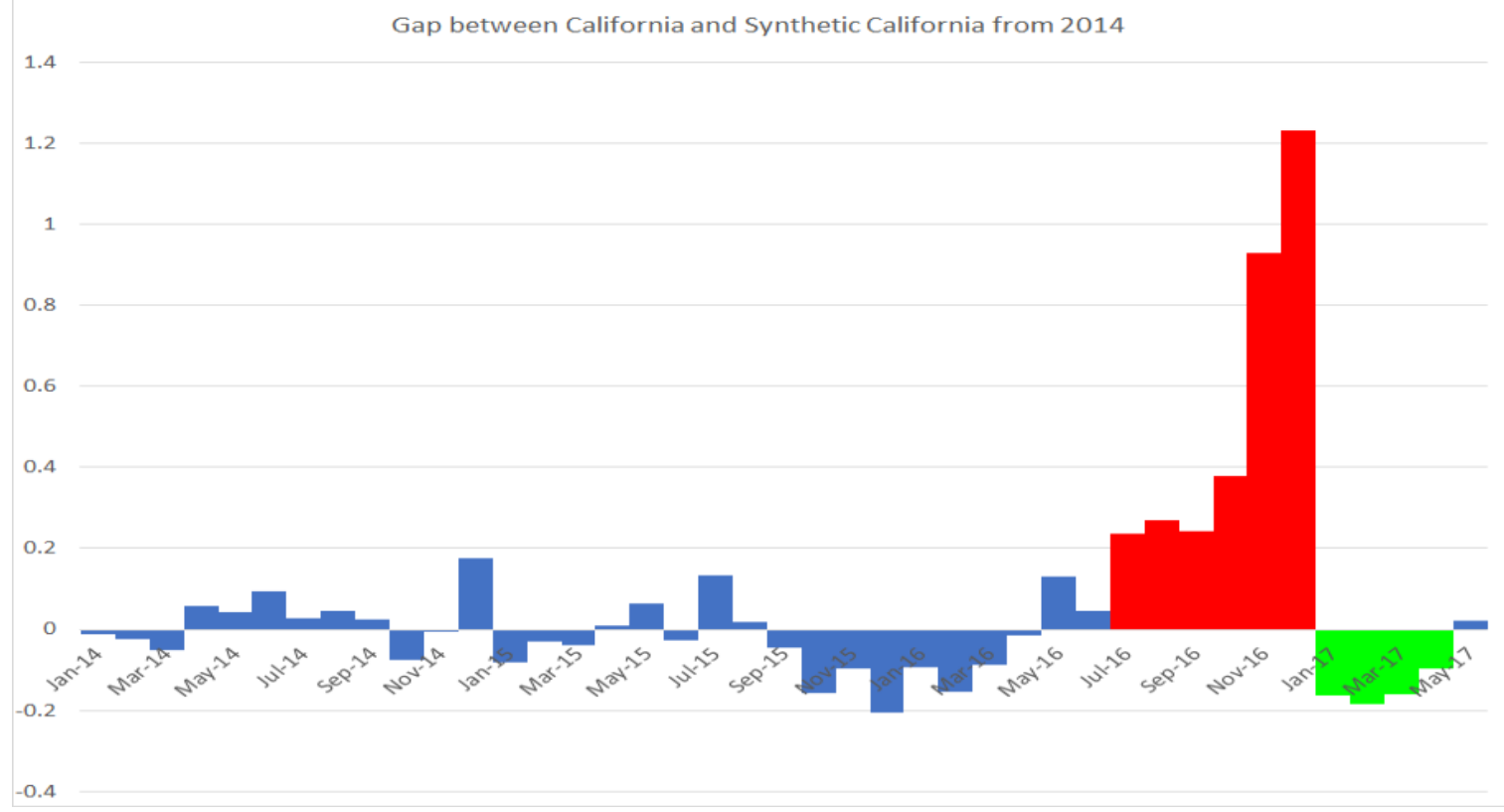

\subsubsection{Similar Legislation in Connecticut and Maryland}

Both Connecticut and Maryland banned assault weapons with state laws similar to California's AWCA. They also extended the ban list to include semi-automatic rifles like the AR-15 and the AK-47 in April 2013 as a reaction to the Sandy Hook Elementary School shooting. Maryland specified a six-month grace period after passage of the bill, whereas Connecticut left no such window. This paper analyzes both states with synthetic control to verify three propositions. Did Maryland experience the same surge during the grace period as California? Does waiving the grace period eliminate the surge in Connecticut? What happens to firearm sales after implementing an injunction on some models? Figure 1-7 shows results of both analyses. The top graph shows that 
Maryland had a similar gap between the predicted and the observed background check rates during the grace period, indicating a positive news effect on firearm sales. Connecticut, without any grace period, did not show any surge in the background check rate. Maryland estimation is statistically significant at 5.6 percent (1/18) level for the third and the last month of the grace period. Connecticut estimation is statistically insignificant during the 10 days period, which is essentially no grace period since Connecticut requires weeks to complete the background check. The enthusiasm for limiting firearm sales has fizzled out in both states. The large increase of background checks in Connecticut in 2014 was caused by a major revision of gun control regulations. 
Figure 1-7 Synthetic Control for Connecticut and Maryland

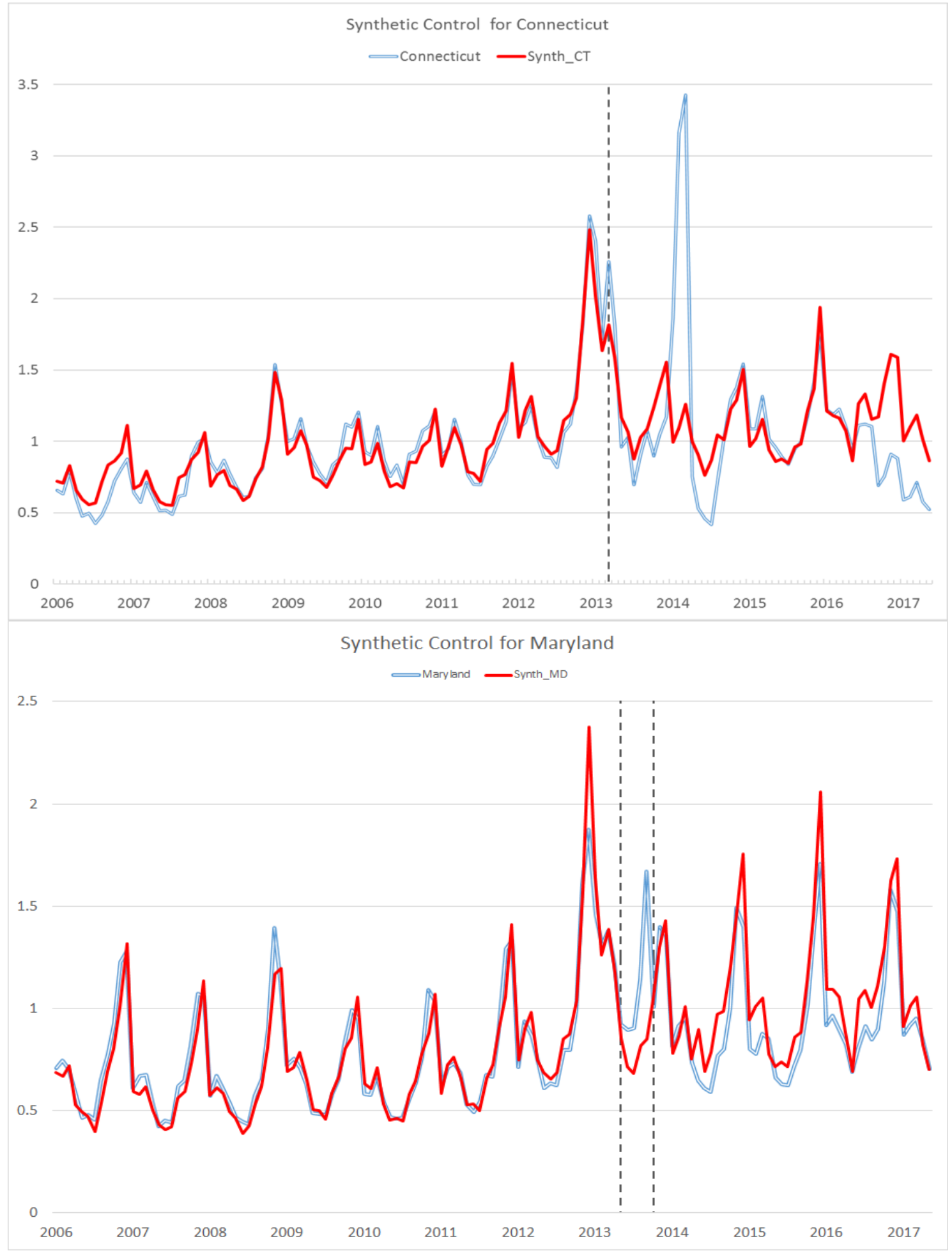




\subsubsection{Difference-in-Difference}

As a further robustness test of the model, I use difference-in-difference method to obtain estimates of the effects of such laws. The treated group includes California, Connecticut, and Maryland. All three states passed acts to expand their existing ban lists. However, Connecticut did not leave any grace period. The first model focuses on the overall news effect and the implementation effect. The OLS regression model is,

$$
B G C_{i t}=\alpha+\theta_{i}+\gamma_{t}+\beta \cdot G P_{i t}+\delta \cdot E F_{i t}+\epsilon_{i t}
$$

where $B G C_{i t}$ is the background check rate of state $i$ at time $t . \alpha$ is the constant term. $\theta_{i}$ and $\gamma_{t}$ are state and time fixed effect. $G P_{i t}$ is an indicator variable that equals one when state $i$ is in the grace period at time $t$ and $E F_{i t}$ is another indicator variable that equals one when state $i$ 's new law becomes effective. $\epsilon_{i t}$ is the error term. $\beta$ and $\delta$ are coefficients identifying the average effects following passage of the law and the implementation, respectively.

The results are shown in column 1 in Table 1-5. Announcing the law increases the monthly background check by 0.425 per thousand population. The estimate of the implementation effect is positive, but not statistically significant. This finding is consistent with the synthetic control. To further compare these two methods, I estimate both effect by months. The regression model is,

$$
B G C_{i t}=\alpha+\theta_{i}+\gamma_{t}+\sum_{j=1}^{6} \beta^{j} \cdot G P_{i t}^{j}+\sum_{k=1}^{5} \delta^{k} \cdot E F_{i t}^{k}+\epsilon_{i t}
$$

where $G P_{i t}^{j}$ (and $\left.E F_{i t}^{k}\right)$ is the indicator for the $j$ th $(k$ th) month in the grace period (implementation period). $\beta^{j}$ and $\delta^{k}$ capture the news effect and implementation effect. The result is shown in column 2 in Table 1-5. The news effect is significant through the grace period. The increase in the first month is big but not statistically significant. The 
news effects in subsequent months are between 0.349 and 0.395 . All effects are at least significant at the 10 percent level. The news effect in the last grace period is 0.628 . The implementation effect is surprising. Not only most of them are not statistically significant, but also three of them are positive. With the bullet button ban in effect, purchasers must buy alternative firearms that are categorized as long gun but not semiautomatic rifle. As a result, the injunction only changes the type of firearms sold as there is a strong substitution effect. 
Table 1-5 Difference-in-Difference Result with Trend Tests

\begin{tabular}{|c|c|c|c|c|}
\hline Coefficient & $\begin{array}{c}\text { OLS } \\
(1) \\
\end{array}$ & $\begin{array}{c}\text { OLS-Month } \\
(2)\end{array}$ & $\begin{array}{c}\text { Granger } \\
\text { (3) }\end{array}$ & $\begin{array}{c}\text { State-Trend } \\
\text { (4) }\end{array}$ \\
\hline Grace Period & $\begin{array}{c}0.425 * * * \\
(0.129)\end{array}$ & & & \\
\hline $1^{\text {st }}$ Month & & $\begin{array}{c}0.429 \\
(0.245)\end{array}$ & $\begin{array}{c}0.415 \\
(0.243)\end{array}$ & $\begin{array}{c}0.516 * * \\
(0.190)\end{array}$ \\
\hline $2^{\text {nd }}$ Month & & $\begin{array}{c}0.395 * * \\
(0.140)\end{array}$ & $\begin{array}{c}0.382^{* * *} \\
(0.137)\end{array}$ & $\begin{array}{c}0.484 * * * \\
(0.135)\end{array}$ \\
\hline $3^{\text {rd }}$ Month & & $\begin{array}{c}0.383 * * \\
(0.130)\end{array}$ & $\begin{array}{c}0.370 * * \\
(0.124)\end{array}$ & $\begin{array}{c}0.475 * * \\
(0.200)\end{array}$ \\
\hline $4^{\text {th }}$ Month & & $\begin{array}{l}0.349^{*} \\
(0.161)\end{array}$ & $\begin{array}{l}0.336^{*} \\
(0.156)\end{array}$ & $\begin{array}{l}0.443^{*} \\
(0.239)\end{array}$ \\
\hline $5^{\text {th }}$ Month & & $\begin{array}{c}0.366^{* *} \\
(0.141)\end{array}$ & $\begin{array}{c}0.353 * * \\
(0.138)\end{array}$ & $\begin{array}{c}0.462 * * * \\
(0.129)\end{array}$ \\
\hline $6^{\text {th }}$ Month & & $\begin{array}{c}0.628 * * * \\
(0.113)\end{array}$ & $\begin{array}{c}0.615 * * * \\
(0.111)\end{array}$ & $\begin{array}{c}0.725 * * * \\
(0.133)\end{array}$ \\
\hline Effect Period & $\begin{array}{c}0.087 \\
(0.056)\end{array}$ & & & \\
\hline $1^{\text {st }}$ Month & & $\begin{array}{c}0.179 \\
(0.210)\end{array}$ & $\begin{array}{c}0.165 \\
(0.208)\end{array}$ & $\begin{array}{c}0.232 \\
(0.175)\end{array}$ \\
\hline $2^{\text {nd }}$ Month & & $\begin{array}{l}-0.035 \\
(0.151)\end{array}$ & $\begin{array}{l}-0.0493 \\
(0.149)\end{array}$ & $\begin{array}{c}0.019 \\
(0.130)\end{array}$ \\
\hline $3^{\text {rd }}$ Month & & $\begin{array}{l}-0.109 \\
(0.238)\end{array}$ & $\begin{array}{l}-0.123 \\
(0.243)\end{array}$ & $\begin{array}{l}-0.053 \\
(0.163)\end{array}$ \\
\hline $4^{\text {th }}$ Month & & $\begin{array}{l}0.235^{*} \\
(0.128)\end{array}$ & $\begin{array}{c}0.221 \\
(0.123)\end{array}$ & $\begin{array}{c}0.291 \\
(0.179)\end{array}$ \\
\hline $5^{\text {th }}$ Month & & $\begin{array}{c}0.161 \\
(0.182)\end{array}$ & $\begin{array}{c}0.147 \\
(0.180)\end{array}$ & $\begin{array}{c}0.218 \\
(0.219)\end{array}$ \\
\hline State FE & $\checkmark$ & $\checkmark$ & $\checkmark$ & $\checkmark$ \\
\hline Year Month FE & $\checkmark$ & $\checkmark$ & $\checkmark$ & $\checkmark$ \\
\hline $\begin{array}{l}\text { Prior Effect }{ }^{\mathrm{a}} \\
\text { State Trend }\end{array}$ & & & $\checkmark$ & $\begin{array}{l}\checkmark \\
\checkmark\end{array}$ \\
\hline $\begin{array}{l}\text { Clustered } \\
\text { F-Test }^{\mathrm{c}}\end{array}$ & Month & Month & $\begin{array}{c}\text { Month } \\
0.063\end{array}$ & Month \\
\hline $\mathrm{N}$ & 6,904 & 6,904 & 6,904 & 6,904 \\
\hline$R^{2}$ & 0.8345 & 0.8345 & 0.8348 & 0.8543 \\
\hline
\end{tabular}

Source: National Instant Criminal Background Check System, from January 2006 to May 2017.

a The prior effect is estimated by six indicators for six months before the treatment.

${ }^{\mathrm{b}}$ State specific trend is measured as an effect linear in $t$.

${ }^{\mathrm{c}}$ The null hypothesis of the F-test is that all coefficients are zero.

*** Significant at the 1 percent level.

** Significant at the 5 percent level.

* Significant at the 10 percent level.

Column 3 shows a test in the spirit of Granger Causality Test (Angrist and Pischke 2009). I estimate the following model with indicators prior to the treatment time,

$$
B G C_{i t}=\alpha+\theta_{i}+\gamma_{t}+\sum_{q=1}^{6} \tau^{q} \cdot P R_{i t}^{q}+\sum_{j=1}^{6} \beta^{j} \cdot G P_{i t}^{j}+\sum_{k=1}^{5} \delta^{k} \cdot E F_{i t}^{k}+\epsilon_{i t}
$$


where $P R_{i t}^{q}$ is the indicator for the $q$ th prior month before the treatment. I can test the null hypothesis that all $\tau^{q}$ are zero. This hypothesis can be rejected at 0.05 level. It is plausible that the market reacts prior to the treatment when legislator announces a new proposal. In this case, the problem is trivial in my opinion for two reasons. First, California legislators frequently make proposals regarding gun controls. Many proposals are not passed. Second, the reaction is more substantial in the last month. Even though a small proportion of people reacts, it is less likely to be very significant.

Column 4 shows the result of another classic robustness test. A state-specific time trend is added in the model,

$$
B G C_{i t}=\alpha+\gamma_{t}+\theta_{0 i}+\theta_{1 i} \cdot \mathrm{t}+\sum_{j=1}^{6} \beta^{j} \cdot G P_{i t}^{j}+\sum_{k=1}^{5} \delta^{k} \cdot E F_{i t}^{k}+\epsilon_{i t}
$$

Adding the state specific trends tells us if the treatment effect can be explained by two linear trends crossing at the treatment time. The result shows that the estimated news effects are still positive and statistically significant with small increases. The implementation effects are still negligible. The above two tests confirm that the model is robust.

\subsection{Conclusion}

Extending a firearm ban list is one of a few options that legislators prefer as a response to mass shootings. There are at least three advantages that may recommend such legislation. First, it seems like legislators are learning lessons from the tragedy. Second, this lesson is straightforward. People are harming our society with a type of firearm. Actually, banning firearms is much easier than dissecting our society to figure out what is wrong with murders. For this reason, the last advantage is that passing this law is easier than other laws, especially with a grace period. 
My result shows that people have plenty of time to purchase firearms during the grace period. Also, any increases are negligible compares to the huge stock of firearms in the U.S. It is hard to believe the regulation would have any effect to the gun problem in the U.S., especially when it shows no negative effect on the firearm market.

The findings of this paper also reveal that firearms buyers may substitute recent banned firearms with permitted firearms in the same category. When a preferred model is not available, customers are likely to buy other firearms.

My contribution also includes two robustness checks for the synthetic control. The setting of synthetic control makes it naturally not fitted for all treated units. When the state with extreme dependent variables has good synthetic unit, it is not guaranteed that the synthetic weights are optimal since the treated group is structurally different from other units. Instead of the more complicated extrapolation synthetic control (allowing for negative and greater than one weight), the synthetic control can be tested with a multiplier method or demeaned data. 


\section{Chapter 2}

Assimilation Estimation Is Less Biased Than Curved: Using Cross-Sectional Data in the U.S. from 1990 to 2010

\subsection{Introduction}

Forty-seven million people living in the U.S. were born outside of the U.S. as of 2015. Throughout American history, immigrants played vital roles in the development of all aspects of this country. However, surviving in the U.S. is a challenge for new immigrants. Assimilation is the process by which immigrants learn and adapt to the new environment by developing skills that bridge the gap between them and the receiving society.

Assimilation can be measured in terms of socioeconomic status, spatial concentration, language assimilation, or intermarriage (Waters and Jimenez 2005). This paper focuses on the economic assimilation of immigrants, which is measured in earnings growth. The idea of economic assimilation is that immigrants may not be fully adapted to the U.S. labor market upon arrival due to a lack of necessary knowledge or skills. Immigrants acquire skills to accommodate to the U.S. labor market as they stay longer. As a result, their earnings growth is due to both increases in their job experience and better adaptation to the job market. For example, the increase in earnings may be related to English proficiency improvement (Bleakley and Chin 2010), intermarriage with natives (Qian and Lichter 2007), or cultural factors that can make immigrants successful in the U.S. labor market.

Measuring accumulation in human capital directly is difficult, as it is often not observable. It is also difficult to pin down a set of skills necessary for assimilation because immigrants are heterogeneous. The skills needed for assimilation depend on the idiosyncratic situation. For example, a foreign professor needs to improve his 
English to express idea, while a foreign gardener may need to find a boss who can handle communications with clients. Both cases enhance the efficiency of working, which is essential to economic success. Fortunately, these skills share three features. First, most of them are communication- or cultural-related. Second, most natives have acquired these skills. Third, immigrants are likely to experience more significant growth in skills as they stay longer in the U.S. As a result, we can proxy the accumulation of human capital due to assimilation using earnings growth due to length of stay.

The U.S. Census and the American Community Survey (ACS) ask immigrants about their earnings and arrival times. The difference between the arrival year and the year of the survey is the length of stay. The relationship between the length of stay and earnings level can be found after controlling for age and other earnings-determining factors.

Both the U.S. Census and the ACS provide cross-sectional data. It is generally recognized that the estimation of assimilation using cross-sectional data is problematic. The potential problem stems from the cohort bias caused by changing cohort quality and the outmigration bias caused by selected immigrants leaving the U.S. In crosssectional data of a given year, differences in length of time in the U.S. imply differences in date of arrival or "arrival cohort." Borjas (1985) points out that the more permissive immigration policy since 1970 has allowed more low-skill immigrants from Asia and Latin America to come to the U.S. As a result, older immigrant cohorts have higher earnings than newer cohorts because of higher productivity, not assimilation. The estimation is positively biased. 
When repeated cross-sectional data from multiple years are available, cohort bias due to cohort quality changes can be eliminated by sampling people from the same cohort at different times. However, estimation of assimilation may still be biased insofar as immigrants leave the U.S., changing the cohort's composition. If we assume low-skilled workers have a more challenging time in the host country and are more likely to leave the U.S., the average earnings of the cohort increases as the fraction of high-skilled workers increases, which is not due to assimilation.

The conventional way of correcting both cohort and outmigration biases is to construct panel data (G. J. Borjas 1985, Hu 2000, Edin, Fredriksson and Aslund 2003, Duleep and Dowhan 2002, Constant and Massey 2003). Panel data include observations of the same sample over time. As a result, panel data can track earnings and exclude outmigration for a set of respondents within a period. Forming a panel dataset in the U.S. raises some technical challenges as there is no public panel dataset of immigrants in the U.S. Analysts must match observations between cross-sectional data to construct panel data and merge it with earnings data. Due to difficulties in matching observations, the method of construction may create selection bias.

In this paper, we find a similar bias in assimilation estimation when comparing estimates using cross-sectional and repeated cross-sectional analysis. The interpretation of the bias is in question. I implement a non-parametric method to estimate assimilation with no constraint in the specification of assimilation. This method is inspired by Chiquiar and Hanson (2005), in which they adjust the earnings distribution of immigrant cohorts based on observed characteristics. The result confirms that the immigration assimilation process is not linear. The process is fast initially and slows down in later years, indicating the conventional model is not correctly specified. Using 
this result, I revisit the conventional model and find that allowing curvature in assimilation reduces the estimation bias significantly.

The remainder of this paper proceeds as follows. Section II provides the literature review and explains the biases in assimilation estimation in detail. Section III describes the dataset and some key variables. Section IV presents the structure of the conventional regression method and the method that adjusts migrant characteristics' distribution. Section V explains the results of both methods. Section VI concludes.

\subsection{Literature Review}

Whether new immigrants can succeed in the U.S. is always raised since many immigrants are from developing countries. The two most recent waves of immigrants were in the late $19^{\text {th }}$ century to the early $20^{\text {th }}$ century and the late $20^{\text {th }}$ century to the early $21^{\text {st }}$ century. There are some common features shared between these two waves. First, national survey data record the change in the immigrant population from both waves. Using the 1970 Census, an early article by Chiswick (1978) finds that immigrants in the country longer have higher earnings than new immigration cohorts. In response, Borjas (1985) argues that the improvement in earnings is subject to the cohort bias. The problem stems from the fact that years since arrival and arrival date are perfectly correlated in cross-sectional data. When the cohort's quality is declining over time, recent immigration cohorts are subject to lower earnings trajectories. Projecting their future based on the earnings levels of older immigrants is too optimistic. Indeed, the current immigration wave contains more low-skilled workers from Asia and Latin America, whereas older migrants from Europe were generally high-skilled. The critical factor is skill difference, not the length of stay. In an article considering migrant assimilation during the age of mass migration, 1880-1920, Abramitzky, Boustan, and 
Eriksson (2014) show the same effect. Immigrants who arrived earlier in that period had higher earnings than immigrants who arrived later because the primary source countries of the majority of immigrants shifted from Britain and Germany to Russia and Italy ${ }^{6}$.

The cohort bias can be addressed by merging cross-sectional data from different survey years to form repeated cross-sectional data. With repeated cross-sectional data, we can estimate the assimilation effect by controlling the cohort fixed effect. Ideally, we are sampling from the same group of people at different times to estimate their earnings growth. However, as noted above, the estimation is subject to the second source of bias - the outmigration bias. Abramitzk et al. (2014) show that negative selected outmigration biases the estimation of assimilation. Immigrants who are not successful in the U.S. job market are more likely to emigrate. When immigrants with lower earnings leave, the average earnings increase.

Since Borjas (1985), it has been recognized that cross-sectional studies have severe disadvantages in estimating the assimilation. As summarized by Abramitzky and Boustan (2017), "Much of the contemporary literature on immigrant assimilation has been focused on solving methodological issues in order to properly measure changes in immigrant earnings with time spent in the United States."

Panel data provide information about the same individuals over time. Also, it is easy to identify and exclude observations that leave the survey. As a result, the estimation of assimilation is not subject to cohort and outmigration biases. Many economists (G. J. Borjas 1985, Duleep and Dowhan 2002, Edin, Fredriksson and

\footnotetext{
${ }^{6}$ Immigrants from western Europe were more skilled than immigrants from eastern and southern Europe at that time.
} 
Aslund 2003, Lubotsky 2007, Kim 2009, Abramitzky, Boustan and Eriksson 2014, Hu 2000) believe regression results using longitudinal panel data are more compelling than those using cross-sectional data. However, panel surveys covering immigrants are not available in the U.S.

Economists construct longitudinal panel data from multiple resources in the U.S. The critical step is to find matching observations from cross-sectional data for two periods or match observations between cross-sectional data and panel data. For example, Kim (2009) exploits the Current Population Survey (CPS) overlapping rotation feature, where individuals who are covered twice by the CPS in one year can be matched. Then, he forms a longitudinal panel dataset using income data from the Survey of Income and Program Participation (SIPP).

Articles using constructed longitudinal data generally show moderate or no assimilation in contrast to studies using cross-sectional data. The findings suggest that Chiswick's estimation may just be due to bias due to decreasing cohort quality and negatively selected outmigration in the 1970s.

Abramitzky, Boustan, and Eriksson (2014) match individuals between 1900, 1910, and 1920 Census to form a panel dataset. All matched individuals must have stayed in the U.S. for at least ten years. They impute immigrants' earnings based on the occupation reported. Using this panel data, they find that immigrants' initial penalty is small, and there is no sign of assimilation. Their methods have two important shortcomings. First, if the assimilation process is significant in the first ten years and diminishes after that, dropping individuals who arrived less than ten years earlier drops observations when assimilation is most significant. Second, although the example above assumes people with lower earnings will leave, there are many reasons that 
migrants may return home. For example, Borjas and Bratsberg (1996) find that the outmigration population does not necessarily consist of immigrants with the lowest earnings. When immigrants from the sending country are negatively selected, this implies that people with lower earnings have greater incentives to immigrate. In this case, after arrival to the host country, it is those immigrants with relatively higher earnings that are more likely to return or remigrate. The opposite holds too. When immigrants are highly skilled relative to others in their home country, people making relatively lower earnings in the host country are more likely to return or remigrate.

Other studies using longitudinal data find that assimilation exists. Duleep and Dowhan (2002) use the Current Population Survey (CPS) in 1994 and obtain longitudinal data on the earnings of immigrants from the Social Security Administration (SSA). No data are dropped to meet a minimum year of stay. Estimates using longitudinal data formed from the CPS and SSA from 1988 to 1993 imply that immigrants experience extra earnings growth in the first ten years of stay compared to native workers. Lubotsky (2011) finds that the difference in earnings growth rates between skilled and unskilled workers leads to an overly pessimistic picture of more recent immigrants' skills. He suggests that high-skilled workers' earnings grow much faster than the earnings of low skilled workers during this period. The widening earnings gap results from the higher return to skills and widening earnings inequality, not declining cohort quality. If the return to skill were stable, he argues that the assimilation effect would be more apparent, especially for low skilled immigrants.

Many European countries have longitudinal panel data of immigrants. Constant and Massey (2003) question if negatively selected outmigration distorts assimilation effect estimates. They use the first 14 waves of German Socioeconomic Panel data (1984-1997). The regression is run separately for stayers and all immigrant workers. 
Their analysis finds that the estimated coefficients are not statistically different. Since immigrants make up about $20 \%$ of the population surveyed, it is unlikely that their results are due to the small sample size. They conclude that return migration by immigrants does little to change the assimilation estimation in Germany.

This paper presents evidence that is the bias derived from comparing estimates using cross-sectional, repeated cross-sectional, and longitudinal data is due to the linear specification of the assimilation process. I verify such findings using an non-parametric method to account for potential biases using cross-sectional and repeated crosssectional data. I find the conventional model using repeated cross-sectional data can be modified to estimate assimilation consistently.

\subsection{Data and Description}

\subsubsection{Census and ACS Data}

The analyses use the 5 percent public use microdata sample (PUMS) of the 1990 and 2000 U.S. Census and the American Community Survey (ACS) of 2010. U.S. censuses are conducted on April $1^{\text {st }}$ of each census year. The PUMS uses a 1-in-20 national random sample. ACS conducts annual surveys of 3.5 million households (about 2.7 percent of all households). The Census long-form was eliminated after 2000, but the ACS inherited many questions asked in the long form of the 2000 decennial census, making it the most consistent data for the subsequent decade. For analysis of the nation as a whole, Census and ACS are two of the best resources. I choose the data from the Integrated Public Use Microdata Series (IPUMS), a dataset from the University of Minnesota (Ruggles, et al. n.d.) that collects, preserves, and harmonizes Census and ACS data from multiple years. The observations are representative of the

entire U.S. population across time, and they have a comprehensive collection of 
socioeconomic variables. Observations are weighted to assure the sample is representative of the U.S. population.

In this paper, earnings used are the annual pre-tax earnings, that is, money received as an employee. ${ }^{7}$ The sources include wages, salaries, commissions, cash bonuses, tips, and other money income from an employer. Earnings in the Census data reflect the income during the previous calendar year, while earnings in the ACS refer to income for the past 12 months. The earnings are adjusted for inflation with the Consumer Price Index. ${ }^{8}$ Other socioeconomic variables include educational attainment, marital status, race, gender, age, and usual residence census division.

Immigrants are defined as people born outside of the U.S. The length of stay is calculated as the difference between the year of observation and the year of arrival. Immigrants are grouped into 9 cohorts based on the arrival time: before 1970, 1970-74, 1975-79, 1980-84, 1985-1990, 1991-95, 1996-2000, 2001-05, and cohort 2006-10.

\subsubsection{Demographic Description}

Cross-sectional data show demographic information of immigrants in the U.S. from 1990 to 2010. Table 2-1 summarizes the population of natives and immigrant cohorts. The predicted numbers of deaths and outmigration in each decade are listed below the population. The death prediction is based on the age structure of each immigrant cohort. The number of deaths is calculated with the number of immigrants in each age cell and the fraction of deaths in the given age cell from the corresponding

\footnotetext{
${ }^{7}$ The business income is elimated as we want to focus on how employer value the employees' work, not how sole proprietorships growth. However, author admit the assimilation effect contributes to the success of sole propreitorships too. It is just hard to distinguish the return to human capital and return to capital for sole propreitorships.

${ }^{8}$ The CPI data is available in the IPUMS dataset. Search "CPI99" on https://usa.ipums.org/usaaction/variables/live search
} 
life table ${ }^{9}$ of that year for ten years. Outmigration is estimated as the reduction in cohort size that is not due to death. Notice that the sizes of the cohort 1985 to 1990 and the cohort 1996 to 2000 increased between two census years. The increase is due to missed counts of immigrants who arrived in the U.S. in the census year after the census date. For example, an immigrant who arrived in October 2000 and missed the Census survey will tell Census 2010 that he arrived in 2000. These immigrants are captured in the next survey, causing an increase in the cohort population. Excluding these cohorts, the cohort population size shrinks at a rate of about one percent per year.

Prior studies ${ }^{10}$ show 20 to 70 percent of migrants return or re-migrate within the first ten years after arrival. The outmigration estimates in Table 2-1 are much lower. However, there is no inconsistency between the estimates in Table 2-1 and the estimates from previous articles. Since many short-term immigrants would leave in less than ten years, most of them would not answer a decennial survey. The calculation relies on population counts both at the beginning and the end of a decade. As a result, the outmigration in Table 2-1 omits many of those who stayed for less than ten years.

The native population has a net growth of 0.89 percent per year from 1990 to 2010. Immigration growth is much more substantial. The immigrant population grew at 4.6 percent per year. There are nine immigrant cohorts based on their years of arrival, as mentioned in the previous section. The size of immigration peaked in the 1996 to 2000 period, during which time over seven million immigrants arrived in the U.S. During the 2006 to 2010 period, around six million new immigrants arrived. The highest rate of outmigration estimated is 12 percent for the 1991 to 1995 cohort from

\footnotetext{
${ }^{9}$ The life table is for all people in the U.S. in a given year. 1990 - https://www.cdc.gov/nchs/data/lifetables/life89 13.pdf 2000 - https://www.cdc.gov/nchs/data/nvsr/nvsr51/nvsr51 03.pdf

${ }^{10}$ See Ahmed and Robinson (1994), Beaujot and Rappak (1989), Borjas and Bratsberg (1994), Dustmann, Fadlon, and Weiss (2011), and Edin, LaLonde, and Aslund (2000)
} 
2000 to 2010. Notice that the estimated outmigration between 1990 to 2000 is extremely small. The reason is probably the economic boom at the end of the 1990s or some unknown changes between the censuses.

Table 2-1 Population Size of Each Cohort by Year (in millions)

\section{Immigrants}

Date of Arrival

\begin{tabular}{|c|c|c|c|c|c|c|c|c|c|c|c|}
\hline Year & Natives & $\begin{array}{l}\text { IMM } \\
\text { Total }\end{array}$ & $<1970$ & $\begin{array}{l}1970 \\
-74\end{array}$ & $\begin{array}{l}1975 \\
-79\end{array}$ & $\begin{array}{l}1980 \\
-84\end{array}$ & $\begin{array}{l}1985 \\
-90\end{array}$ & $\begin{array}{l}1991 \\
-95\end{array}$ & $\begin{array}{c}1996 \\
-2000\end{array}$ & $\begin{array}{l}2001 \\
-05\end{array}$ & $\begin{array}{l}2006 \\
-10\end{array}$ \\
\hline 1990 & 225 & 22.91 & 7.6 & 2.45 & 3.11 & 4.21 & 5.53 & - & - & - & - \\
\hline Death & & (1.75) & (1.26) & $(0.11)$ & $(0.11)$ & (0.13) & (0.14) & - & - & - & - \\
\hline Emigrate & & $(0.46)$ & $(0.40)$ & $(0.06)$ & $(0.01)$ & $(0.00)$ & - & - & - & - & - \\
\hline 2000 & 247 & 34.65 & 5.95 & 2.29 & 2.99 & 4.08 & 6.52 & 6.05 & 6.78 & - & - \\
\hline Death & & (2.12) & (1.08) & $(0.16)$ & $(0.16)$ & $(0.18)$ & (0.21) & (0.18) & (0.15) & - & - \\
\hline Emigrate & & (1.66) & (0.10) & $(0.01)$ & $(0.18)$ & $(0.21)$ & (0.44) & $(0.73)$ & & - & - \\
\hline 2010 & 265 & 44.13 & 4.77 & 2.12 & 2.65 & 3.70 & 5.86 & 5.14 & 7.15 & 6.81 & 5.93 \\
\hline
\end{tabular}

Note: The sources of data are the 1990 U.S. Census, the 2000 U.S. Census, and the American Community Survey of 2010. Populations are in thousands. The cohort categorization rule before 1990 is based on the survey question from the census in 1990, in which respondents were asked "When did this person come to the United States to stay?" The answers include year ranges, 1987 to 1990, 1985 or 1986, 1982 to 1984,1980 or 1981 , and others. For immigrants with an arrival range, the last year in the range is used as the arrival year indicator in the data. In 2000 and 2010, respondents answer, "When did this person come to live in the United States?" with the answer recorded as the calendar year. Predicted death is calculated with the life table based on the age structure.

Table 2-2 presents the race composition of immigrants and natives based on our samples. Most natives are white. In contrast, less than 20 percent of the most recent wave of immigrants are white. The second-largest race in the U.S. is African American, representing approximately 11 to 12 percent of the native population. The proportion of black immigrants has increased, but black accounts for less than 10 percent of the immigrant population. If immigration continues at its current rate, the black population will be surpassed by Asians and Latin Americans shortly.

The current immigration wave includes many immigrants from Asia and Latin America. Table 2-2 shows three race categories, Chinese, other Asian, and Hispanic. None of these groups account for more than 4.3 percent of the native population (less 
than 0.5 percent for Asian). However, the Asian and Hispanic groups make up more than 40 percent of immigrants arriving since 1970.

The country of origin affects immigrants' performance in the receiving country (Borjas \& Bratsberg, 1994; Abramitzky, Boustan, \& Eriksson, 2014). Many factors, such as the development level, culture, and relationship with the U.S., determine how well an immigrant can fit into the U.S. There are two differences between the current wave and the mass migration wave between 1880 and 1920. First, immigrants during the earlier period were mostly from developed countries in Europe. Second, Asian and Hispanic immigrants and their descendants have unique physical peculiarities that distinguish them from the native-born white population. The shifting race composition points to the possibility of changing cohort quality, which raises questions for the estimation of assimilation. 
Table 2-2 Selected Race Composition of Each Cohort by Year

Date of Arrival

\begin{tabular}{|c|c|c|c|c|c|c|c|c|c|c|c|}
\hline \multirow{2}{*}{ Year } & \multirow[b]{2}{*}{ Native } & \multirow[b]{2}{*}{$\begin{array}{l}\text { IMM } \\
\text { total }\end{array}$} & \\
\hline & & & $<1970$ & $1970-74$ & $1975-79$ & $1980-84$ & $1985-90$ & $1991-95$ & $1996-2000$ & 2001-05 & 2006-10 \\
\hline \multicolumn{12}{|l|}{ White } \\
\hline 1990 & $84.5 \%$ & $32.3 \%$ & $57.5 \%$ & $21.2 \%$ & $20.9 \%$ & $15.7 \%$ & $21.4 \%$ & - & - & - & - \\
\hline 2000 & $81.6 \%$ & $23.6 \%$ & $52.9 \%$ & $22.3 \%$ & $19.3 \%$ & $13.1 \%$ & $13.9 \%$ & $19.3 \%$ & $22.1 \%$ & - & - \\
\hline 2010 & $78.7 \%$ & $20.2 \%$ & $50.2 \%$ & $23.0 \%$ & $20.6 \%$ & $14.5 \%$ & $13.8 \%$ & $16.6 \%$ & $16.3 \%$ & $15.5 \%$ & $18.4 \%$ \\
\hline \multicolumn{12}{|l|}{ Black } \\
\hline 1990 & $11.0 \%$ & $7.4 \%$ & $4.4 \%$ & $9.7 \%$ & $8.3 \%$ & $10.3 \%$ & $7.7 \%$ & - & - & - & - \\
\hline 2000 & $11.6 \%$ & $6.9 \%$ & $4.3 \%$ & $8.4 \%$ & $7.1 \%$ & $8.8 \%$ & $7.4 \%$ & $6.8 \%$ & $6.7 \%$ & - & - \\
\hline 2010 & $12.3 \%$ & $8.2 \%$ & $4.5 \%$ & $8.6 \%$ & $7.3 \%$ & $9.6 \%$ & $8.5 \%$ & $7.6 \%$ & $8.3 \%$ & $9.1 \%$ & $8.9 \%$ \\
\hline \multicolumn{12}{|c|}{ Chinese } \\
\hline 1990 & $0.1 \%$ & $5.1 \%$ & $2.6 \%$ & $5.2 \%$ & $6.7 \%$ & $7.9 \%$ & $9.0 \%$ & - & - & - & - \\
\hline 2000 & $0.1 \%$ & $5.1 \%$ & $2.6 \%$ & $4.5 \%$ & $6.0 \%$ & $6.9 \%$ & $6.6 \%$ & $6.6 \%$ & $6.4 \%$ & - & - \\
\hline 2010 & $0.2 \%$ & $5.5 \%$ & $2.6 \%$ & $4.4 \%$ & $5.6 \%$ & $6.5 \%$ & $6.1 \%$ & $6.2 \%$ & $5.8 \%$ & $5.3 \%$ & $7.6 \%$ \\
\hline \multicolumn{12}{|c|}{ Other Asian } \\
\hline 1990 & $0.2 \%$ & $14.6 \%$ & $4.2 \%$ & $16.8 \%$ & $22.1 \%$ & $22.7 \%$ & $20.8 \%$ & - & - & - & - \\
\hline 2000 & $0.3 \%$ & $15.0 \%$ & $4.6 \%$ & $15.4 \%$ & $19.0 \%$ & $21.2 \%$ & $17.0 \%$ & $19.5 \%$ & $17.0 \%$ & - & - \\
\hline 2010 & $0.5 \%$ & $16.9 \%$ & $5.0 \%$ & $15.8 \%$ & $19.9 \%$ & $22.6 \%$ & $17.9 \%$ & $19.7 \%$ & $15.9 \%$ & $17.8 \%$ & $23.6 \%$ \\
\hline \multicolumn{12}{|c|}{ Hispanic } \\
\hline 1990 & $2.0 \%$ & $20.0 \%$ & $18.1 \%$ & $23.4 \%$ & $19.1 \%$ & $21.1 \%$ & $19.4 \%$ & - & - & - & - \\
\hline 2000 & $2.4 \%$ & $21.2 \%$ & $20.2 \%$ & $21.6 \%$ & $17.8 \%$ & $20.9 \%$ & $22.3 \%$ & $20.6 \%$ & $21.2 \%$ & - & - \\
\hline 2010 & $4.3 \%$ & $29.3 \%$ & $25.4 \%$ & $30.1 \%$ & $25.4 \%$ & $28.5 \%$ & $31.5 \%$ & $29.2 \%$ & $32.4 \%$ & $30.8 \%$ & $24.5 \%$ \\
\hline
\end{tabular}

The population includes people age 25 and above. Observations with missing education attainment are dropped. Unselected race categories include American Indian, Japanese, and other races. 
Table 2-3 shows the education composition of natives and immigrant cohorts. Education is reported in three categories for simplicity, instead of five education attainment levels used in the analysis. Only people over 24 years old are included. Immigrants have heavy tails at both ends of the distribution. Natives are overrepresented among the categories some college or bachelor's degree.

There is no evidence of decreasing cohort quality in educational attainment. When comparing immigrants who stayed less than ten years in 1990, 2000, and 2010, later cohorts contain more people with bachelor's degrees or advanced degrees. Since educational attainment is an essential factor in skills, this suggest that the cohort quality has been increasing since 1980. It is reasonable to have a pessimistic projection by looking at immigrants in the 1970s and 1980s since they have less education than previous immigrants. However, the trend turns to positive from 1980 to 2010. The assimilation estimates would be negatively biased if Borjas (1985) were right.

Table 2-3 Education Composition by Cohort and Year

Date of Arrival

\begin{tabular}{ccccccccccc}
\multirow{2}{*}{ Year } & Nativ & $<197$ & 1970 & 1975 & 1980 & 1985 & 1991 & $1996-$ & $2001-$ & $2006-$ \\
& $\mathrm{e}$ & 0 & -74 & -79 & -84 & -90 & -95 & 2000 & 05 & 10 \\
\hline
\end{tabular}

High School or Less

$1990 \quad 54.1 \% \quad 62.0 \% \quad 61.2 \% \quad 59.7 \% \quad 60.9 \% \quad 56.6 \%$

$2000 \quad 46.8 \% \quad 55.6 \% \quad 54.7 \% \quad 54.4 \% \quad 58.8 \% \quad 61.6 \%$

$2010 \quad 40.6 \% \quad 50.8 \% \quad 51.8 \%$

Some College or College

$1990 \quad 38.9 \% \quad 30.2 \% \quad 30.3 \% \quad 31.9 \% \quad 31.0 \% \quad 32.3 \%$

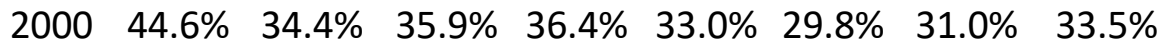

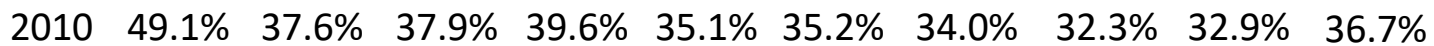

Master's Degree and Higher

\begin{tabular}{ccccccccccc}
1990 & $7.1 \%$ & $7.7 \%$ & $8.5 \%$ & $8.4 \%$ & $8.1 \%$ & $11.1 \%$ & - & - & - & - \\
2000 & $8.7 \%$ & $10.0 \%$ & $9.4 \%$ & $9.0 \%$ & $8.3 \%$ & $8.7 \%$ & $11.4 \%$ & $14.4 \%$ & - & - \\
2010 & $10.3 \%$ & $11.7 \%$ & $10.4 \%$ & $11.7 \%$ & $8.7 \%$ & $8.7 \%$ & $10.3 \%$ & $11.0 \%$ & $12.0 \%$ & $15.2 \%$ \\
\hline
\end{tabular}

Note: Sources of data are the Censuses of 1990 and 2000, and the American Community Survey of 2010. The data include people with age strictly greater than 24 . 
Some studies suggest that the shift in the country of origin changes the quality of education of immigrants. A Mexican immigrant with a college degree is probably less competitive than a college graduate from Germany because higher education is more advanced in Germany. This issue can be addressed by controlling for educational attainment and country of origin.

Table 2-3 also shows that the proportion of immigrants with the lowest educational attainment in a cohort drops from 1990 to 2010. This pattern holds for all cohorts, except the 1985 to 1990 cohort. The negatively selected outmigration of immigrants is not the only explanation. Other explanations include that most immigrants who die have lower levels of education, and some immigrants finished higher education. These two reasons can be distinguished by comparing the older cohorts with newer cohorts. Since the decrease in the size of older cohort is dominated by death, the decrease in the proportion of less educated people in older cohorts is primarily due to death of less educated. On the other hand, the more recent cohorts are generally made up of young people who are less likely to die. The education distribution of cohort 1985-90, 1991-95, and 1996-2000 does not show substantial negatively selected outmigration in the early age of immigration. Negatively selected outmigration by education attainment is moderate, consistent with Constant and Massey's (2003) findings in Germany.

It is critical to adjust for age in the assimilation study because it determines earnings both as a proxy for experience and the aging process. In general, older people are more experienced and productive. Table 2-4 shows the age composition of natives and immigrants. Immigrants are overrepresented in the working-age range from 20 years to 60 years of age in all three cross-sectional datasets. Most immigrants, legal or illegal, asylee or economic immigrants, choose the U.S. partially for its developed 
economy and abundant job opportunities. The most recent immigrants are much younger than both the native population and previous immigrants.

Chueng et al. (2011) find that younger immigrants acculturate faster. As a result, the economic assimilation process should be faster when immigrants are young. In contrast, older immigrants are less able to adjust to the host culture. This finding raises the question, "Is the assimilation effect linear as newer cohorts are over-represented with young immigrants?" With a linear model, the assimilation effect is implicitly assumed to contribute to wage growth at a constant rate over time. Recently arrived cohorts may have faster assimilation rates because they have more young immigrants, but estimates may appear to show that the difference in wage growth is due to cohort differences. 
Table 2-4 Age Composition of Natives and Immigrants by Cohort and Year

Immigrant Arrival Year

<197 1970- 1975- 1980- 1985- 1991-1996- 2001- 2006-

\begin{tabular}{cccccccccccc} 
Age Native Imm & Imm & 0 & 74 & 79 & 84 & 90 & 95 & 2000 & 05 & 10 \\
\cline { 2 - 11 } 1990 & & & & & & & & & & & \\
$0-9$ & $15.6 \%$ & $5.3 \%$ & - & - & - & $5.8 \%$ & $17.7 \%$ & - & - & - & - \\
$10-19$ & $14.3 \%$ & $11.0 \%$ & - & $9.7 \%$ & $18.7 \%$ & $17.5 \%$ & $17.3 \%$ & - & - & - & - \\
$20-29$ & $15.6 \%$ & $20.4 \%$ & $8.3 \%$ & $20.0 \%$ & $20.6 \%$ & $27.8 \%$ & $31.3 \%$ & - & - & - & - \\
$30-39$ & $16.5 \%$ & $21.2 \%$ & $14.6 \%$ & $26.3 \%$ & $31.5 \%$ & $26.9 \%$ & $18.0 \%$ & - & - & - & - \\
$40-49$ & $12.5 \%$ & $15.2 \%$ & $19.0 \%$ & $25.5 \%$ & $16.2 \%$ & $11.7 \%$ & $7.7 \%$ & - & - & - & - \\
$50-59$ & $8.7 \%$ & $10.2 \%$ & $18.7 \%$ & $10.5 \%$ & $6.8 \%$ & $5.2 \%$ & $3.8 \%$ & - & - & - & - \\
$60-69$ & $8.4 \%$ & $7.9 \%$ & $17.2 \%$ & $4.7 \%$ & $3.6 \%$ & $3.0 \%$ & $2.7 \%$ & - & - & - & - \\
$70+$ & $8.5 \%$ & $8.8 \%$ & $22.2 \%$ & $3.2 \%$ & $2.8 \%$ & $2.0 \%$ & $1.4 \%$ & - & - & - & - \\
\hline 2000 & & & & & & & & & & & \\
$0-9$ & $15.5 \%$ & $4.4 \%$ & - & - & - & - & - & $7.0 \%$ & $16.1 \%$ & - & - \\
$10-19$ & $15.0 \%$ & $9.9 \%$ & - & - & - & $4.6 \%$ & $15.5 \%$ & $17.0 \% 17.7 \%$ & - & - \\
$20-29$ & $12.8 \%$ & $19.4 \%$ & - & $7.1 \%$ & $16.7 \%$ & $17.5 \%$ & $21.3 \%$ & $29.7 \% 31.8 \%$ & - & - \\
$30-39$ & $14.4 \%$ & $22.5 \%$ & $9.1 \%$ & $21.9 \%$ & $22.5 \%$ & $31.1 \%$ & $32.9 \%$ & $23.6 \%$ & $18.3 \%$ & - & - \\
$40-49$ & $14.9 \%$ & $18.1 \%$ & $17.4 \%$ & $29.0 \%$ & $34.1 \%$ & $27.5 \%$ & $17.4 \%$ & $11.6 \%$ & $8.6 \%$ & - & - \\
$50-59$ & $10.9 \%$ & $11.3 \%$ & $23.1 \%$ & $25.9 \%$ & $15.7 \%$ & $10.8 \%$ & $6.8 \%$ & $5.5 \%$ & $3.8 \%$ & - & - \\
$60-69$ & $7.2 \%$ & $7.2 \%$ & $22.3 \%$ & $10.0 \%$ & $6.4 \%$ & $4.7 \%$ & $3.3 \%$ & $3.2 \%$ & $2.3 \%$ & - & - \\
$70+$ & $15.2 \%$ & $7.3 \%$ & $28.1 \%$ & $6.2 \%$ & $4.6 \%$ & $3.7 \%$ & $2.7 \%$ & $2.4 \%$ & $1.3 \%$ & - & - \\
\hline 2010 & & & & & & & & & & & \\
$0-9$ & $14.8 \%$ & $2.7 \%$ & - & - & - & - & - & - & $0.1 \%$ & $6.3 \%$ & $12.8 \%$ \\
$10-19$ & $14.9 \%$ & $7.4 \%$ & - & - & - & - & $0.1 \%$ & $7.3 \%$ & $14.3 \%$ & $14.8 \% 14.1 \%$ \\
$20-29$ & $13.4 \%$ & $15.9 \%$ & - & - & - & $5.7 \%$ & $15.9 \%$ & $16.0 \%$ & $19.3 \%$ & $27.2 \% 31.0 \%$ \\
$30-39$ & $11.6 \%$ & $21.3 \%$ & - & $9.0 \%$ & $19.0 \%$ & $18.0 \%$ & $20.4 \%$ & $29.8 \% 32.5 \%$ & $26.5 \%$ & $20.1 \%$ \\
$40-49$ & $13.2 \%$ & $20.0 \%$ & $11.9 \%$ & $21.9 \%$ & $21.8 \%$ & $30.0 \%$ & $33.5 \%$ & $24.9 \% 19.0 \%$ & $13.4 \%$ & $9.9 \%$ \\
$50-59$ & $13.3 \%$ & $15.0 \%$ & $21.4 \%$ & $28.3 \%$ & $34.1 \%$ & $28.0 \%$ & $18.0 \%$ & $11.7 \%$ & $8.7 \%$ & $6.7 \%$ & $5.4 \%$ \\
$60-69$ & $9.6 \%$ & $9.4 \%$ & $27.1 \%$ & $27.7 \%$ & $16.3 \%$ & $11.6 \%$ & $7.1 \%$ & $5.9 \%$ & $3.6 \%$ & $3.0 \%$ & $3.9 \%$ \\
$70+$ & $9.2 \%$ & $8.3 \%$ & $39.5 \%$ & $13.1 \%$ & $8.8 \%$ & $6.7 \%$ & $5.0 \%$ & $4.5 \%$ & $2.5 \%$ & $2.2 \%$ & $2.9 \%$ \\
\hline \hline
\end{tabular}

Note: The source of data are the Census of 1990, the Census of 2000, and the American Community Survey of 2010. The fraction is over the cohort size.

\subsubsection{Sampling Description}

In order to make a meaningful inference, some tables in the previous section use different samples. This section briefly summarizes the sample selection criteria. The Appendix provides a detailed description of the sample.

The analysis excludes people who are less than 25 years of age for two reasons.

First, many young people are recent graduates. Their wage increases are more related 
to graduation and less to assimilation. The inclusion of young people would also create technical issues for implementing a multivariate logit model used in the later section since there are no people under 25 in the immigration cohort of people arriving before 1970 in the 2000 and 2010 surveys.

\subsection{Main Analysis}

\subsubsection{Conventional Regression Model Using Cross-Sectional Data}

The conventional model used to estimate the immigrant assimilation is an extension of the classic wage function. The classic wage function, known as the Mincer (1958) earnings function, explains the wage as a function of experience and education. Mincer's model is common in many labor economics studies that include a broader set of covariates, such as gender, race, marital status, and region. This paper includes all the covariates above.

The base model using cross-sectional data can be written as

$$
\ln \left(\text { wage }_{i}\right)=\alpha+\beta \cdot y s m_{i}+\gamma_{1} \cdot a g e_{i}+\gamma_{2} \cdot a g e_{i}^{2}+\boldsymbol{\theta} \cdot \boldsymbol{X}_{\boldsymbol{i}}+\varepsilon_{i}
$$

where wage $_{i}$ is the annual earnings of individual $i ; y s m$ stands for years since migration; $a g e_{i}$ is age, a common proxy for experience when a direct measure is not available and education attainment is controlled. $\boldsymbol{X}_{\boldsymbol{i}}$ are control variables, like educational attainment, gender, and other factors; $\varepsilon_{i}$ is the error term with mean zero.

Coefficient $\beta$ measures the average growth in earnings for staying one more year in the U.S. This model exploits the variance in the length of stay after the initial migration of different individuals while controlling for all earnings determinants. The idea is to compare immigrants' earnings residuals in addition to the prediction using the earnings 
function. The difference shows whether staying in the host country for more time contributes to earnings growth.

This model can be estimated with both cross-sectional data and panel data. Many articles using panel datasets, such as Kim (2006) and Abramitzky, Boustan, and Eriksson (2014), also include a regression model using cross-sectional data for comparison. This paper begins with an OLS regression using cross-sectional data to replicate those studies.

The OLS regression using cross-sectional data is subject to biases since the model compares immigrants in different cohorts. The sign of the bias is determined by whether the "cohort quality" increases or decreases over time. As per our previous discussion, recent immigration cohorts may have lower quality due to the inflow of a large share of low-skilled Hispanic immigrants. As a result, the average earnings of immigrants who arrived recently are expected to be lower than that of immigrants who arrived earlier. The cohort bias is positive under this circumstance.

With repeated cross-sectional data, the cohort bias can be corrected with the following model,

$$
\begin{aligned}
& \ln \left(\text { wage }_{i j t}\right)=\alpha+\mu_{j}+\beta \cdot y s m_{i j t}+\gamma_{1} \cdot a g e_{i j t}+\gamma_{2} \cdot a g e_{i j t}^{2}+y e a r_{t}+\boldsymbol{\theta} \cdot \boldsymbol{X}_{i j t}+ \\
& \varepsilon_{i j t}
\end{aligned}
$$

The time subscript indicates the time when this data are collected. The subscript, $j$, stands for the immigrant cohort. The year fixed effect, year $r_{t}$ captures market conditions at time $t . \mu_{j}$ is a cohort indicator, which categorizes immigrants based on their arrival periods. In addition to Mincer's specification, I allow a quadratic age 
function. In practice, there is little difference except quadratic age function can explain more earnings growth.

After adding the cohort fixed effect, $\mu_{j}$, the estimated coefficient $\hat{\beta}$ uses the within-cohort variation to identify the assimilation rate. Earnings differences due to length of stay in the U.S. are compared between people in the same immigration cohort. As a result, the cohort bias is corrected, changing the assimilation estimate. Given the assumption that cohort quality is declining over time, the estimated $\hat{\beta}$ should be smaller.

We can run a simple test to verify if the estimate's decrease is due to decreasing cohort quality. comparing the importance of fix effects in one regression without other control variables and one regression with control variables. When there is no control variable, the assimilation rate estimates include changes in education, marital status, region, race, and other factors. After adding these control variables, the bias should be smaller as the comparison is based on cohort differences not related to these factors.

Insofar as the cohort fixed effect controls for differences in cohort quality, the difference between two estimated $\hat{\beta}$ should decrease if more control variables are included. For example, if the average educational attainment decreases from the older cohort to the newer cohort, what appears as assimilation in the cross-sectional data partially reflects the difference in educational attainment. When education is included as an explanatory variable, the model identifies assimilation within the same education group. The bias should be smaller.

In actual data, cohort quality is probably a mix of both smooth trends and sudden shocks. Controlling grouped cohort fixed effects may not be very useful since cohort groups are mostly arbitrarily chosen without identifying when a shock occurs in cohort quality. 
Both estimates in equation (2.1) and (2.2) are subject to outmigration bias on unmeasured factors, which cannot be resolved with the conventional cross-sectional analysis. When leaving immigrants are predominately lower skilled, the remaining immigrants' average earnings become higher without any assimilation. Research using panel data where no assimilation effect occurs may conclude that estimates of assimilation using cross-sectional data are positive due to cohort bias and outmigration bias. The question regarding whether outmigration bias is large enough to explain assimilation estimates is examined in Section V.

\subsubsection{Estimating Assimilation with Panel Data}

A longitudinal panel dataset has repeated observations of the same person over time. This property is ideal for correcting the cohort bias since all the people are compared with themselves over time. The wage growth path is specific. Migrants who left are self-identified as missing in subsequent surveys. The room for outmigration bias is small. As a result, estimating assimilation with a longitudinal panel dataset is compelling in assimilation research.

The problem is in the process of constructing the longitudinal panel data with cross-sectional data. To form longitudinal datasets as Abramitzky, Boustan, and Erikson (2014) and others do, the most recent immigrants must be dropped from the data because they are not present in the prior survey. For example, Abramitzky, Boustan, and Erikson (2014) match observations across two censuses, which means all observations pertain to those who stayed in the U.S. for at least ten years. Only such matched observations are merged with income data from the Social Security Administration and the SIPP. 
Although I focus on a different period than Abramitzky, Boustan, and Erikson (2014), their paper identifies relevant issues with the panel data construction process. A constructed panel dataset is generally small due to the low match rate and limitations on income history data. Whether the sample from the panel dataset represents the assimilation process of all immigrants depends on the selection process. If the selection process is not random, the authors need to identify who are excluded and how they are different. The general solution is to test if the matching process leads to a significant change in the distribution of selected characteristics, although there may be unobservables that may lead to bias in estimation.

Even when return migration is not selective-i.e., when the characteristics of those immigrants who return are not different from those who stay-estimates of assimilation may be biased. The problem relates to the length of stay for those in the matched sample. Only individuals who stay in the U.S. for at least one complete survey period are in the matched sample. Suppose the two cross-sectional surveys used for matching separate by ten years, immigrants who were in the U.S. for less than ten years, are automatically excluded from the panel dataset. ${ }^{11}$ This selection bias could be severe for two reasons. First, immigrants who are already more acculturated to U.S. society upon arrival may be over-represented in the longitudinal dataset. These people may not be very different from native workers at the beginning. Second, short-term immigrants may be more sensitive to assimilation effects. Interpersonal and language skills may accumulate faster in the early years after arrival. Dropping short-term immigrants may reduce estimated assimilation.

\footnotetext{
${ }^{11}$ The most exreme case will be 19 years as one came right after a decennial survey.
} 
Chiswick (1978) concludes that the assimilation process ends after 10 to 15 years. I use repeated cross-sectional data to replicate the conventional model's findings with data from 1990 to 2010 . The findings call into question the size of the cohort and outmigration biases. Then, I use a more flexible model that adjusts for migrant characteristics to learn more about the assimilation processes and cohort bias. It turns out that assimilation is fast in the first ten years and slows down in later years. When we add a quadratic term of the years since migration variable to the existing models, the results are consistent with this explanation.

Lubotsky (2011) discusses both disadvantages mentioned above and three other challenges when matching cross-sectional data to construct a longitudinal dataset. These challenges include: some matched data cannot be matched with any earnings record; some observations are moving back and forth across borders; and there may be measurement error in earnings data due to the top coding of data. As a result, he argues that the comparison between estimates using cross-sectional data and estimates using longitudinal data may not be very informative. It is hard to measure any cross-sectional biased in estimates are when the validity of the longitudinal estimates is in question.

\subsubsection{Controlling for Observed Characteristics}

The non-parametric approach is inspired by Chiquiar and Hanson (2005). This approach reweights the observed distribution of immigrants' characteristics, such as gender, education, and age, to a native-born benchmark distribution and constructs a counterfactual earnings distribution based on this benchmark. The counterfactual earnings distribution is then compared with the native-born earnings distribution. Since differences in characteristics are accounted for, the comparison can be taken to indicate 
how employers treat immigrants with specified characteristics, based on length of stay in the U.S.

The earnings distribution of immigrant cohort $j$ is decomposed as,

$g(w \mid C=j, D=1)=\int f^{j}(w \mid x) h(x \mid C=j, D=1) d x \quad j=0,1, \ldots, J$

where $w$ is earnings. $f^{j}(w \mid x)$ is the earnings assignment function given characteristics $x$ of cohort $j ; h(\cdot)$ is the distribution of characteristics; and $C$ stands for the cohort. There are $J+1$ cohorts, one native-born cohort, cohort 0 , and $J$ immigrant cohorts, based on when the immigrant arrived in the U.S. $D$ is an indicator of being in the labor force.

The counterfactual earnings distribution of cohort $j$ based on the native-born distribution of characteristics $h(x \mid C=0, D=1)$ from cohort 0 is written as,

$g_{0}^{j}(w \mid D=1)=\int f^{j}(w \mid x) h(x \mid C=0, D=1) d x \quad j=1, \ldots, J$

This counterfactual earnings distribution can be tied to the observed distribution in (3) as,

$$
\begin{aligned}
& g_{0}^{j}(w \mid D=1)=\int f^{j}(w \mid x) h(x \mid C=0, D=1) \times \frac{h(x \mid C=j, D=1)}{h(x \mid C=j, D=1)} d x \\
& \quad=\int \theta^{j} f^{j}(w \mid x) h\left(x \mid C_{i}=j, D_{i}=1\right) d x \\
& \theta^{j}(x)=\frac{h\left(x \mid C_{i}=0, D_{i}=1\right)}{h\left(x \mid C_{i}=j, D_{i}=1\right)}
\end{aligned}
$$

$\theta^{j}(x)$ is the weight adjustment ratio reflecting the difference between the distributions of the natives and an immigration cohort on observed characteristics. As shown in equation (2.5), the counterfactual earnings distribution can be derived from 
the earnings distribution of an immigrant cohort by adjusting the distribution to correspond to the distribution of characteristics for natives.

Using Bayes' theorem and the property of conditional probability,

$$
\begin{aligned}
& h(x)=\frac{h\left(x \mid C_{i}=j, D_{i}=1\right) \cdot \operatorname{Pr}\left(C_{i}=j, D_{i}=1\right)}{\operatorname{Pr}\left(C_{i}=j, D_{i}=1 \mid x\right)} \\
& =\frac{h\left(x \mid C_{i}=j, D_{i}=1\right) \cdot \operatorname{Pr}\left(C_{i}=j, D_{i}=1\right)}{\operatorname{Pr}\left(D_{i}=1 \mid C_{i}=j, x\right) \cdot \operatorname{Pr}\left(C_{i}=j \mid x\right)}
\end{aligned}
$$

Using equation $(2.7), \theta^{j}(x)$ can be written as,

$$
\begin{gathered}
\theta^{j}(x)=\frac{\operatorname{Pr}\left(D_{i}=1 \mid C_{i}=0, x\right)}{\operatorname{Pr}\left(D_{i}=1 \mid C_{i}=j, x\right)} \cdot \frac{\operatorname{Pr}\left(C_{i}=0 \mid x\right)}{\operatorname{Pr}\left(C_{i}=j \mid x\right)} \\
\cdot \frac{\operatorname{Pr}\left(C_{i}=j, D_{i}=1\right)}{\operatorname{Pr}\left(C_{i}=0, D_{i}=1\right)}
\end{gathered}
$$

The adjustment factor, $\theta^{j}(x)$, has three components. The last component is the joint probability that one is in cohort $j$ and labor force regardless of skill. It is constant since it is irrelevant to $x$. We can ignore this component since the total weight after the reweighting process will be adjusted to ensure the total represented population does not change. The first term captures the labor force participation rate of cohort $j$ given observed characteristics. For example, if native workers with higher skills tend to leave their highly educated partners at home to raise kids, and immigrant couples tend to maximize the total income regardless of skill level, high skilled immigrants would receive less weight because of this ratio. However, such a shift in earnings distribution is not a function of the market. As a result, it is excluded so that the adjustment does not consider the difference in labor force participation across different cohort-skill cells. 
The middle term is then used to adjust for the characteristic difference between cohort $j$ and natives. As a result, the adjustment factor is,

$$
\theta^{j}(x)=\frac{\operatorname{Pr}\left(C_{i}=0 \mid x\right)}{\operatorname{Pr}\left(C_{i}=j \mid x\right)}
$$

For multiple-year data, the earnings distribution of immigrant cohorts in year $t$ is reweighted with a factor for that year,

$$
\theta_{t}^{j}=\frac{\operatorname{Pr}\left(C_{i}=0 \mid x, t\right)}{\operatorname{Pr}\left(C_{i}=j \mid x, t\right)}
$$

where I suppress the dependence of $\theta_{t}^{j}$ on x. The earnings distribution of immigrant cohorts is made comparable to the earnings distribution of natives of that year using the distribution of characteristics for natives in that year as the benchmark. Then, earnings distributions are reweighted again by the following factor so that all earnings distributions of immigrant cohorts are comparable to the earnings distribution of natives in the base year,

$$
\theta_{t}^{T}=\frac{\operatorname{Pr}\left(C_{i}=0 \mid x, t=\text { base year }\right)}{\operatorname{Pr}\left(C_{i}=0 \mid x, t\right)}
$$

As a result, the weight factor for repeated cross-sectional data is,

$$
\theta_{t}^{j T} \propto \theta_{t}^{j} \theta_{t}^{T}
$$

The advantage of this approach is that it adjusts different cohorts' characteristics at different times to the same benchmark. The earnings assignment to all immigrant cohorts is based on the same observed variables, so that neither cohort differences nor 
outmigration can affect the counterfactual earnings distribution ${ }^{12}$ if all relevant variables are observed. As shown in Section III, the shift in race composition indicates that cohort quality may be dropping and that the average educational attainment of a cohort grows as immigrants die or leave the U.S. However, after adjusting the race and education distributions, the counterfactual earnings distributions of immigrant cohorts are not affected by these variables' changes.

In theory, $\mathrm{x}$ would include as variables that affect earnings. In practice, $\theta_{t}^{j T}(x)$ must be estimated based on a set of measured variables. The earnings differences between immigrant cohorts and natives are due to immigration cohorts' different earnings assignment functions.

The constructed counterfactual earnings distribution,

$$
g_{0 t}^{j}\left(w \mid D_{i}=1\right)=\int \theta_{t}^{j T} f^{j}(w \mid x) h\left(x \mid C_{i}=j, D_{i}=1, t\right) d x
$$

represents how employers value immigrants who have the same distribution of characteristic as natives, holding labor force participation unchanged. The difference in earnings distribution,

$$
g_{0 t}^{j}\left(w \mid D_{i}=1\right)-g\left(w \mid C_{i}=0, D_{i}=1, t=\text { base year }\right)
$$

shows the difference in the density for each earnings level $w$ for natives and immigrants with the same distribution of measured characteristics. When immigrants and natives with the same measured characteristics are perfect substitutes from the employers' points of view, the earnings assignment function for immigrant cohort $j, f^{j}(w \mid x)$, is

${ }^{12}$ For example, $\mathrm{Hu}$ (2000) finds that the educational attainment improves in each immigrant cohort across 1970, 1980, and 1990 Censuses, indicating negatively self-selected outmigration on educational attainment. 
identical to the earnings assignment function of natives, i.e., the earnings distribution of natives and the adjusted earnings distribution of the immigration cohort are identical. Assimilation is defined as a convergence of the earnings assignment function of immigrants to that of natives. People who alter their characteristics in the U.S., for example, obtaining an advanced education degree, cannot contribute to estimated assimilation based on this measure.

Unlike Abramitzky, Boustan, and Erikson (2014), who use occupational improvement to measure the assimilation process, ${ }^{13}$ this paper focuses on earnings. Whether or not they are associated with occupational changes is irrelevant. The improvements in communication skills, cultural knowledge, and other skills may or may not lead to occupation changes. For example, a math professor from Russia may receive higher earnings when his English writing and speaking skills improve to describe his ideas more clearly to editors and his students, even if there is no change to his occupational designation.

This non-parametric method is more flexible than OLS regression. I can also specify any distribution of characteristics as the base distribution. A corresponding wage distribution would be created. I choose the distribution of characteristics of natives in accord with assimilation theory. This method estimates the distribution of earnings that employers would offer to a native group and an immigrant group with an identical observed characteristics distribution.

${ }^{13}$ They use occupation scores to proxy earnings. In their analysis, earnings improvement only occurs when an immigrant moves into an occupation with higher average earnings. 


\subsection{Results}

\subsubsection{Conventional Estimates of Assimilation}

This section presents four regression estimates of assimilation. The results call into question the role of cohort bias and the outmigration bias in assimilation estimation using conventional methods. Table 2-5 shows the results of a regression based on equations (2.2) using repeated cross-sectional data.

Table 2-5 Regression

\begin{tabular}{ccccc}
\multicolumn{5}{c}{ Regression Results } \\
& (A) & (B) & (C) & (D) \\
\hline \multirow{2}{*}{ Year since migration } & $0.013^{* * *}$ & $0.006^{*}$ & $0.012^{* * *}$ & 0.002 \\
& $(0.001)$ & $(0.003)$ & $(0.002)$ & $(0.002)$ \\
Cohort & & & & $\checkmark$ \\
year \& age & $\checkmark$ & $\checkmark$ & $\checkmark$ & $\checkmark$ \\
other control & & $\checkmark$ & $\checkmark$ & $\checkmark$ \\
\hline \hline
\end{tabular}

Data from the 1990 and 2000 Censuses, and the 2010 ACS. The standard error is robust and clustered by cohorts. Cohort indicator: immigrants arrived: before 1970, 1970-74, 1975-79, 1980-84, 1985-1990, 1991-95, 1996-2000, 2001-05, 2006-10. Age is controlled as a quadratic function. Other control variables include gender, race, marital status, educational attainment, and region. Educational attainment is classified as less than high school, high school or equivalent, some college, bachelor's degree, and advanced degree. The regional classification is: New England Division, Middle Atlantic Division, East North Division, West North Central Division, South Atlantic Division, East South Central Division, West South Central Division, Mountain Division, and Pacific Division. Individual weights based on the survey design are used for all regression. ${ }^{* * *} p<0.01,{ }^{* *} p<0.05,{ }^{*} p<0.1$

Column A shows the simple regression controlling only years since migration, calendar year fixed effects, and a quadratic age function. The estimated assimilation coefficient is 1.3 percent, implying that, for two otherwise identical immigrants, the one who stayed one more year has 1.3 percent higher earnings in addition to the earnings growth predicted by age and year. Column B adds the cohort fixed effect. With cohort controlled, the assimilation estimate exploits the within-cohort variance only. The estimated coefficient drops to 0.6 percent. This result is similar to findings of 
Borjas (1985) and Abramitzky, Boustan, and Eriksson (2014). Their interpretation is that the unaccounted differences between cohorts account for half of the estimated assimilation in Column A. For example, since the regression does not control race, the assimilation estimate is positively biased. An immigrant who came earlier is more likely to be non-Hispanic and has higher earnings, creating a positive bias.

Column $\mathrm{C}$ shows the regression without the cohort fixed effect but with more control variables. The extended set of control variables include a quadratic age function, year fixed effects, gender, race, educational attainment, marital status, and residence region. This set of variables includes all determinants that are generally used in studies of earnings. The estimated assimilation is 1.2 percent per year, similar to the previous estimate. The assimilation appears to have a relatively independent effect on earnings growth.

Column D shows the regression with both the cohort fixed effects and the extended set of controls. The estimated assimilation is statistically insignificant. This result calls into question the conclusion that the assimilation estimation is biased by dropping cohort quality. Since the difference between Column A and B estimates is smaller than the difference between Column C and D estimates, the "bias" appears larger with more covariates. In contrast, the difference between cohorts should get smaller with more controls (see discussion above in section IV.i).

The patterns observed in Table 2-1 are also not consistent with the assertions that cohort bias is due to return migration among immigrants. Most studies (Abramitzky, Boustan and Eriksson 2014, G. J. Borjas 1985, Kim 2009) using panel data conclude that there is no evidence of assimilation. Assuming the "true" assimilation effect is zero, I can infer the extent to which the estimated positive assimilation effects after 
controlling for cohort fixed effects are due to outmigration bias. Then, I can calculate the outmigration's size that would lead to the bias and compared it with the observed size of outmigration.

Table 2-1 shows that about 27.88 million immigrants who arrived before 1996 live in the U.S. in 2000 (we exclude immigrants who arrived between 1996 and 2000 due to incomplete count). The average annual earnings are around $\$ 27,580$ per immigrant worker at that time. We assume that there is a constant proportion of people in the labor force and the average earnings level of these short-term immigrants is assumed to be two-thirds of the average earnings. The question is to find the smallest number of outmigrants needed to create a bias of 0.6 percent per year in the assimilation estimation. I also assume no real earnings improvement for either stayers or leavers to simplify the calculation. The labor force participation rate of immigrants is 67 percent in 2000. As a result, there are about 18.68 million immigrant workers, making 515 billion dollars per year. To make the average income increase by 6 percent solely by filtering out low-income earners ( 0.6 percent per year for ten years), the number of immigrants in the labor force would decline by 2.87 million. The population size should be roughly 23.6 million ( 15.81 million / 67\%) by 2010, implying 4.28 million of working and non-working outmigrants. The data show that outmigration is about 1.66 million immigrants. The argument of outmigration creates bias in the assimilation estimation is dubious.

\subsubsection{The Nonparametric Method Controlling for Observed}

\section{Characteristics}

To explain this inconsistency, we need to know more about the assimilation process. This section applies the non-parametric method introduced above. We can 
compare the earnings distribution of different groups to learn about the assimilation process.

Figure 2-1 depicts the earnings distribution of the natives and all immigrant cohorts using the 1990 census data. The earnings distribution of older immigrant cohorts is to the right of the earnings distribution of newer immigrant cohorts, indicating a shift to higher earnings for more extended stays. The shift rate appears to be stable. Notice that the earnings distribution of workers who have stayed for 16 to 20 years is still on the left of the native earnings distribution. Immigrants who have stayed for more than 20 years have a similar earnings distribution to natives but with slightly more significant variation.

Figure 2-2 shows differences in the distribution density between each immigrant cohort's earnings and the native earnings distribution. The thin black line stands for new immigrants who had arrived within the previous five years. When the line intercepts with the horizontal axis, the fraction of natives and immigrants at that earnings level are identical. When the line is above the horizontal axis, there are relatively more immigrants at this earnings level and vice versa. Immigrants are overrepresented in the lower end of the distribution (below $\$ 22,026$ per year ${ }^{14}$ ). Earlier cohorts have fewer low-income workers. The earliest cohort has a nearly identical distribution to that of the natives.

\footnotetext{
${ }^{14}$ All dollar values are in 1999 dollars.
} 
Figure 2-1 Earnings Distribution by Immigrant Cohorts Compared to Natives Earnings distribution of Immigrant Cohorts and Natives in 1990

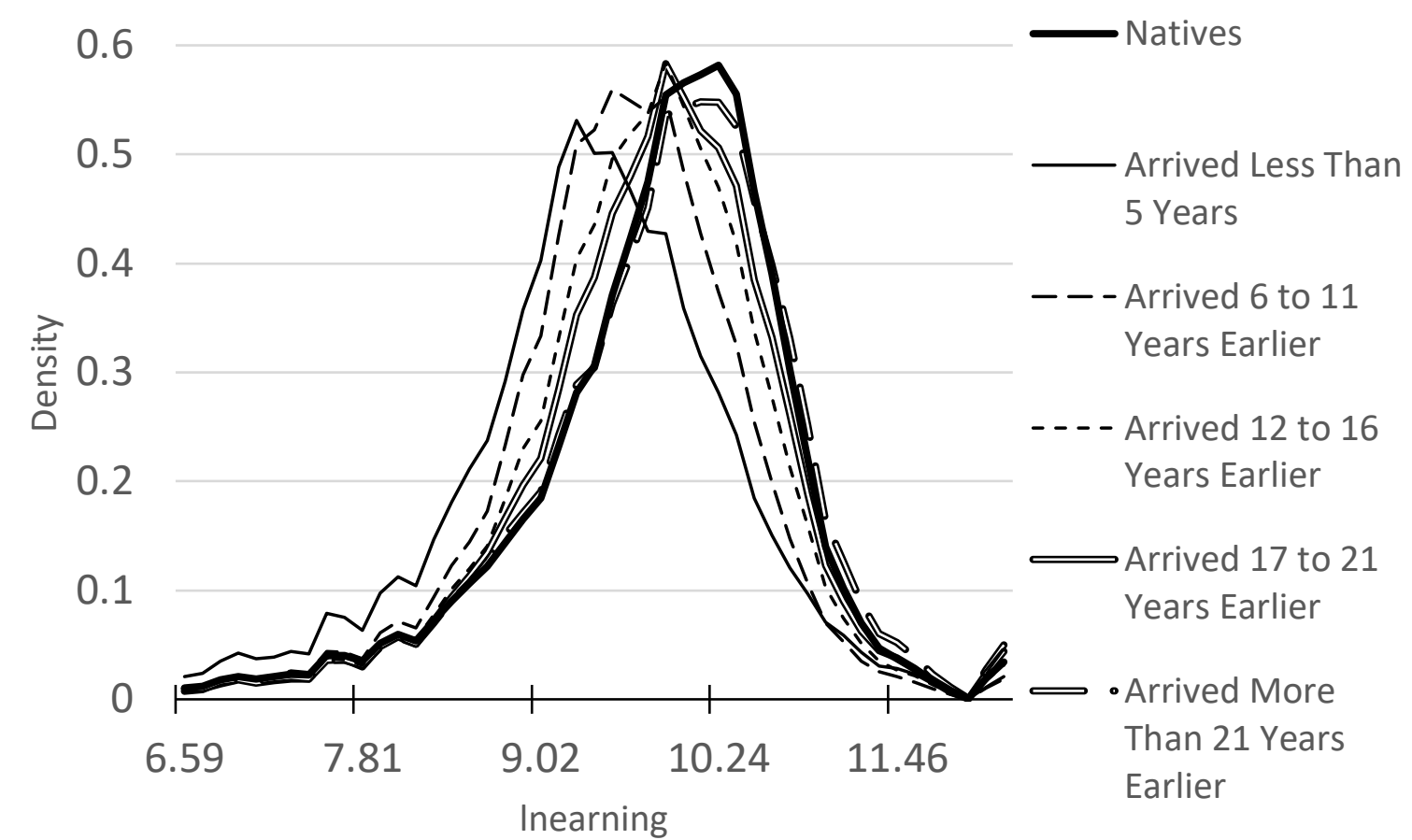

Note: The source of data is the U.S. census of 1990 from IPUMS. The width of kernel density is 0.1 .

The distribution differences are partially due to cohort quality differences. As described in the data section, immigrant characteristics vary by cohorts. The most recent immigration wave is largely driven by migration from developing countries from Latin America and Asia. Immigrants who arrived before 1970 were mostly from Europe. Immigrants from different source countries may differ in terms of education, race, work experience, and other factors summarized as cohort quality. However, as noted in the data description section, decreasing cohort quality is not apparent. The observed differences in characteristics for immigrant cohorts are not large, especially for cohorts after 1970. 
Figure 2-2 Difference in Earnings Distribution Between Immigrant Cohorts and Natives

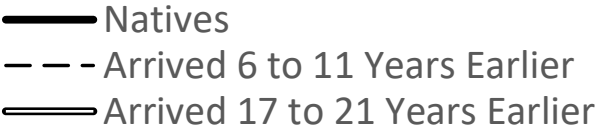

- Arrived Less Than 5 Years

- - - - Arrived 12 to 16 Years Earlier

• Arrived More Than 21 Years Earlier

0.4

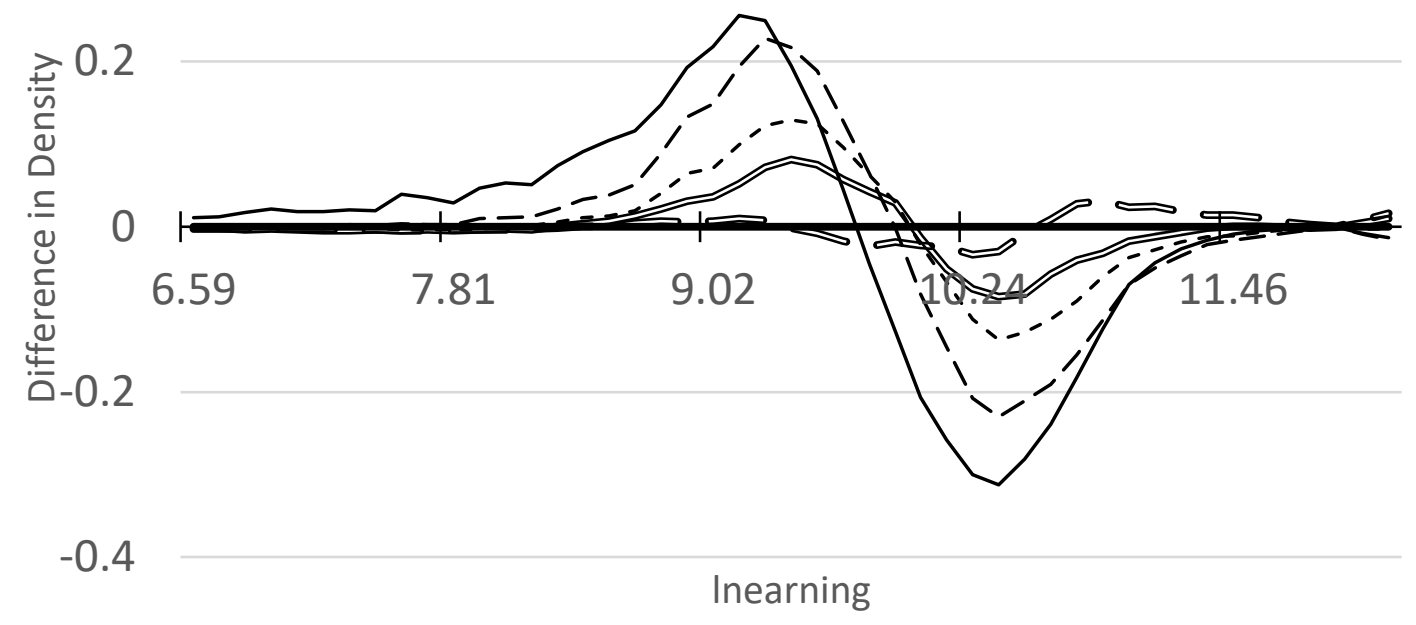

Note: The source of data is the U.S. census of 1990 from IPUMS.

Figure 2-3 depicts the earnings distribution after unifying the underlying characteristics distribution. The sample weights of all immigrants are adjusted with $\theta_{1990}^{j}$, as in formula (9). The earnings distribution differences between immigration cohorts and the natives become smaller compare to Figure 2-2. Controlling characteristics reduces both the cohort bias and the outmigration bias. Notice the reduction varies by cohort. New immigrants, who have lived five years or less in the U.S., are still over-represented in the low-income range. Immigrants who had arrived 5 to 10 years before the survey still make less money but with far fewer people at the bottom of the distribution. Immigrants who arrived more than ten years earlier have a similar earnings distribution to that of the natives. 
Figure 2-3 Difference in Earnings Distribution Between Immigrant Cohorts and Natives After Modification

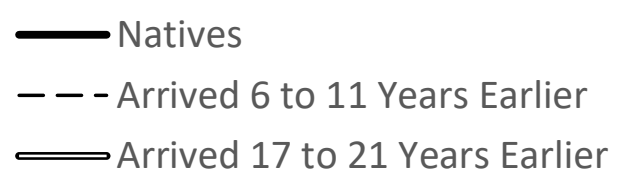

- Arrived in Last 5 Years

- - - - Arrived 12 to 16 Years Earlier

• Arrived More Than 21 Years Earlier

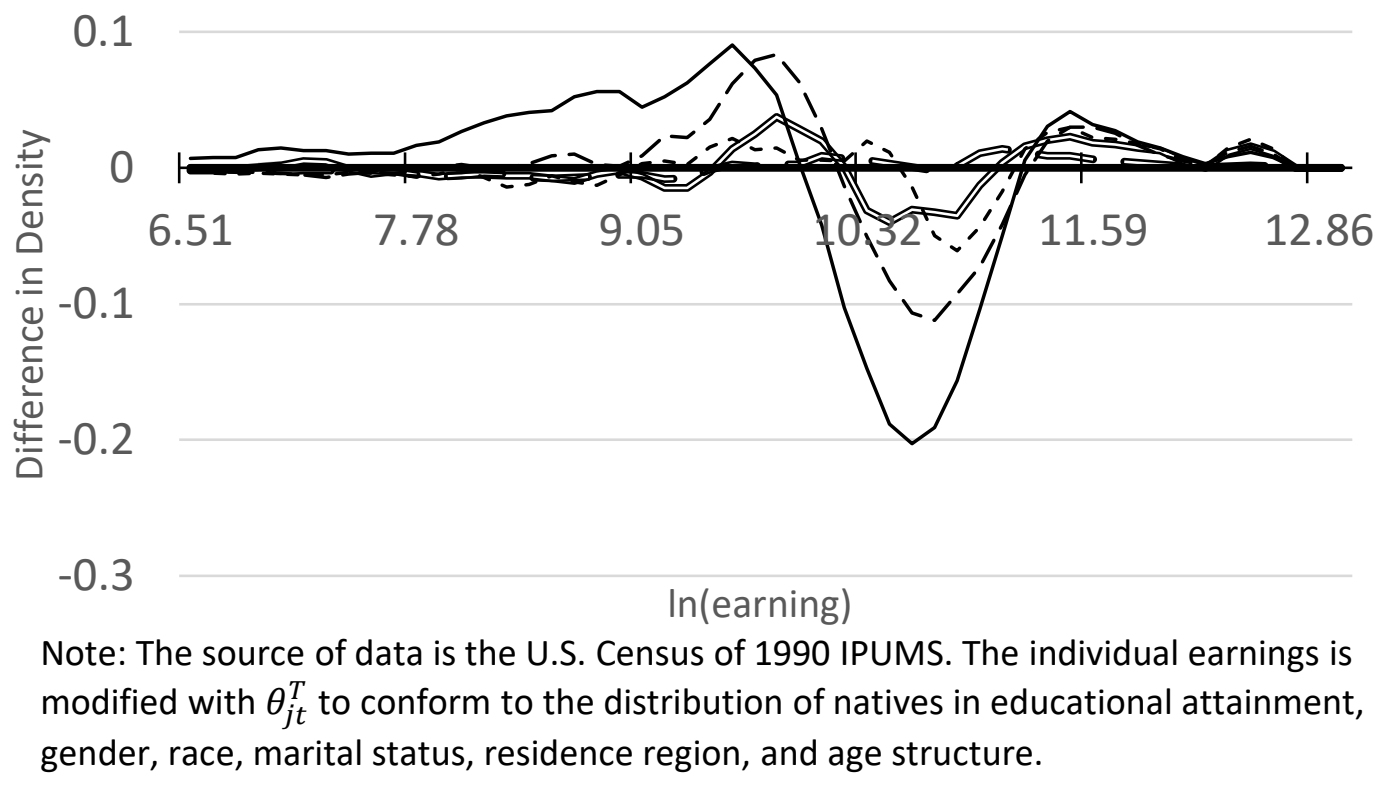

Figure 2-3 indicates how employers assign earnings based on length of stay for individuals in each cohort with the same observed characteristics. There are more migrants than natives for the most recent immigrants making less than $\$ 16,000$ per year (measured in 1999 dollars). The conventional argument is that many immigrants are young, with low education, and little experience, and are thus making less money. The results suggest that they receive lower earnings than natives and receive lower earnings than immigrants who arrived earlier, even with the same characteristics. For the cohort that stayed only five more years, far fewer people make meager earnings. That is, employers are willing to offer higher earnings, presumably reflecting improvements in factors not captured in our observed measures, like communication ability and jobrelated skills.

Among immigrants who stayed for more than ten years, those with incomes between $\$ 26,600$ and $\$ 73,900$ per year are under-represented relatives. However, they 
are over-represented both below and above this range, indicating a larger variance in the earnings distribution than natives. The difference in variance also decreases as immigrants stay longer in the U.S. For the group that migrated 20 years earlier, their earnings distribution shows only small differences from the earnings distribution of natives.

Figure 2-3 also suggests that the assimilation process is not linear. Although the earnings distribution converges to that of the natives, the longer immigrants stay, the smaller the marginal improvement is. For immigrants who stayed more than 16 years, their earnings distribution is less than 0.05 density points from the natives' earnings distribution across all possible earnings levels.

In Figure 2-4, I use data on immigrants who arrived in the five years before 1990 to explore how adding each control variable affects the earnings distribution. A variable must meet two conditions to impact the earnings distribution. First, there must be an identifiable difference between immigrants and natives in this variable. Second, the variable must affect earnings, that is, the difference in this variable must produce a difference in earnings. Given the description of data in section III, six variables are chosen, $s_{i}=\{$ Age, Gender, Race, Education Attainment, Region, Marital Status $\}$, since immigrants and natives are statistically different in these variables. The analysis is repeated seven times. In the $i^{\text {th }}$ step, the first $i$ variables are included. The unadjusted wage distribution of immigrants is step zero. The adjusted wage distribution changes for each set of variables. The result from the $i$ th step is then compared with the result from the previous $i-1$ th step to determine how the inclusion of variable $i$ affects the result. 
Race is the most essential measure explaining the difference between the original earnings distribution and the adjusted earnings distribution. The race composition varies significantly based on immigration status. As a result, we can confirm that the wage assignment function, as described in equation (2.4), considers race an essential factor in determining wages. After adjusting for race composition, the difference in earnings distribution between immigrants and natives shrinks perceptibly, with far fewer immigrants in the lower earnings ranges. Notice, the distribution adjustment does not include country of origin by construction, as the base distribution is natives. To some degree, race may proxy for the country of origin. Another variable, that makes noticeable but moderate changes, is the composition of residence regions. Other variables in the sequence are relatively unimportant.

Figure 2-4 Adding Control Variables to Distribution Adjustment Method Wage Distribution Adjustment With Different Control Variables Set

For Immigrants Who Arrived Within Five Years At 1990

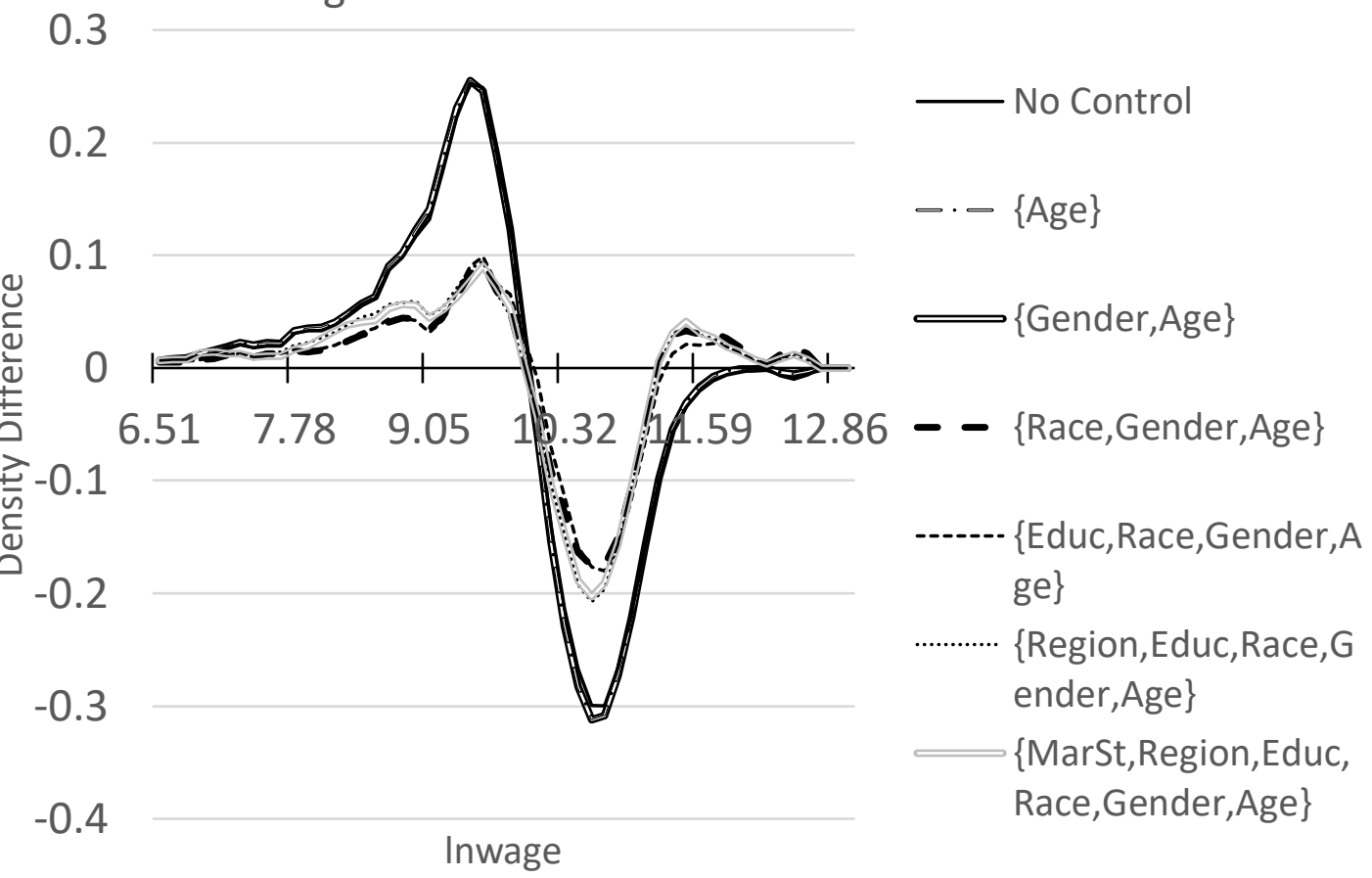

Note: The source of data is the U.S. census of 1990 from IPUMS. 
The changes in the distributions of cohorts over time confirms our interpretation. Figure 2-5 presents changes in the earnings distribution of each cohort over time. With three censuses, changes in the earnings distribution of a cohort over 20 years can be evaluated. The thick solid line is the earnings distribution measured using the 1990 census. The thin solid line is the 2000 census. The dashed line is the 2010 census. Figure 2-5a shows the cohort's earnings distribution arriving before 1970, observed in 1990, 2000, and 2010. For example, when immigrants had been in the country for over 20 years, over 30 years, and over 40 years. The earnings distribution change is small. Figure $2-5 b$ to $2-5 d$ do not show any obvious change in the earnings distribution. Figure $2-5$ e represents the shift in the earnings distribution in the first 20 years after migration. These graphs suggest that the assimilation effect is only significant for the first ten years in the country. 
Figure 2-5 Adjusted Earning Distribution by Cohort in Different Years

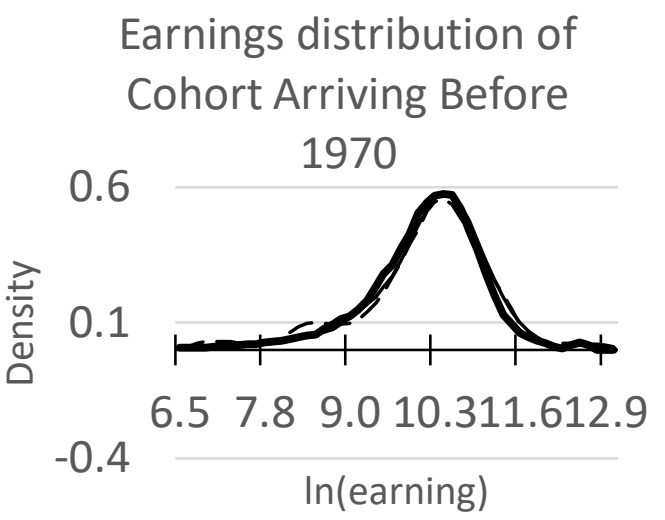

(a)

Earnings distribution of

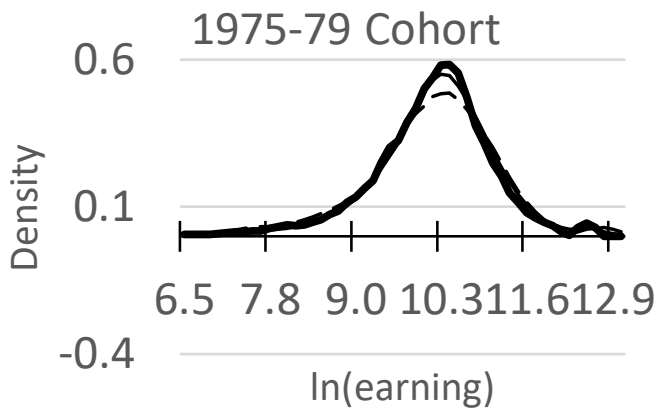

(c)

Earnings distribution of

$0.6 \quad$ 1985-90 Cohort

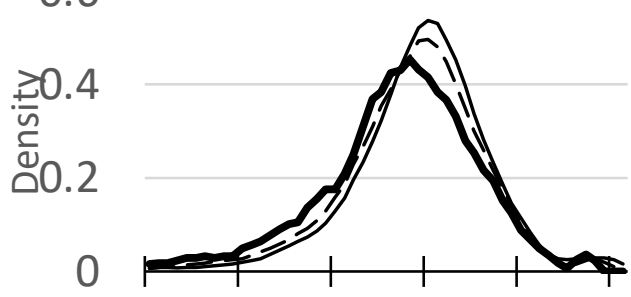

$\begin{array}{llll}6.5 & 7.8 & 9.0 & 10.311 .612 .9\end{array}$ In(earning)

(e)
Earnings distribution of

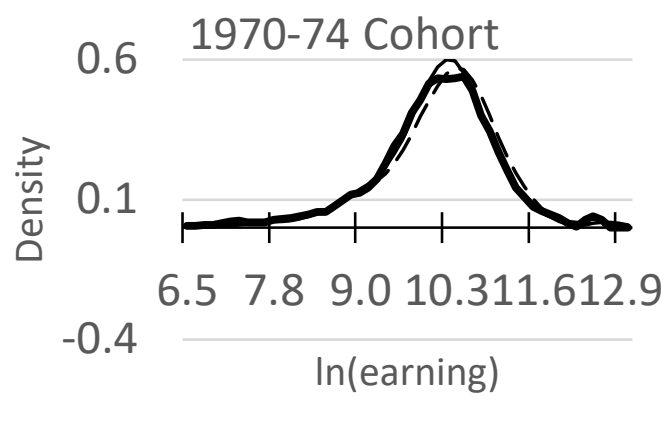

(b)

Earnings distribution of

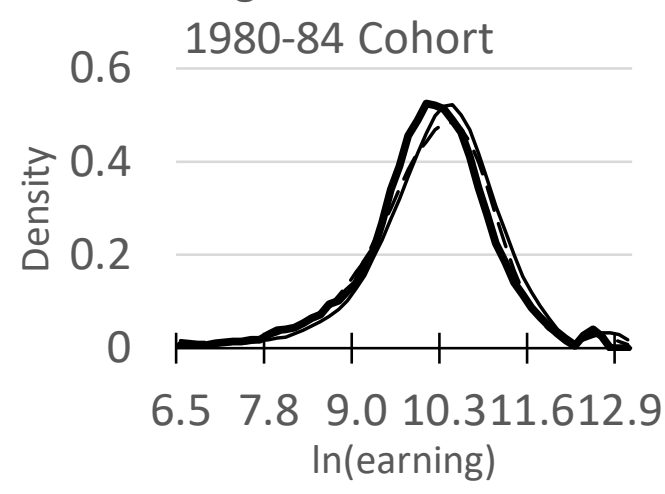

(d) 
The conclusion is that the assimilation process slows down after the first ten years of stay in the U.S. Using what we learned from the above analysis, we return to equation (2.2) with a specification that allows for a nonlinear assimilation process.

\subsubsection{Revisiting Conventional Model}

To capture the curvature of the assimilation process, I add a quadratic term of years since migration.

$$
\begin{gathered}
\ln \left(\text { wage }_{i j t}\right)= \\
\alpha+\mu_{j}+\beta_{1} y s m_{i j t}+\beta_{2} y s m_{i j t}^{2}+\gamma_{1} a g e_{i j t}+\gamma_{2} a g e_{i j t}^{2}+ \\
y_{e a r_{t}}+\boldsymbol{\theta} \boldsymbol{X}_{i j t}+\varepsilon_{i j t}
\end{gathered}
$$

Estimates for regressions that include such quadratic terms are shown in Table 6, along with linear regression coefficients (D) and (E) from Table 2 for comparison.

Column (A) shows the regression without additional control variables. The assimilation rate is about 2.4 percent in the first year. The square term coefficient shows that the speed slows down by 0.045 percentage points each year. Column (B) shows that new immigrants who just arrived improve their earnings by 2.9 percent in the model with controls in the first year. The rate of earnings growth is slowing down by 0.078 percentage points each year as immigrants stay longer. The quadratic function implies that the assimilation effect reaches a maximum around the 37 th year after arrival. The full assimilation effect implies a growth of about 42 percent in earnings in 30 to 40 years after arrival. In contrast to the linear specification, the regression with the quadratic term is not sensitive to controlling the cohort's fixed effects. 
Table 2-6 Revisit Regression

(A)

(B)

Regression Results

\begin{tabular}{|c|c|c|c|c|c|}
\hline & (A) & (B) & (C) & (D) & (E) \\
\hline Ysm & $\begin{array}{c}0.024 * * * \\
(0.002)\end{array}$ & $\begin{array}{c}0.029 * * * \\
(0.004)\end{array}$ & $\begin{array}{c}0.024^{* *} \\
(0.008)\end{array}$ & $0.012 * * *$ & 0.002 \\
\hline ysm_sq & $\begin{array}{c}-0.00023^{* * *} \\
(0.00004)\end{array}$ & $\begin{array}{c}-0.00039 * * * \\
(0.00008)\end{array}$ & $\begin{array}{c}-0.00034^{* *} \\
(0.00011)\end{array}$ & - & - \\
\hline \multicolumn{2}{|l|}{ Cohort $^{1}$} & & $\checkmark$ & & $\checkmark$ \\
\hline \multirow[t]{2}{*}{$1970-74$} & & & 0.007 & & -0.033 \\
\hline & & & $(0.026)$ & & $(0.029)$ \\
\hline \multirow[t]{2}{*}{$1975-79$} & & & 0.005 & & $-0.080^{*}$ \\
\hline & & & $(0.043)$ & & $(0.038)$ \\
\hline \multirow[t]{2}{*}{$1980-84$} & & & -0.032 & & $-0.159 * *$ \\
\hline & & & $(0.060)$ & & $(0.048)$ \\
\hline \multirow[t]{2}{*}{$1985-90$} & & & -0.071 & & $-0.271 * * *$ \\
\hline & & & $(0.084)$ & & (0.055) \\
\hline \multirow[t]{2}{*}{ 1991-95 } & & & -0.039 & & $-0.288^{* * *}$ \\
\hline & & & $(0.098)$ & & $(0.052)$ \\
\hline \multirow[t]{2}{*}{$1996-2000$} & & & -0.098 & & $-0.426 * * *$ \\
\hline & & & $(0.125)$ & & $(0.060)$ \\
\hline \multirow[t]{2}{*}{$2001-05$} & & & -0.098 & & $-0.444^{* * *}$ \\
\hline & & & (0.141) & & (0.063) \\
\hline \multirow[t]{2}{*}{$2006-10$} & & & -0.183 & & $-0.617^{* * *}$ \\
\hline & & & $(0.171)$ & & $(0.072)$ \\
\hline year \& age & $\checkmark$ & $\checkmark$ & $\checkmark$ & $\checkmark$ & $\checkmark$ \\
\hline $\begin{array}{c}\text { other } \\
\text { control }\end{array}$ & & $\checkmark$ & $\checkmark$ & $\checkmark$ & $\checkmark$ \\
\hline
\end{tabular}

${ }^{1}$ The reference group is immigrants arrived before 1970.

Data from the 1990 and 2000 Censuses, and 2010 ACS. The standard error is robust and clustered by cohorts. Other controls include gender, race, educational attainment, marital status, and region. ${ }^{* * *} p<0.01,{ }^{* *} p<0.05, * p<0.1$

All estimates of cohort fixed effects become insignificant after adding the quadratic term for years since the migration. The reason is that the linear assimilation process with the cohort fixed effect assumes that the assimilation is an exact linear process across cohorts. The nonlinear assimilation effect is captured by the cohort fixed effects, given that cohorts differ in their distributions of years since migration. Also, because of the squared term, the linear years since migration measure reflects the initial 
earnings growth, instead of a fitted linear annual earnings growth as in the linear model. The quadratic estimates of the assimilation process exhibit the same pattern as suggested in the method that adjusted for the distribution of migrant characteristics. Immigrants assimilate quickly initially, and the pace slows down after that, as shown in Figure 2-6.

Figure 2-6 Estimated Assimilation using Different Models
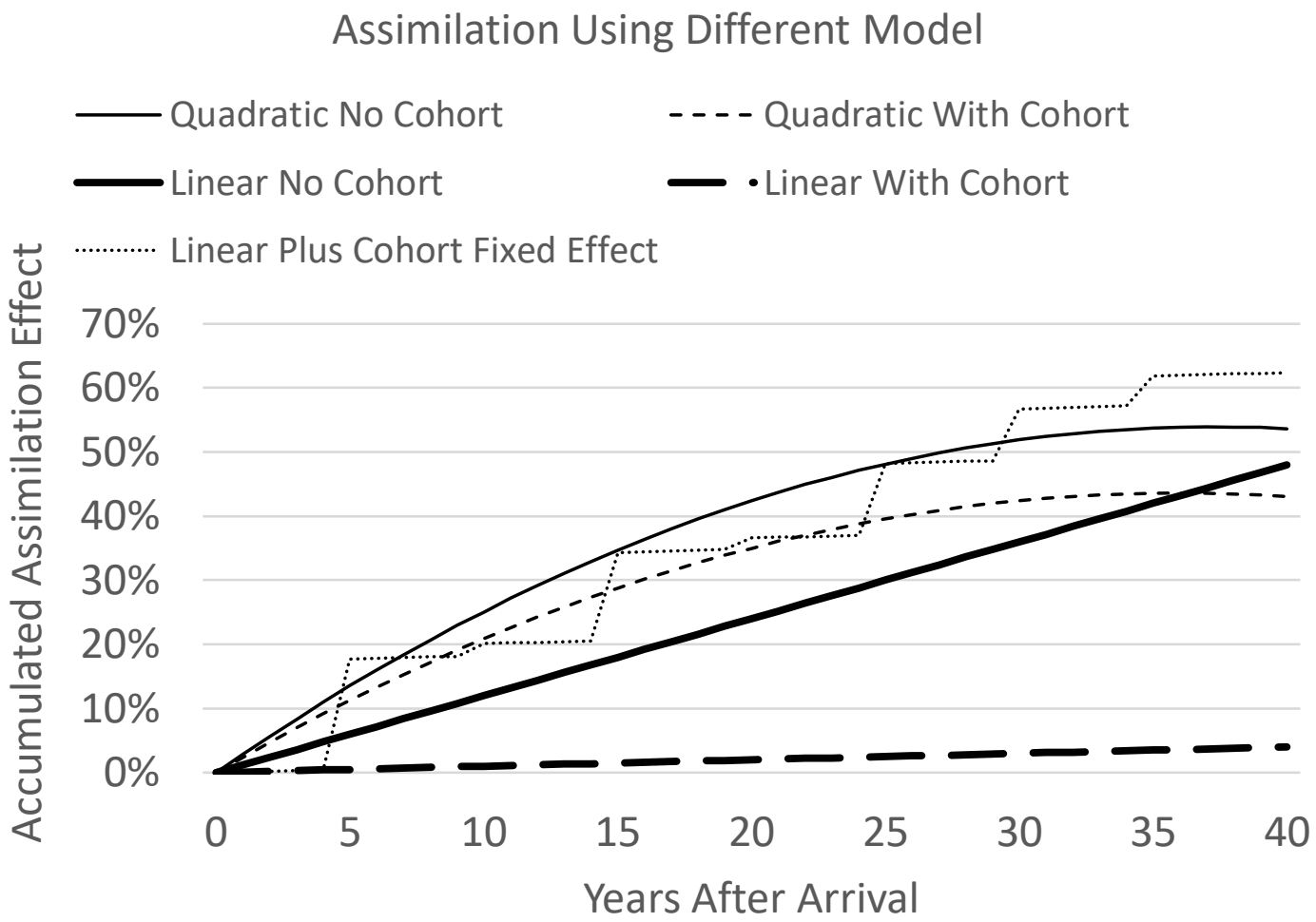

Figure 2-7 depicts the projected earnings growth after arrival due to assimilation using four different specifications. When using the quadratic term, the assimilation rate is much higher than that estimated based on the simple linear model. Adding cohort fixed effects does not lower the estimation of assimilation by much. The assimilation (thin dashed line) in the first ten years contributes 20 percent to earnings. This contribution is about 15 percent for the next ten years and 7 percent in the following decade. From the third decade to the fourth decade after arrival, assimilation increases earnings by less than 1 percent. The linear model without cohort fixed effects works 
like a linear estimation of the thin dashed line. The linear assimilation effect estimate drops significantly after adding the cohort fixed effect. The dotted line adds the cohort fixed effect to the assimilation estimates. The earnings growth of the step function is very similar to the nonlinear assimilation estimation.

Why does the speed of assimilation decline over time? Psychologists have argued that human beings have different learning abilities at different ages; a typical example is language learning (Lenneberg 1967). Cheung, Chudek, and Heine (2011) discovered a sensitive period, less than 14.5 years old, for "acculturation." The idea of acculturation is the cornerstone of assimilation, focused on learning new skills, knowledge, and apprehension about the host society. These psychologists find differences between acculturation rates for child immigrants and adult immigrants. They wonder if this difference is due to the length of exposure or exposure during the sensitive period, during which immigrants adapt to the new environment faster than they would have if they had arrived at older ages. They confirmed it is the latter reason that makes the difference.

Our sample does not include teenagers. Nevertheless, the idea that assimilation rate is sensitive to migration age can be examined with an interactive term between age and years since migration. The model used for assimilation can be modified as:

$$
\begin{aligned}
& \ln \left(\text { wage }_{i j g t}\right)=\alpha+\beta_{0} \cdot y s m_{i j g t}+\beta_{1} \cdot y s m_{i j g t}^{2}+\delta_{0} \cdot a g e_{g} \cdot y s m_{i j g t}+\delta_{1} \\
& a g e_{g} \cdot y s m_{i j g t}^{2}+a g e_{g}+\mu_{j}+y e a r_{t}+\gamma \cdot X_{i j t}+\varepsilon_{i j t}
\end{aligned}
$$

In equation (2.15), age is grouped into five age groups. $\delta_{0}$ and $\delta_{1}$ are estimates of the interactive terms between years since migration and the age groups. These estimates indicate whether the assimilation effect varies by age at arrival. Table 2-7 shows the result of the estimation of equation (2.15). The assimilation effect of young 
immigrants, whose ages are between 25 and 34, are used as the reference group. The assimilation effect is slower for immigrants who arrived in their older years of age. Figure 2-8 shows the projection of the assimilation effect for the first ten years after arrival based on estimates in Table 2-7. The two lines at the top represent the assimilation of immigrants who came to the U.S. at ages 35 to 44 and 45 to 54 . These two groups have intermediate assimilation effects, where the younger group has slightly more advantage in assimilation. Both groups' earnings upon arrival are 15 percent higher than the reference group. As a result, they are the most successful group among all immigrants. In articles regarding return migration, for example, Borjas and Bratsberg (1996), it is common to assume that temporary immigrants migrate at the beginning of their career and stay for a fixed amount of time. The second assumption can be relaxed to include the endogeneity of time in the host country spent to optimize the lifetime utility. In any event, the first assumption is rarely critical since many immigrants are, indeed, very young. The findings of this paper indicate another possibility. That is, the optimal time to migrate in the first place may not be right after completion of education. Of course, the conclusion cannot be generalized since immigrants who arrive in later years are likely to be selected.

Immigrants who arrived at age 55 to 64 show no difference in earnings from the reference group, those age 25-34. Neither of these groups is the most preferred worker in the labor market. One group has little experience; the other includes workers near the end of their careers. Surprisingly, immigrants in their late 50s and early 60s can still improve their earnings by almost 25 percent ten years after arrival by successfully assimilate to the host country. Not surprisingly, immigrants in their $20 \mathrm{~s}$ and $30 \mathrm{~s}$ are assimilating faster. Immigrants who arrived after age 64 had lower average earnings and showed moderate assimilation. 
The findings in this section are consistent with the idea of a "sensitive period" of acculturation. In the early years after arrival, when immigrants are generally young, their ability to learn new skills and embrace new culture leads to higher earnings growth rates. The rate of earnings growth is lower for immigrants who arrive at an older age. Findings in this paper suggest young immigrants can project higher rates of growth in their earnings than older immigrants. 
Table 2-7 Estimated Assimilation by Age of Arrival

Regression with Interactive Term

Coef.

Std. Err.

Year Since Migration

Ysm Square

$[35,44]$

$[45,54]$

$[55,64]$

$[65+]$
$0.043 * * *$
$-0.00106 * * *$

0.151

0.153

$-0.002$

$-0.117 *$
(0.010)

(0.000)

$(0.022)$

(0.037)

(0.032)

(0.054)

\section{Age Interactive Term}

$[35,44]$

Year Since Migration

Ysm Square

$[45,54]$

Year Since Migration

Ysm Square

$-0.015$

$(0.005)$

0.00056

(0.000)

$-0.020 * *$

0.00056

(0.000)

$[55,64]$

Year Since Migration

Ysm Square

$-0.015 *$

$0.00069 *$

(0.000)

[65+]

Year Since Migration

Ysm Square

$-0.031$

(0.006)

0.00085

(0.000)

Control Variables

Number of Observations

$1,310,535$

R Square

0.2528

Note: Data from 1990 and 2000 Census and 2010 ACS. The standard error is robust and clustered in cohorts. Control variables include gender, race, educational attainment, marital status, and region. ${ }^{* * *} p<0.01, * * p<0.05, * p<0.1$ 
Figure 2-7 Estimated Assimilation by Age of Arrival

\section{First Ten Years Earnings Growth Of Different Age} Groups

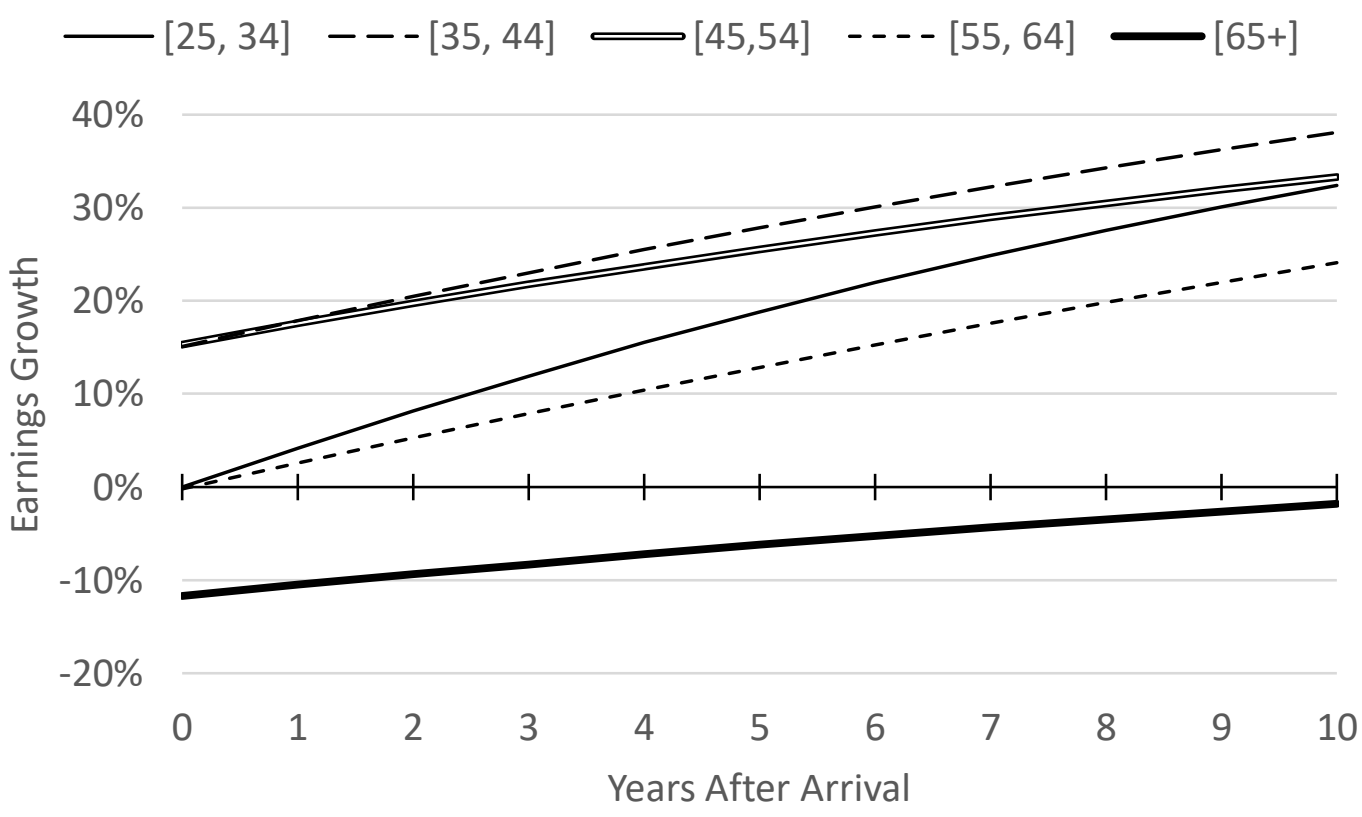

Many studies (Feliciano 2005, Kim 2009, Abramitzky, Boustan and Eriksson 2014) find that the assimilation processes vary by country of origin. The findings from the modified distribution method also confirm the importance of racial composition.

The regression results are listed in Table 2-8. The regression model is similar to equation (2.10), except we use immigrants' birthplace as the interactive term with assimilation terms. Notice that countries with relatively fewer immigrants are grouped with other countries within the same geographical area. For instance, North America, the reference group, immigrants from Canada with the small number of people from St. Pierre and Miquelon.

Canadians are used as the reference group since they are similar to Americans both culturally and economically. Unsurprisingly, there is no evidence that Canadians are significantly different from Americans nor that they assimilate. 
The first column in Table 8 shows the ethnic fixed effect compared to immigrants from Canada. No immigrants have higher average earnings than Canadians except immigrants from the UK. The ethnic fixed effect is transformed into a percentage difference and summarized in Figure 2-8. In the figure, these countries are classified into three groups by the average wage gaps. North America, Japan, and most European countries have less than $20 \%$ to no earnings disadvantage. People from China and former USSR territories have significant earnings disadvantages of more than 55 percent. The middle group includes Mexico, the Philippines, and African countries, with earnings disadvantages between 35 percent to 50 percent.

Figure 2-8 Estimated Assimilation by Country of Origin

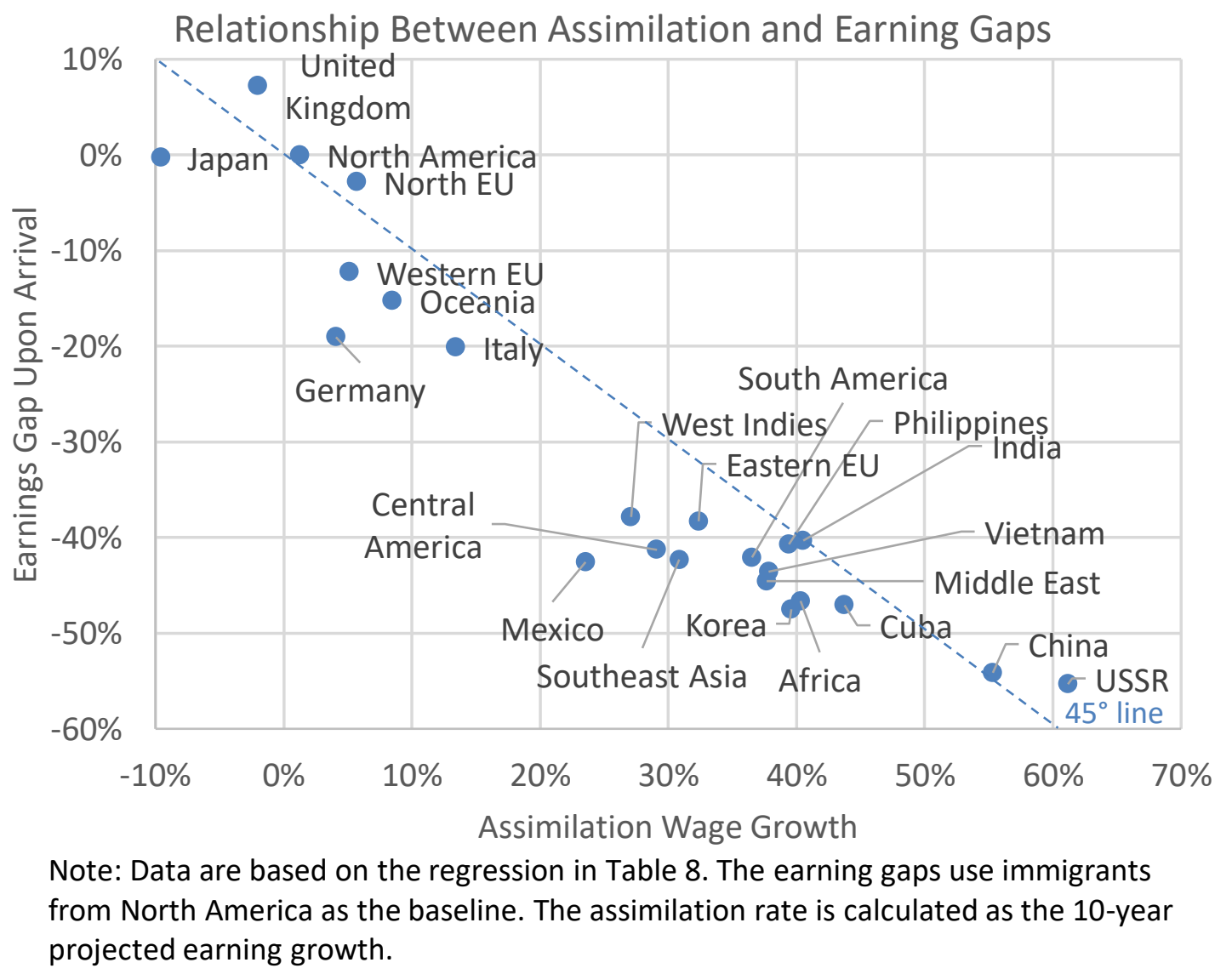

The second and third columns in Table 2-8 show different patterns of assimilation. Most estimates are statistically significant. The most common pattern is 
increasing earnings with decreasing speed as immigrants stay longer in the U.S. Six exceptions include Germany, Northern Europe, Oceania, and Western Europe that show no assimilation, and Japan and UK that show negative assimilation. Among those countries with similar assimilation patterns, the initial assimilation rate and their assimilation curve's shape are different from each other. Figure 2-8 also indicates a negative correlation between the assimilation rate for the first ten years of stay and the earnings gaps, as most countries are close to the 45-degree line.

Among all immigrant groups, immigrants from Mexico have the lowest net earnings growth within the first ten years of stay. Mexican immigrants face 43 percent initial earning gaps, with only 23 percent growth due to assimilation in the first ten years. A report (Noe-Bustamante, Flores and Shah 2019) of the Pew Research Center states that Hispanic immigrants comprised the largest share of all immigrants in the U.S. in 2017. Most of them reside in the southern border states. The slower assimilation rate of Hispanics may be due to large Hispanic communities with many internal economic activities.

Among immigrants from developing countries, Indians, Chinese, and immigrants from the former USSR countries can gain positive net earnings growth within the first ten years of arrival in the U.S. For these ethnic groups, the reason for success is probably different. For Indians, one possible reason is that many Indians speak English since English is a lingua franca and an important language of higher education in India. Chinese immigrants have considerably higher levels of educational attainment than all immigrants from developing countries. However, their lack of language skills might hamper their productivity initially. 
Table 2-8 Assimilation by Country of Origin

Assimilation Regression by Country

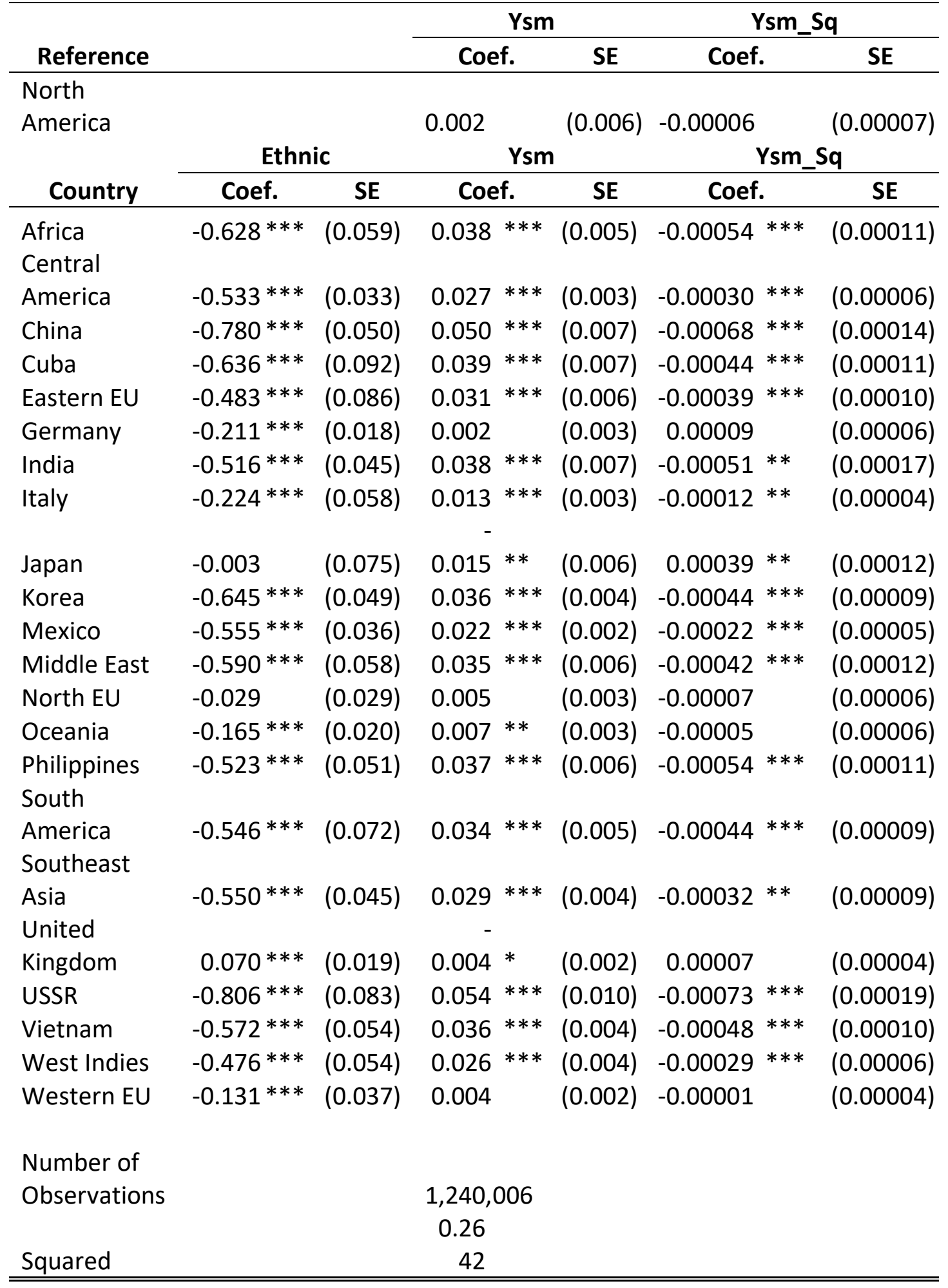

Note: Data from 1990 and 2000 Census and 2010 ACS. The standard error is robust and clustered in cohorts. Control variables include the year, gender, race, education, marital status, region, and age. Countries with relatively fewer immigrants are grouped with other countries within the same geographical area. 


\subsection{Conclusion}

Economic assimilation can be estimated with repeated cross-sectional data. The models that assumes linear assimilation and cohort fixed effect are misleading since cohort indicators capture the curvature in the assimilation process when the only measured assimilation effect is constrained to be linear. Researchers may falsely conclude that the difference between estimates from cross-sectional data and longitudinal data is due to cohort and outmigration biases. This paper shows neither decreasing cohort quality nor immigrants' return can account for the large difference between cross-sectional and longitudinal estimates.

A potential simple check to run with longitudinal data analysis is to calculate the average years since migration of the longitudinal sample and the cross-sectional data used.

This paper also sheds some light on the heterogeneity of the assimilation process. The assimilation process is sensitive to age at arrival and country of origin. The larger the difference is between the level of economic development of the home country and the host country, the more significant the assimilation effect will be. Even for immigrants facing large initial gaps in earnings, the first ten years after arrival is usually sufficient for an immigrant to close most of the gap.

Based on the findings of this paper, I propose the following conjecture. The assimilation process is a projection of immigrants' learning curve of accumulating a package of skills for accommodating the host country's labor market. The assimilation path is determined by the level of skills they have attained before immigration and the shape of their learning curves after arrival. 
Appendix A

Data Description Tables

Table 2-9 Data Description of Census 1990

\begin{tabular}{|c|c|c|c|c|c|c|}
\hline & \multicolumn{6}{|c|}{ Census 1990} \\
\hline & Native & $\begin{array}{l}1970 \\
\text { Earlier }\end{array}$ & $\begin{array}{l}{[1970,} \\
1975)\end{array}$ & $\begin{array}{l}1975, \\
1980)\end{array}$ & $\begin{array}{l}{[1980,} \\
1985)\end{array}$ & $\begin{array}{l}\text { [1985, } \\
1990]\end{array}$ \\
\hline \multicolumn{7}{|l|}{ Observation } \\
\hline (000) & 141,430 & 7,409 & 1,939 & 2,264 & 2,757 & 2,714 \\
\hline \multicolumn{7}{|l|}{ AGE } \\
\hline$[25,44]$ & $50.56 \%$ & $30.45 \%$ & $63.91 \%$ & $73.83 \%$ & $77.41 \%$ & $77.57 \%$ \\
\hline$[45,64]$ & $29.47 \%$ & $38.07 \%$ & $29.68 \%$ & $20.28 \%$ & $17.47 \%$ & $16.92 \%$ \\
\hline $64+$ & $19.97 \%$ & $31.48 \%$ & $6.41 \%$ & $5.89 \%$ & $5.12 \%$ & $5.51 \%$ \\
\hline \multicolumn{7}{|l|}{ GENDER } \\
\hline Male & $47.33 \%$ & $44.10 \%$ & $48.07 \%$ & $50.62 \%$ & $51.91 \%$ & $50.21 \%$ \\
\hline Female & $52.67 \%$ & $55.90 \%$ & $51.93 \%$ & $49.38 \%$ & $48.09 \%$ & $49.79 \%$ \\
\hline \multicolumn{7}{|l|}{ RACE } \\
\hline White & $84.48 \%$ & $57.52 \%$ & $21.22 \%$ & $20.85 \%$ & $15.73 \%$ & $21.39 \%$ \\
\hline \multicolumn{7}{|l|}{ American } \\
\hline Indian & $0.73 \%$ & $0.20 \%$ & $0.22 \%$ & $0.25 \%$ & $0.24 \%$ & $0.28 \%$ \\
\hline Hispanic & $1.97 \%$ & $18.13 \%$ & $23.40 \%$ & $19.09 \%$ & $21.11 \%$ & $19.38 \%$ \\
\hline Black & $10.97 \%$ & $4.39 \%$ & $9.73 \%$ & $8.28 \%$ & $10.34 \%$ & $7.73 \%$ \\
\hline Chinese & $0.12 \%$ & $2.62 \%$ & $5.25 \%$ & $6.71 \%$ & $7.87 \%$ & $9.02 \%$ \\
\hline Japanese & $0.27 \%$ & $1.30 \%$ & $1.26 \%$ & $0.76 \%$ & $0.77 \%$ & $2.87 \%$ \\
\hline Other Asia & $0.20 \%$ & $4.19 \%$ & $16.83 \%$ & $22.06 \%$ & $22.65 \%$ & $20.75 \%$ \\
\hline Other Race & $1.27 \%$ & $11.65 \%$ & $22.08 \%$ & $22.00 \%$ & $21.29 \%$ & $18.57 \%$ \\
\hline \multicolumn{7}{|l|}{ EDUC } \\
\hline$<$ High School & $22.83 \%$ & $39.38 \%$ & $43.14 \%$ & $42.69 \%$ & $42.82 \%$ & $38.07 \%$ \\
\hline High School & $31.25 \%$ & $22.65 \%$ & $18.05 \%$ & $17.01 \%$ & $18.11 \%$ & $18.48 \%$ \\
\hline Some College & $25.58 \%$ & $20.51 \%$ & $18.57 \%$ & $18.84 \%$ & $18.71 \%$ & $17.27 \%$ \\
\hline \multicolumn{7}{|l|}{ Bachelor } \\
\hline Degree & $13.28 \%$ & $9.73 \%$ & $11.74 \%$ & $13.05 \%$ & $12.26 \%$ & $15.05 \%$ \\
\hline $\begin{array}{l}\text { Bachelor } \\
\text { Degree }\end{array}$ & $7.07 \%$ & $7.73 \%$ & $8.51 \%$ & $8.41 \%$ & $8.10 \%$ & $11.12 \%$ \\
\hline \multicolumn{7}{|l|}{ REGION } \\
\hline New England & $5.41 \%$ & $7.48 \%$ & $5.31 \%$ & $4.22 \%$ & $4.34 \%$ & $5.49 \%$ \\
\hline Middle & & & & & & \\
\hline Atlantic & $14.64 \%$ & $26.89 \%$ & $24.57 \%$ & $18.32 \%$ & $21.42 \%$ & $22.62 \%$ \\
\hline \multicolumn{7}{|l|}{ East North } \\
\hline Central & $17.66 \%$ & $11.73 \%$ & $8.99 \%$ & $8.16 \%$ & $6.53 \%$ & $7.73 \%$ \\
\hline \multicolumn{7}{|l|}{ West North } \\
\hline Central & $7.70 \%$ & $2.12 \%$ & $1.17 \%$ & $1.56 \%$ & $1.43 \%$ & $1.86 \%$ \\
\hline South Atlantic & $18.31 \%$ & $15.66 \%$ & $13.60 \%$ & $11.70 \%$ & $14.85 \%$ & $14.84 \%$ \\
\hline \multicolumn{7}{|l|}{ East South } \\
\hline Central & $6.62 \%$ & $1.11 \%$ & $0.75 \%$ & $0.75 \%$ & $0.63 \%$ & $0.89 \%$ \\
\hline
\end{tabular}




\begin{tabular}{lcccccc} 
West South & & & & & & \\
Central & $10.56 \%$ & $6.43 \%$ & $8.84 \%$ & $10.93 \%$ & $10.12 \%$ & $7.18 \%$ \\
Mountain & $5.49 \%$ & $4.04 \%$ & $3.25 \%$ & $3.40 \%$ & $2.98 \%$ & $3.28 \%$ \\
$\begin{array}{l}\text { Pacific } \\
\text { MARST }\end{array}$ & $13.61 \%$ & $24.54 \%$ & $33.52 \%$ & $40.96 \%$ & $37.69 \%$ & $36.11 \%$ \\
Married, & & & & & & \\
Present & $63.58 \%$ & $61.94 \%$ & $68.71 \%$ & $67.49 \%$ & $61.77 \%$ & $56.41 \%$ \\
Married, & & & & & & \\
Absent & $1.26 \%$ & $2.03 \%$ & $3.24 \%$ & $3.61 \%$ & $5.17 \%$ & $9.28 \%$ \\
Separated & $2.48 \%$ & $2.71 \%$ & $3.82 \%$ & $3.88 \%$ & $4.33 \%$ & $3.47 \%$ \\
Divorced & $10.32 \%$ & $8.85 \%$ & $7.63 \%$ & $6.37 \%$ & $5.78 \%$ & $3.99 \%$ \\
Widowed & $9.09 \%$ & $14.96 \%$ & $4.18 \%$ & $3.85 \%$ & $3.62 \%$ & $4.10 \%$ \\
Single & $13.27 \%$ & $9.50 \%$ & $12.43 \%$ & $14.81 \%$ & $19.32 \%$ & $22.76 \%$ \\
\hline
\end{tabular}

Note: Data from the 1990 Census. The sample includes people over 24 years old. 
Table 2-10 Data Description of Census 2000

Census 2000

\begin{tabular}{|c|c|c|c|c|c|c|c|c|}
\hline & Natives & 1970 Earlier & {$[1970,1975)$} & {$[1975,1980)$} & {$[1980,1985)$} & {$[1985,1990]$} & $(1990,1995]$ & $(1995,2000]$ \\
\hline Observation (000) & 55,474 & 5,950 & 2,285 & 2,815 & 3,524 & 4,965 & 3,799 & 3,370 \\
\hline$[25,44]$ & $45.31 \%$ & $17.59 \%$ & $41.15 \%$ & $54.99 \%$ & $64.75 \%$ & $74.40 \%$ & $74.87 \%$ & $77.95 \%$ \\
\hline $64+$ & $20.17 \%$ & $38.54 \%$ & $9.80 \%$ & $7.50 \%$ & $6.48 \%$ & $5.46 \%$ & $6.02 \%$ & $4.78 \%$ \\
\hline \multicolumn{9}{|l|}{ GENDER } \\
\hline Male & $47.62 \%$ & $43.67 \%$ & $47.98 \%$ & $50.15 \%$ & $51.64 \%$ & $50.91 \%$ & $48.22 \%$ & $50.96 \%$ \\
\hline \multicolumn{9}{|l|}{ RACE } \\
\hline White & $81.64 \%$ & $52.86 \%$ & $22.34 \%$ & $19.26 \%$ & $13.08 \%$ & $13.91 \%$ & $19.29 \%$ & $22.12 \%$ \\
\hline American Indian & $0.80 \%$ & $0.29 \%$ & $0.42 \%$ & $0.41 \%$ & $0.44 \%$ & $0.47 \%$ & $0.38 \%$ & $0.38 \%$ \\
\hline Hispanic & $2.41 \%$ & $20.24 \%$ & $21.62 \%$ & $17.85 \%$ & $20.88 \%$ & $22.30 \%$ & $20.55 \%$ & $21.15 \%$ \\
\hline Black & $11.62 \%$ & $4.26 \%$ & $8.43 \%$ & $7.10 \%$ & $8.78 \%$ & $7.38 \%$ & $6.79 \%$ & $6.69 \%$ \\
\hline Chinese & $0.14 \%$ & $2.57 \%$ & $4.52 \%$ & $5.97 \%$ & $6.92 \%$ & $6.58 \%$ & $6.58 \%$ & $6.43 \%$ \\
\hline Japanese & $0.24 \%$ & $1.22 \%$ & $1.01 \%$ & $0.65 \%$ & $0.54 \%$ & $0.59 \%$ & $0.93 \%$ & $2.14 \%$ \\
\hline High School & $30.20 \%$ & $22.52 \%$ & $18.72 \%$ & $17.56 \%$ & $18.40 \%$ & $19.25 \%$ & $19.20 \%$ & $18.10 \%$ \\
\hline Some College & $28.78 \%$ & $22.72 \%$ & $21.33 \%$ & $20.91 \%$ & $19.36 \%$ & $17.49 \%$ & $16.87 \%$ & $15.13 \%$ \\
\hline Bachelor Degree & $15.81 \%$ & $11.67 \%$ & $14.53 \%$ & $15.49 \%$ & $13.61 \%$ & $12.27 \%$ & $14.11 \%$ & $18.38 \%$ \\
\hline > Bachelor Degree & $8.65 \%$ & $10.00 \%$ & $9.44 \%$ & $9.20 \%$ & $8.26 \%$ & $8.69 \%$ & $11.38 \%$ & $14.37 \%$ \\
\hline \multicolumn{9}{|l|}{ REGION } \\
\hline New England & $5.17 \%$ & $6.70 \%$ & $5.02 \%$ & $4.09 \%$ & $3.93 \%$ & $4.37 \%$ & $4.26 \%$ & $5.17 \%$ \\
\hline Middle Atlantic & $13.53 \%$ & $23.56 \%$ & $21.29 \%$ & $16.48 \%$ & $18.95 \%$ & $20.31 \%$ & $20.76 \%$ & $18.30 \%$ \\
\hline
\end{tabular}




\begin{tabular}{|c|c|c|c|c|c|c|c|c|}
\hline East North Central & $17.22 \%$ & $10.83 \%$ & $8.83 \%$ & $8.36 \%$ & $6.69 \%$ & $7.39 \%$ & $9.22 \%$ & $10.23 \%$ \\
\hline West North Central & $7.58 \%$ & $2.12 \%$ & $1.61 \%$ & $1.84 \%$ & $1.71 \%$ & $1.82 \%$ & $2.64 \%$ & $3.24 \%$ \\
\hline South Atlantic & $19.24 \%$ & $18.44 \%$ & $15.50 \%$ & $13.18 \%$ & $15.96 \%$ & $14.96 \%$ & $17.62 \%$ & $20.17 \%$ \\
\hline East South Central & $6.89 \%$ & $1.41 \%$ & $1.12 \%$ & $0.95 \%$ & $0.86 \%$ & $0.87 \%$ & $1.32 \%$ & $1.96 \%$ \\
\hline West South Central & $10.88 \%$ & $7.25 \%$ & $9.75 \%$ & $11.57 \%$ & $11.21 \%$ & $9.18 \%$ & $10.15 \%$ & $10.53 \%$ \\
\hline Mountain & $6.41 \%$ & $5.28 \%$ & $4.79 \%$ & $4.93 \%$ & $4.57 \%$ & $5.17 \%$ & $5.46 \%$ & $6.08 \%$ \\
\hline Pacific & $13.08 \%$ & $24.41 \%$ & $32.09 \%$ & $38.60 \%$ & $36.13 \%$ & $35.92 \%$ & $28.56 \%$ & $24.31 \%$ \\
\hline \multicolumn{9}{|l|}{ MARST } \\
\hline Married, Present & $60.02 \%$ & $60.93 \%$ & $64.80 \%$ & $65.06 \%$ & $64.65 \%$ & $64.20 \%$ & $61.20 \%$ & $55.59 \%$ \\
\hline Married, Absent & $2.41 \%$ & $2.51 \%$ & $3.40 \%$ & $3.61 \%$ & $4.34 \%$ & $5.25 \%$ & $6.62 \%$ & $10.42 \%$ \\
\hline Separated & $2.30 \%$ & $2.57 \%$ & $3.75 \%$ & $3.62 \%$ & $4.00 \%$ & $3.83 \%$ & $3.57 \%$ & $2.97 \%$ \\
\hline Divorced & $12.30 \%$ & $11.52 \%$ & $9.94 \%$ & $8.25 \%$ & $7.76 \%$ & $6.25 \%$ & $5.33 \%$ & $4.38 \%$ \\
\hline Widowed & $8.32 \%$ & $15.00 \%$ & $5.02 \%$ & $4.16 \%$ & $3.87 \%$ & $3.28 \%$ & $3.37 \%$ & $3.16 \%$ \\
\hline Single & $14.65 \%$ & $7.47 \%$ & $13.09 \%$ & $15.29 \%$ & $15.38 \%$ & $17.19 \%$ & $19.91 \%$ & $23.48 \%$ \\
\hline
\end{tabular}

Note: Data from 2000 Census. The sample includes people over 24 years old. 
Table 2-11 Data Description for ACS 2010

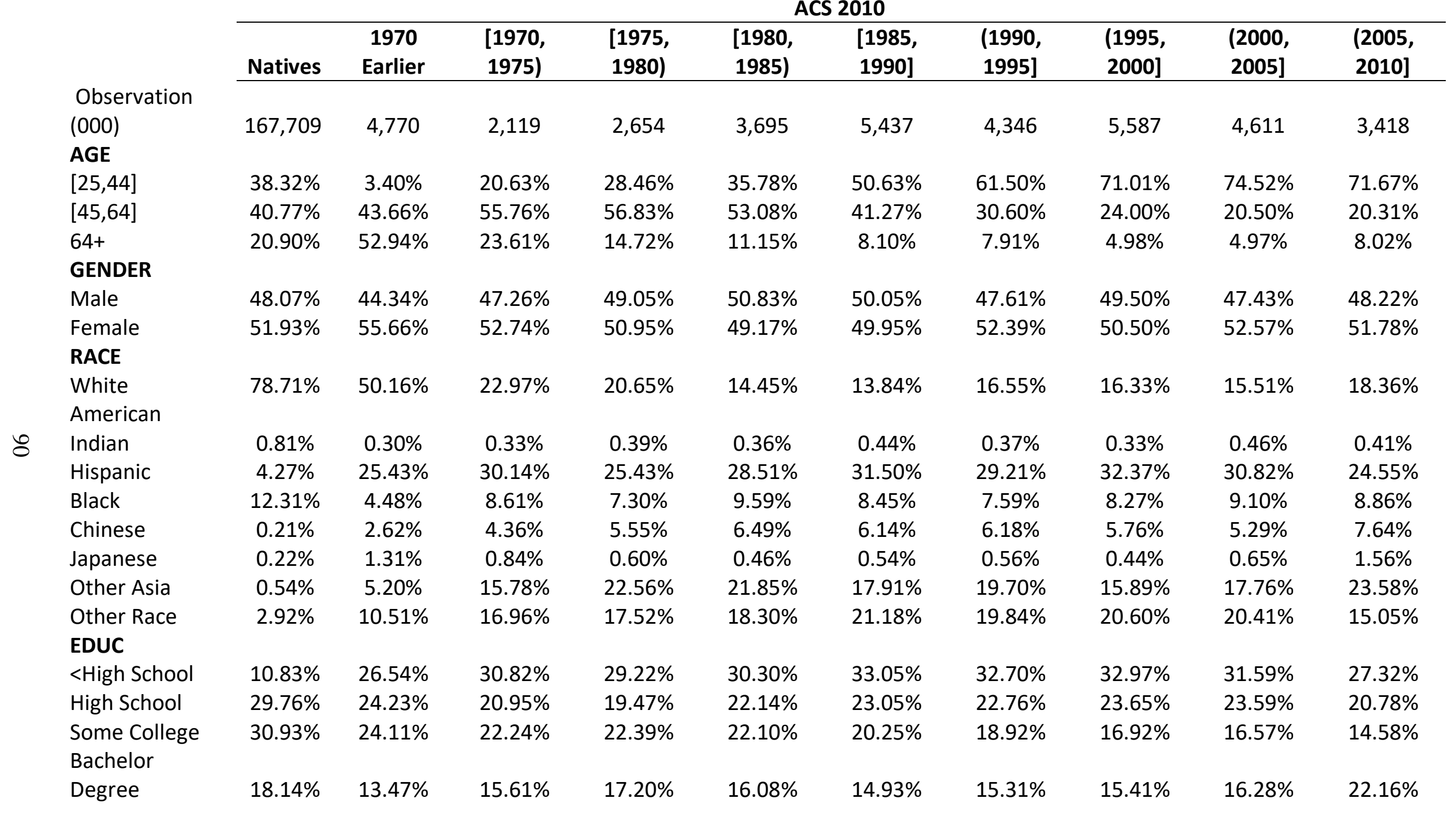




\begin{tabular}{|c|c|c|c|c|c|c|c|c|c|c|}
\hline $\begin{array}{l}\text { > Bachelor } \\
\text { Degree }\end{array}$ & $10.33 \%$ & $11.65 \%$ & $10.38 \%$ & $11.73 \%$ & $9.38 \%$ & $8.72 \%$ & $10.30 \%$ & $11.04 \%$ & $11.97 \%$ & $15.16 \%$ \\
\hline \multicolumn{11}{|l|}{ REGION } \\
\hline New England & $4.87 \%$ & $6.34 \%$ & $5.06 \%$ & $3.79 \%$ & $3.86 \%$ & $4.06 \%$ & $4.24 \%$ & $4.33 \%$ & $5.13 \%$ & $5.29 \%$ \\
\hline $\begin{array}{l}\text { Middle Atlantic } \\
\text { East North }\end{array}$ & $12.60 \%$ & $20.82 \%$ & $19.41 \%$ & $15.23 \%$ & $16.97 \%$ & $18.37 \%$ & $19.20 \%$ & $16.83 \%$ & $16.69 \%$ & $17.96 \%$ \\
\hline $\begin{array}{l}\text { Central } \\
\text { West North }\end{array}$ & $16.57 \%$ & $9.51 \%$ & $8.95 \%$ & $8.18 \%$ & $6.51 \%$ & $6.65 \%$ & $8.10 \%$ & $9.19 \%$ & $8.33 \%$ & $8.88 \%$ \\
\hline Central & $7.53 \%$ & $2.23 \%$ & $1.57 \%$ & $2.07 \%$ & $2.12 \%$ & $1.95 \%$ & $2.82 \%$ & $3.00 \%$ & $2.90 \%$ & $3.27 \%$ \\
\hline $\begin{array}{l}\text { South Atlantic } \\
\text { East South }\end{array}$ & $19.83 \%$ & $20.48 \%$ & $16.97 \%$ & $14.27 \%$ & $17.68 \%$ & $16.89 \%$ & $17.94 \%$ & $20.88 \%$ & $22.59 \%$ & $21.56 \%$ \\
\hline $\begin{array}{l}\text { Central } \\
\text { West South }\end{array}$ & $6.94 \%$ & $1.53 \%$ & $1.21 \%$ & $1.32 \%$ & $1.14 \%$ & $0.98 \%$ & $1.15 \%$ & $1.91 \%$ & $2.27 \%$ & $2.81 \%$ \\
\hline Central & $11.34 \%$ & $8.30 \%$ & $10.00 \%$ & $11.65 \%$ & $12.04 \%$ & $10.42 \%$ & $11.18 \%$ & $12.49 \%$ & $11.69 \%$ & $11.83 \%$ \\
\hline Mountain & $7.17 \%$ & $6.30 \%$ & $5.80 \%$ & $6.15 \%$ & $5.75 \%$ & $5.77 \%$ & $5.90 \%$ & $6.41 \%$ & $6.05 \%$ & $5.41 \%$ \\
\hline Pacific & $13.15 \%$ & $24.50 \%$ & $31.03 \%$ & $37.33 \%$ & $33.94 \%$ & $34.91 \%$ & $29.48 \%$ & $24.95 \%$ & $24.34 \%$ & $22.99 \%$ \\
\hline $\begin{array}{l}\text { MARST } \\
\text { Married, }\end{array}$ & & & & & & & & & & \\
\hline $\begin{array}{l}\text { Present } \\
\text { Married, }\end{array}$ & $54.81 \%$ & $56.62 \%$ & $62.36 \%$ & $63.33 \%$ & $59.93 \%$ & $60.00 \%$ & $61.18 \%$ & $60.67 \%$ & $56.61 \%$ & $51.59 \%$ \\
\hline Absent & $1.71 \%$ & $2.22 \%$ & $2.90 \%$ & $2.73 \%$ & $3.84 \%$ & $4.29 \%$ & $4.45 \%$ & $4.97 \%$ & $6.36 \%$ & $9.51 \%$ \\
\hline Separated & $2.42 \%$ & $2.37 \%$ & $3.65 \%$ & $3.45 \%$ & $3.87 \%$ & $3.97 \%$ & $3.77 \%$ & $3.63 \%$ & $3.34 \%$ & $2.36 \%$ \\
\hline Divorced & $14.07 \%$ & $13.83 \%$ & $12.53 \%$ & $11.74 \%$ & $10.85 \%$ & $9.03 \%$ & $8.00 \%$ & $6.50 \%$ & $5.87 \%$ & $4.46 \%$ \\
\hline Widowed & $7.66 \%$ & $17.12 \%$ & $8.06 \%$ & $5.92 \%$ & $4.76 \%$ & $3.83 \%$ & $3.70 \%$ & $2.76 \%$ & $2.77 \%$ & $4.62 \%$ \\
\hline Single & $19.33 \%$ & $7.84 \%$ & $10.51 \%$ & $12.82 \%$ & $16.75 \%$ & $18.88 \%$ & $18.90 \%$ & $21.48 \%$ & $25.05 \%$ & $27.46 \%$ \\
\hline
\end{tabular}

Note: Data from 2010 ACS. The sample includes people over 24 years old. 


\section{Chapter 3}

\section{Matching Immigrant Cohorts Using American Community Survey Data}

\subsection{Introduction}

The American Community Survey (ACS) is a comprehensive, rolling sample, nationally representative survey administrated by the U.S. Census Bureau. As a replacement for the Census long form, the ACS inherited many socioeconomic questions that are no longer asked in the decennial census. The ACS test surveys were conducted in 2000-2004. The 2005-onward ACS selected over 2.9 million (3.54 million after 2011) household addresses per year to sample.

As the successor of the census long form, the ACS is authorized by Title 13, under which participation is mandatory by law. As a result, the ACS has high response rate and is used for many governmental and non-governmental purposes, such as drawing congressional and state legislative district within states, distributing federal funds, planning decisions, as for example those involving public transportation, and academic research.

The mission of the ACS program is to collect data and provide quality statistics for America about all its communities ${ }^{15}$. The primary goal is for "the ACS program [to] produce quality statistics for the nation.” High quality statistics are specified as timely, accurate, relevant, accessible/usable information. This goal is decomposed into the ten objectives. Unfortunately, none of these objectives focuses on the foreign-born population.

\footnotetext{
${ }^{15}$ For more information, see ACS Program Strategic Plan (U.S. Census Bureau n.d.).
} 
Most immigration studies in the U.S. are based on census data before $2000^{16}$. As the Census Bureau discontinued the long form in 2010, immigrants are no longer identifiable in the census. The ACS and the Current Population Survey (CPS) have become the most popular datasets for immigration studies. For the purpose of preserving data consistency, the ACS is most commonly used with previous censuses.

This article verifies whether the ACS is appropriate to be used in immigration studies. Specifically, under what condition the ACS can create accurate estimates. I look at the validity of statistics based using multiple ACS surveys to follow immigrant cohort. Some important anomalies appear in the analysis.

\subsection{Data Description}

Immigrants are people who were born outside of the U.S., excepting those with a U.S. parent. The ACS is weighted to represent the full U.S. population. Table 3-1 shows the average weight, number of observations, and the population estimates for natives, immigrants, and these two groups together using the Integrated Public Use Microdata Series ${ }^{17}$ (IPUMS). The U.S. population increased by 28.8 million (about 9.2 percent) from 2006 to 2019. The native population increased by 21.5 million (about 7.9 percent), and the immigrant population increased much more rapidly, by 7.3 million (about 17.8 percent). The proportion of foreign-born in the U.S. population increased from 12.5 percent to 13.6 percent.

\footnotetext{
${ }^{16}$ For example, some influential work using the census includes Borjas (1985), Altonji and Card (1989), Card (2001) and many others.

17 The IPUMS dataset is provided by a group of astonishing demographers (Ruggles, et al. n.d.) at the University of Minnesota.
} 
Immigrants have higher personal weight on average. Personal weight primarily reflects the response rate in each block. A block is the basic geographic area, such as a county or a school district, of the ACS sampling process. In addition, a higher fraction of population is sampled in areas with lower population densities to reduce the sampling error. The sampling rates range from 0.5 percent to 15 percent. Lower sampling rates translate into higher weights. Since immigrants prefer cities over rural area (Chiswick and Miller 2004), their weights tend to be higher. Also, Illegal immigrants are less willing to respond to the ACS, lowering the response rate of immigrants. In a Pew Research Center report about counting undocumented immigrants in the U.S., Passel (2019) adjusted upward their initial estimates for undocumented immigrants by 5 percent to 15 percent.

Figure 3-1 shows the population estimates of the IPUMS (solid lines) and the ACS (dashed) between 2012 and 2019. ACS is the tabulation done by the Census and IPUMS is the microdata file of the ACS. Immigrants are separated into two cohorts, those that arrived before 2000 and those arriving between 2000 and 2009. By combining data from multiple years ACS, population estimates of these two cohorts identified by the same arrival years are compared across years. Notice the estimates of IPUMS and the ACS are not identical. The difference is probably due to the lag in updating the IPUMS data within a short period after the release of new ACS data. In September of every year, the latest release of the ACS updates previous estimates using new information.

Both cohorts' population show decreasing trends. The older cohort has steeper decline in population compared to the younger cohort. Two factors behind the reduction in population are outmigration and death. Immigrants are subject to outmigration when they leave the U.S.; these are also known as return migration or 
emigration. Outmigration may be driven by various factors, such as an original migration plan, erroneous information before initial migration, or shocks in the U.S. labor market (Borjas and Bratsberg 1994). Difference in the death rates between these two cohorts is a more plausible reason for the difference in slopes.

The ACS uses population control from the Population Estimates Program ${ }^{18}$ (PEP) to design sampling procedures and assign weights. The PEP program produces estimates of the population for different geographical areas from the whole nation to towns in the U.S., including Puerto Rico and its municipios. The population control in the ACS reweights samples in the ACS so that the number of housing units and people in certain categories are in line with the PEP estimates for the subcounty area.

The $\mathrm{PEP}^{19}$ provides estimates for the number of immigrants in an area as well. This paper will give more details about the PEP estimates in section Country of Origin.

\footnotetext{
${ }^{18}$ For detailed relationship between the ACS and PEP, see Chapter 11 of the American Community Survey Design and Methodology (United States Census Bureau 2020),

${ }^{19}$ For details regarding the PEP, see Methodology for the United States Population Estimates: Vintage 2019 (United States Census Bureau 2020)
} 
Table 3-1 Population Estimates Decomposition

\begin{tabular}{|c|c|c|c|c|c|c|c|c|c|}
\hline \multirow[b]{2}{*}{ Year } & \multicolumn{3}{|c|}{ Total } & \multicolumn{3}{|c|}{ Native } & \multicolumn{3}{|c|}{ Immigrants } \\
\hline & $\begin{array}{l}\text { Pop. } \\
\text { (000) }\end{array}$ & $\begin{array}{l}\text { \# of } \\
\text { Obs. } \\
(000)\end{array}$ & $\begin{array}{l}\text { Average } \\
\text { Weight }\end{array}$ & $\begin{array}{l}\text { Pop. } \\
\text { (000) }\end{array}$ & $\begin{array}{l}\text { \# of } \\
\text { Obs. } \\
(000)\end{array}$ & $\begin{array}{l}\text { Average } \\
\text { Weight }\end{array}$ & $\begin{array}{l}\text { Pop. } \\
\text { (000) }\end{array}$ & $\begin{array}{l}\text { \# of } \\
\text { Obs. } \\
(000)\end{array}$ & $\begin{array}{l}\text { Average } \\
\text { Weight }\end{array}$ \\
\hline & 299,39 & & & 261,92 & & & 37,46 & & 118.6 \\
\hline 2006 & $\begin{array}{c}8 \\
301,62\end{array}$ & 2,970 & 100.82 & $\begin{array}{c}9 \\
263,57\end{array}$ & 2,654 & 98.69 & $\begin{array}{c}9 \\
38,04\end{array}$ & 316 & $\begin{array}{c}8 \\
117.8\end{array}$ \\
\hline 2007 & $\begin{array}{c}1 \\
304,06\end{array}$ & 2,995 & 100.72 & $\begin{array}{c}3 \\
266,04\end{array}$ & 2,672 & 98.65 & $\begin{array}{c}8 \\
38,01\end{array}$ & 323 & $\begin{array}{c}1 \\
117.5\end{array}$ \\
\hline 2008 & $\begin{array}{c}0 \\
307,00\end{array}$ & 3,001 & 101.33 & $\begin{array}{c}4 \\
268,55\end{array}$ & 2,677 & 99.37 & $\begin{array}{c}6 \\
38,45\end{array}$ & 323 & $\begin{array}{c}4 \\
115.3\end{array}$ \\
\hline 2009 & $\begin{array}{c}7 \\
309,35\end{array}$ & 3,031 & 101.30 & $\begin{array}{c}4 \\
269,43\end{array}$ & 2,697 & 99.56 & $\begin{array}{c}3 \\
39,91\end{array}$ & 333 & $\begin{array}{c}9 \\
114.7\end{array}$ \\
\hline 2010 & $\begin{array}{c}0 \\
311,59\end{array}$ & 3,062 & 101.04 & $\begin{array}{c}3 \\
271,21\end{array}$ & 2,714 & 99.28 & $\begin{array}{c}7 \\
40,38\end{array}$ & 348 & $\begin{array}{c}2 \\
115.6\end{array}$ \\
\hline 2011 & $\begin{array}{c}2 \\
313,91\end{array}$ & 3,112 & 100.13 & $\begin{array}{c}0 \\
273,17\end{array}$ & 2,763 & 98.16 & $\begin{array}{c}2 \\
40,73\end{array}$ & 349 & $\begin{array}{c}5 \\
115.0\end{array}$ \\
\hline 2012 & $\begin{array}{c}4 \\
316,12\end{array}$ & 3,113 & 100.84 & $\begin{array}{c}6 \\
274,78\end{array}$ & 2,759 & 99.02 & $\begin{array}{c}8 \\
41,34\end{array}$ & 354 & $\begin{array}{c}4 \\
115.6\end{array}$ \\
\hline 2013 & $\begin{array}{c}9 \\
318,85\end{array}$ & 3,133 & 100.91 & $\begin{array}{c}8 \\
276,62\end{array}$ & 2,775 & 99.01 & $\begin{array}{c}1 \\
42,23\end{array}$ & 357 & $\begin{array}{c}6 \\
117.1\end{array}$ \\
\hline 2014 & $\begin{array}{c}7 \\
321,41\end{array}$ & 3,133 & 101.79 & $\begin{array}{c}1 \\
278,26\end{array}$ & 2,772 & 99.79 & $\begin{array}{c}6 \\
43,15\end{array}$ & 361 & $\begin{array}{c}0 \\
117.6\end{array}$ \\
\hline 2015 & $\begin{array}{c}9 \\
323,12\end{array}$ & 3,147 & 102.13 & $\begin{array}{c}1 \\
279,44\end{array}$ & 2,780 & 100.09 & $\begin{array}{c}8 \\
43,68\end{array}$ & 367 & $\begin{array}{c}5 \\
117.7\end{array}$ \\
\hline 2016 & $\begin{array}{c}8 \\
325,71\end{array}$ & 3,156 & 102.37 & $\begin{array}{c}6 \\
281,31\end{array}$ & 2,785 & 100.32 & $\begin{array}{c}2 \\
44,40\end{array}$ & 371 & $\begin{array}{c}2 \\
117.4\end{array}$ \\
\hline 2017 & $\begin{array}{c}9 \\
327,16\end{array}$ & 3,190 & 102.11 & $\begin{array}{c}3 \\
282,40\end{array}$ & 2,812 & 100.04 & $\begin{array}{c}6 \\
44,76\end{array}$ & 378 & $\begin{array}{c}6 \\
118.3\end{array}$ \\
\hline 2018 & $\begin{array}{c}7 \\
328,24\end{array}$ & 3,215 & 101.78 & $\begin{array}{c}7 \\
283,45\end{array}$ & 2,836 & 99.57 & $\begin{array}{c}1 \\
44,78\end{array}$ & 378 & $\begin{array}{c}3 \\
118.8\end{array}$ \\
\hline 2019 & 0 & 3,240 & 101.32 & 1 & 2,863 & 99.01 & 8 & 377 & 7 \\
\hline
\end{tabular}

Note: Data source is the ACS from 2006 to 2019.

Figure 3-1 Cohort Population Estimation using ACS and IPUMS 


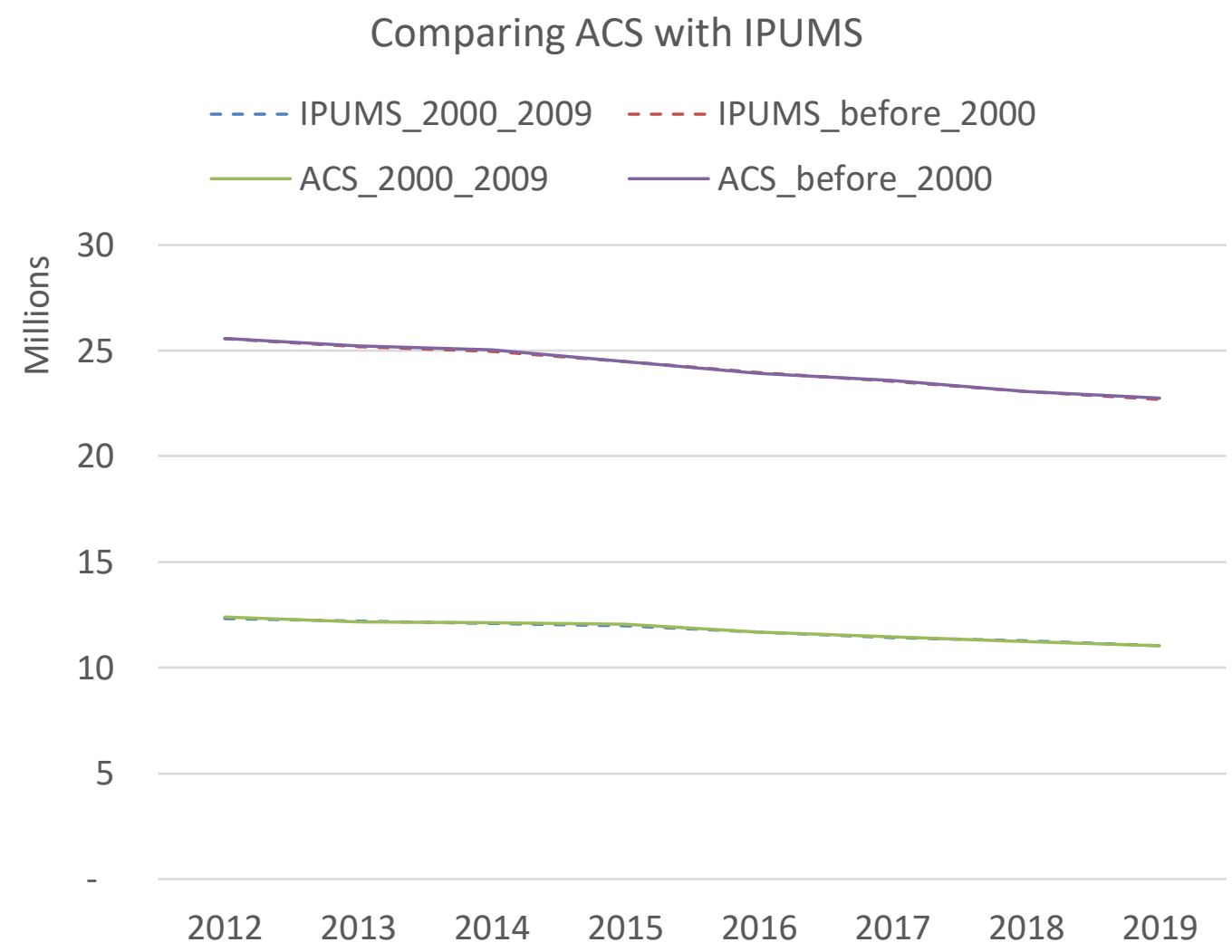

\subsection{The Ten-Year Puzzle}

The decreasing trend in population is less clear when breaking the immigrant cohorts by arrival year. Figure 3-2 shows the cohort population of 27 cohorts, from cohort 1991 to cohort 2017, by years since migration. In addition to the long-term decreasing trend, there are some spikes, which imply increases in the cohort population.

Curves in Figure 3-2 are less smooth than in Figure 3-1 due to reduced sample size of a cohort. Sampling error is larger with smaller sample size. However, spikes due to sampling error are not randomly distributed. The substantial spikes for all cohorts in the $10^{\text {th }}$ year and the $20^{\text {th }}$ year after arrival cannot be coincidence. The increase in the population between the $9^{\text {th }}$ year and the $10^{\text {th }}$ year ranges from 
9.9 percent to 20.3 percent $^{20}$. The increase in the population between the $19^{\text {th }}$ and the $20^{\text {th }}$ year ranges from 7.2 percent to 18.5 percent. Some cohorts also show increasing population in the $5^{\text {th }}$ and $15^{\text {th }}$ year after arrival that cannot be explained by sampling error. Shall we believe that hundreds of thousands of people are moving back to the U.S. in the exact tenth year since their first arrival? This paper refers all these unexplained spikes at year with multiple of ten as the ten-year puzzle.

Figure 3-2 Cohort Size by Year Since Migration
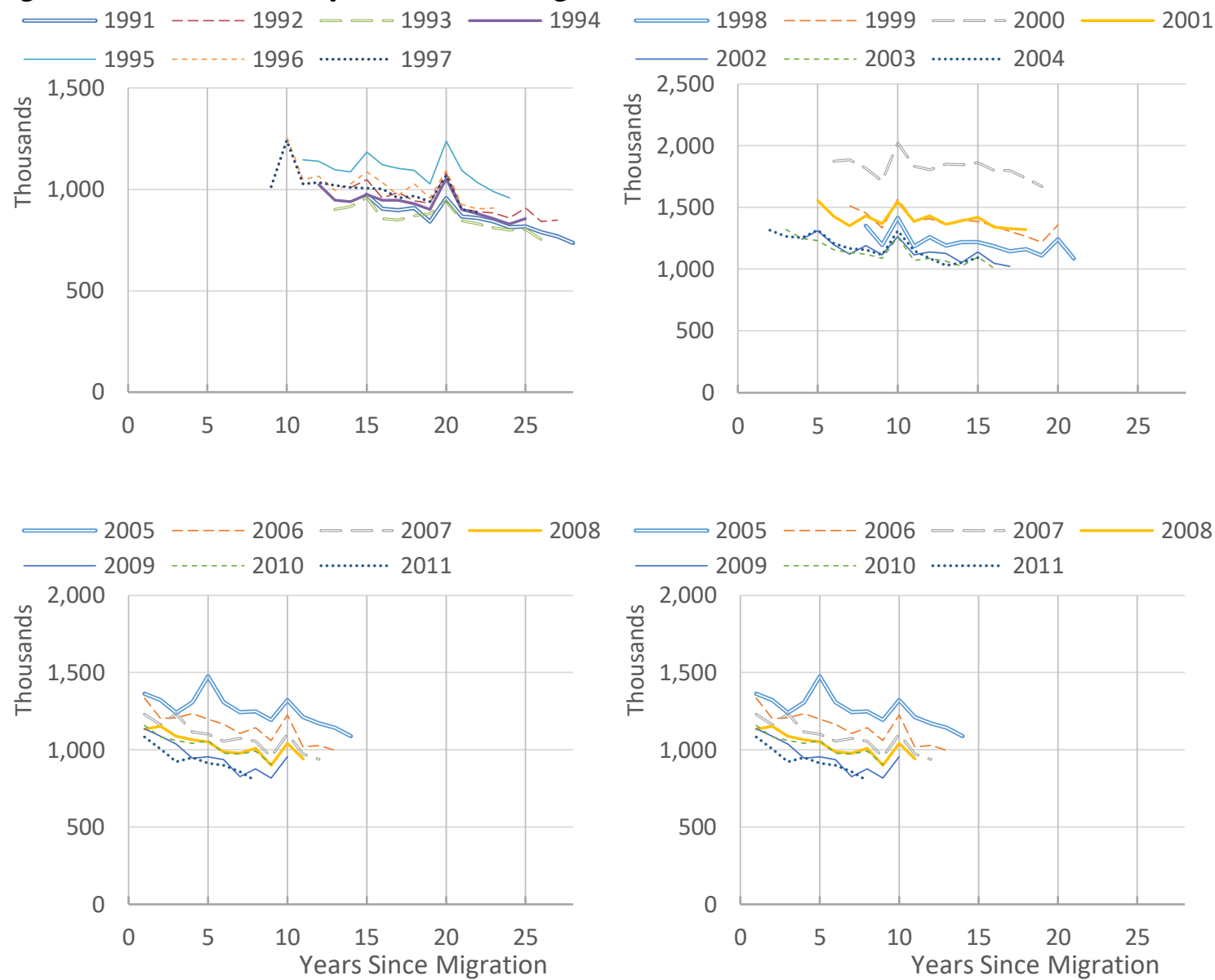

Another problem with ACS presenting immigrant cohorts is about the firstyear count. Cohort size is at maximum in the first year after arrival as new immigrants arrived in later years belong to later cohorts. Unfortunately, the first-

20 The increase is calculated as $r_{c}=\frac{\text { oop }_{c, 10}-p o p_{c, 9}}{\left(\frac{\operatorname{pop}_{c, 10}+p o p_{c, 9}}{2}\right)}$ 
year estimates of population based on the ACS are significant underestimates of the number of arrivals for all cohorts, as many immigrants arriving in the year of the survey are missing from the survey. For example, an immigrant who arrived in April would miss the ACS survey sent in February to the house where he would stay later that year. This is a flaw of the ACS as the personal weight for new arrivals are not separately modified with more information in later releases. As a result, immigrants who stayed for more than one year have an over-estimated weight. ${ }^{21}$ However, this positive bias in weight cannot explain the ten-year spikes as it applies to all population estimates after year 1. The first-year estimates are dropped from this analysis.

The change in estimated population is,

$$
\Delta \text { Pop }_{9-10}=\mathrm{Obs}_{10} \cdot \text { Weight }_{10}-\mathrm{Obs}_{9} \cdot \text { Weight }_{9}
$$

where $\Delta P o p_{9-10}$ shows the difference between the estimated population for the $9^{\text {th }}$ and $10^{\text {th }}$ year. Obs represents the number of observations. Weight is the personal weight. Subscription represent how many years these immigrants have stayed in the U.S. With some basic algebra transformation, the above equation is decomposed into three parts,

$$
\begin{gathered}
\Delta \text { Pop }_{9-10}=\Delta \text { Weight }_{9 \_10} \cdot \text { Obs }_{9}+\Delta \mathrm{Obs}_{9 \_10} \cdot \text { Weight }_{9}+\Delta \text { Weight }_{9 \_10} \cdot \\
\Delta \text { Obs }_{9 \_10}
\end{gathered}
$$

where the change in population estimation between the $9^{\text {th }}$ year and $10^{\text {th }}$ year are decomposed into three parts: $\Delta W$ eight $_{9-10}$ is the increase in the average personal weight from year 9 to $10 ; \Delta O b s_{9-10}$ is the increase in observations from year 9 to 10; and the last term on the RHS represents the increase in both factors. For all

\footnotetext{
${ }^{21}$ The positive bias is about 1 percent to 1.5 percent based on some rough calculation.
} 
cohorts with the $9^{\text {th }}$ year and $10^{\text {th }}$ year are available, the increase in personal weight accounts for 18.1 percent of the total increase. The increase in observations accounts for 79.4 percent. Increment in both factors counts for 2.5 percent of total increase. The same decomposition between the $19^{\text {th }}$ year and $20^{\text {th }}$ year shows the fraction of contribution is 23.8 percent, 73.7 percent, and 2.4 percent for corresponding parts.

A plausible reason for an increase in the observation is remigration. Remigration is the process where immigrants return to the U.S. after leaving at an earlier point but are identified with their first arrival. For example, an U.K. student who graduated from a U.S. college before working in his home country returns to the U.S. for a doctoral program. As more immigrants leave the U.S., the pool of outmigrants who return might will get larger. When such remigration exceeds the number of deaths and outmigration for a cohort, the cohort size increases.

The other possibility is that the PEP estimates of the immigrant population impose a structural error in estimates of population change at the $10^{\text {th }}$ and $20^{\text {th }}$ year after arrival. For example, when the $9^{\text {th }}$ year cohort size is underestimated and the $10^{\text {th }}$ year cohort size is overestimated, the change between the $9^{\text {th }}$ and $10^{\text {th }}$ year population will be positively biased. This change is expected to correspond to an increase in average personal weight through population control, as mentioned above.

\subsection{Regression Model}

A theoretical framework is crucial to test hypothesis regarding the cause behind the ten-year puzzle. The basic model is as follow,

$$
\ln \left(\operatorname{pop}_{\mathrm{ct}}\right)=\alpha+\beta \cdot \mathrm{ysm}_{\mathrm{ct}}+\operatorname{cohort}_{\mathrm{c}}+\epsilon_{\mathrm{ct}}
$$


where $p o p_{c t}$ is the population of cohort $c$ in year $t, y s m$ is the year since migration, and $\operatorname{cohort}_{c}$ is the cohort fixed effect. The regression result is summarized in Table $3-2$.

Table 3-2 Linear Regression of Cohort Size Trend

\begin{tabular}{|c|c|c|c|c|c|c|}
\hline \multicolumn{7}{|c|}{ Linear Regression } \\
\hline $\ln (P o p)$ & Coef. & & Std. Err. & P-Value & [95\% Co & Interval] \\
\hline $\begin{array}{l}\text { years_in_us } \\
\text { cohort }\end{array}$ & -0.015 & $* * *$ & 0.001 & 0 & -0.017 & -0.013 \\
\hline 1992 & 0.075 & $* * *$ & 0.001 & 0 & 0.073 & 0.077 \\
\hline 1993 & -0.025 & $* * *$ & 0.002 & 0 & -0.030 & -0.021 \\
\hline 1994 & 0.038 & $* * *$ & 0.003 & 0 & 0.031 & 0.044 \\
\hline 1995 & 0.187 & $* * *$ & 0.004 & 0 & 0.179 & 0.196 \\
\hline 1996 & 0.102 & $* * *$ & 0.005 & 0 & 0.091 & 0.114 \\
\hline 1997 & 0.073 & $* * *$ & 0.006 & 0 & 0.059 & 0.086 \\
\hline 1998 & 0.246 & $* * *$ & 0.008 & 0 & 0.231 & 0.262 \\
\hline 1999 & 0.360 & $* * *$ & 0.009 & 0 & 0.343 & 0.378 \\
\hline 2000 & 0.625 & $* * *$ & 0.010 & 0 & 0.605 & 0.645 \\
\hline 2001 & 0.350 & $* * *$ & 0.011 & 0 & 0.328 & 0.372 \\
\hline 2002 & 0.133 & $* * *$ & 0.012 & 0 & 0.109 & 0.158 \\
\hline 2003 & 0.106 & $* * *$ & 0.013 & 0 & 0.080 & 0.133 \\
\hline 2004 & 0.129 & $* * *$ & 0.014 & 0 & 0.101 & 0.158 \\
\hline 2005 & 0.180 & $* * *$ & 0.015 & 0 & 0.149 & 0.212 \\
\hline 2006 & 0.079 & $* * *$ & 0.016 & 0 & 0.047 & 0.111 \\
\hline 2007 & 0.013 & & 0.016 & 0.419 & -0.020 & 0.047 \\
\hline 2008 & -0.041 & $* *$ & 0.017 & 0.02 & -0.076 & -0.007 \\
\hline 2009 & -0.127 & $* * *$ & 0.017 & 0 & -0.162 & -0.091 \\
\hline 2010 & -0.060 & $* * *$ & 0.018 & 0.002 & -0.097 & -0.024 \\
\hline 2011 & -0.170 & $* * *$ & 0.018 & 0 & -0.207 & -0.132 \\
\hline 2012 & -0.055 & $* * *$ & 0.019 & 0.007 & -0.094 & -0.016 \\
\hline 2013 & 0.006 & & 0.019 & 0.743 & -0.033 & 0.046 \\
\hline 2014 & 0.144 & $* * *$ & 0.020 & 0 & 0.103 & 0.185 \\
\hline 2015 & 0.247 & $* * *$ & 0.021 & 0 & 0.205 & 0.289 \\
\hline 2016 & 0.330 & $* * *$ & 0.021 & 0 & 0.287 & 0.374 \\
\hline 2017 & 0.166 & $* * *$ & 0.022 & 0 & 0.122 & 0.211 \\
\hline 2018 & 0.149 & $* * *$ & 0.022 & 0 & 0.103 & 0.194 \\
\hline Cons & 13.976 & $* * *$ & 0.023 & 0 & 13.928 & 14.023 \\
\hline
\end{tabular}

Number of Obs $=301$

R-squared $=0.9338$

On average, the net change of population is negative 1.5 percent. That is the net effect of death, outmigration, and remigration. The reference group for the cohort fixed effect is the cohort arriving in 1991. The immigration cohort was 
increasing in 1990s. The cohort size peaked in 2000 and plummeted along with the burst of the dot-com bubble. The cohort size was at the lowest during the subprime mortgage recession from 2008 to 2011 . The cohort fixed effect estimates clearly show that the flow of immigrants is sensitive to expectation of economic gains in the U.S.

Figure 3-3 Component Plus Residual Graph

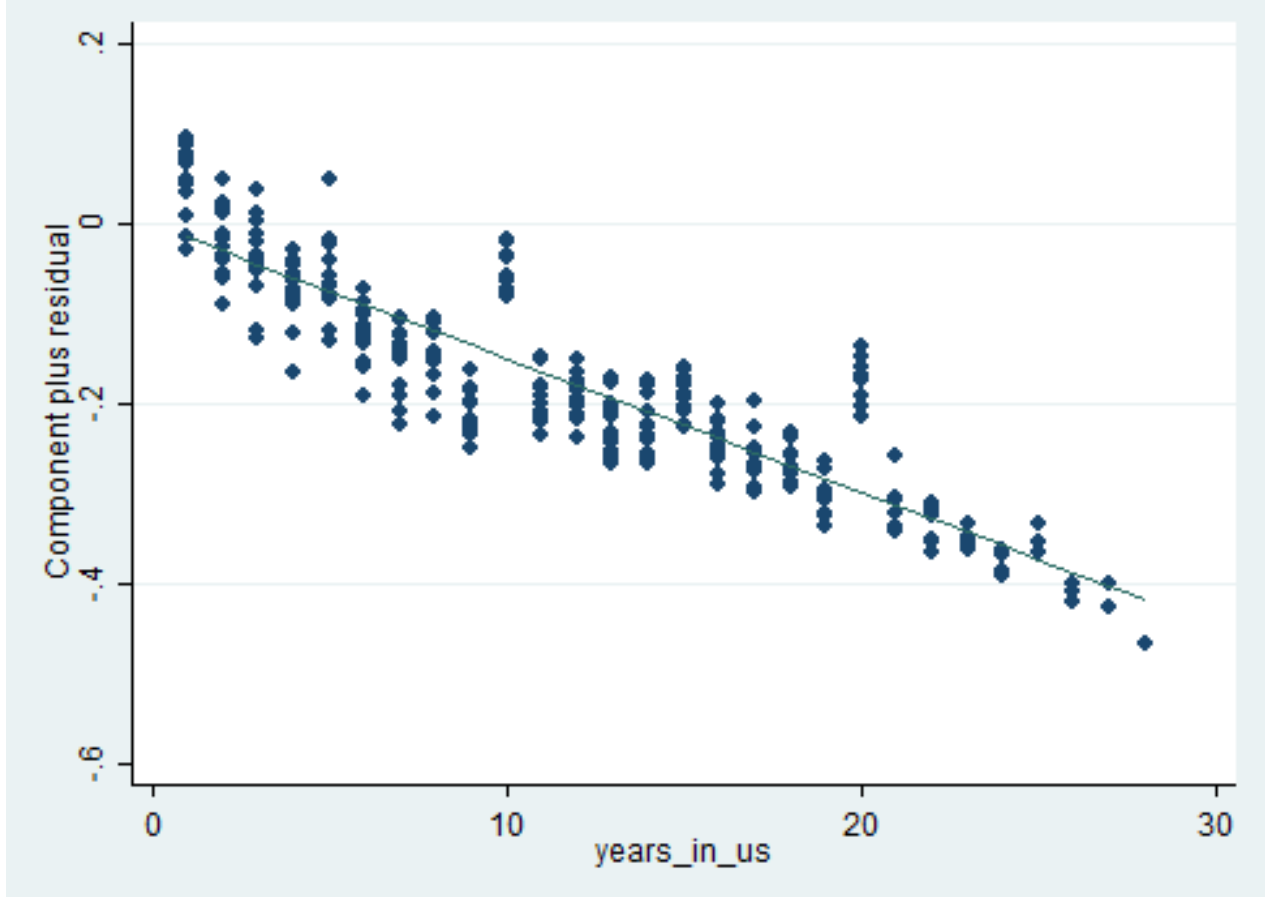

Figure 3-3 shows the component plus residual graph using the results from regression (2). The residual for the $10^{\text {th }}$ year and $20^{\text {th }}$ year are clearly higher than the predicted line. The residuals are also not linear. As a result, a model with fixed year since migration effect,

$$
\ln \left(\text { pop }_{\mathrm{ct}}\right)=\alpha+\mathrm{ysm}_{\mathrm{t}}+\text { cohort }_{\mathrm{c}}+\epsilon_{\mathrm{ct}}
$$

is more appropriate. This model estimates the population growth for each year in the U.S. The results are summarized in Table 3-3.

The second column of Table 3-3 shows the estimated year since migration fixed (ysm) effect. The third column is the standard error. The fourth column shows 
the difference between the ysm fixed effect of one year compared to that of the previous year. The asterisks show the result of a test with null hypothesis of the ysm effect between two years are zero. The last two columns show the upper bound and lower bound of the 95 percent confidence interval.

The estimated coefficient only reveals a small corner of the iceberg as the estimation of fixed variable only tells the difference between a group and the reference group. In this case, the reference group is the first-year cohort. By the difference column, only the $10^{\text {th }}$ year and $20^{\text {th }}$ year differences are positive and statistically significant at 0.99 level. 
Table 3-3 Cohort Size by Year Since Migration

\begin{tabular}{|c|c|c|c|c|c|c|c|}
\hline \multicolumn{8}{|c|}{ Linear regression } \\
\hline $\ln ($ Pop) & \multicolumn{2}{|l|}{ Coef. } & Std. Err. & \multicolumn{2}{|l|}{ Diff. } & \multicolumn{2}{|c|}{ [95\% Conf. Interval] } \\
\hline \multicolumn{8}{|l|}{ years_in_us } \\
\hline 2 & -0.078 & $* * *$ & 0.012 & -0.078 & $* * *$ & -0.103 & -0.052 \\
\hline 3 & -0.101 & $* * *$ & 0.015 & -0.023 & $*$ & -0.131 & -0.071 \\
\hline 4 & -0.141 & $* * *$ & 0.020 & -0.040 & $* *$ & -0.181 & -0.100 \\
\hline 5 & -0.129 & $* * *$ & 0.026 & 0.012 & & -0.182 & -0.076 \\
\hline 6 & -0.192 & $* * *$ & 0.021 & -0.063 & $* * *$ & -0.236 & -0.148 \\
\hline 7 & -0.222 & $* * *$ & 0.024 & -0.031 & $* *$ & -0.272 & -0.173 \\
\hline 8 & -0.211 & $* * *$ & 0.024 & 0.011 & & -0.261 & -0.162 \\
\hline 9 & -0.278 & $* * *$ & 0.022 & -0.067 & $* * *$ & -0.323 & -0.233 \\
\hline 10 & -0.126 & $* * *$ & 0.019 & 0.152 & $* * *$ & -0.165 & -0.087 \\
\hline 11 & -0.263 & $* * *$ & 0.023 & -0.137 & $* * *$ & -0.309 & -0.216 \\
\hline 12 & -0.260 & $* * *$ & 0.021 & 0.003 & & -0.302 & -0.218 \\
\hline 13 & -0.292 & $* * *$ & 0.022 & -0.032 & $* * *$ & -0.338 & -0.246 \\
\hline 14 & -0.292 & $* * *$ & 0.021 & -0.001 & & -0.336 & -0.249 \\
\hline 15 & -0.253 & $* * *$ & 0.022 & 0.040 & $* * *$ & -0.299 & -0.207 \\
\hline 16 & -0.308 & $* * *$ & 0.023 & -0.055 & $* * *$ & -0.355 & -0.261 \\
\hline 17 & -0.323 & $* * *$ & 0.024 & -0.015 & $*$ & -0.372 & -0.273 \\
\hline 18 & -0.323 & $* * *$ & 0.023 & -0.001 & & -0.370 & -0.277 \\
\hline 19 & -0.364 & $* * *$ & 0.023 & -0.041 & $* * *$ & -0.411 & -0.317 \\
\hline 20 & -0.235 & $* * *$ & 0.025 & 0.129 & $* * *$ & -0.286 & -0.185 \\
\hline 21 & -0.372 & $* * *$ & 0.025 & -0.137 & $* * *$ & -0.423 & -0.322 \\
\hline 22 & -0.392 & $* * *$ & 0.024 & -0.020 & $* * *$ & -0.442 & -0.343 \\
\hline 23 & -0.410 & $* * *$ & 0.022 & -0.018 & $* *$ & -0.456 & -0.364 \\
\hline 24 & -0.436 & $* * *$ & 0.023 & -0.026 & $* * *$ & -0.483 & -0.390 \\
\hline 25 & -0.408 & $* * *$ & 0.023 & 0.028 & $* *$ & -0.455 & -0.361 \\
\hline 26 & -0.465 & $* * *$ & 0.023 & -0.057 & $* * *$ & -0.512 & -0.419 \\
\hline 27 & -0.468 & $* * *$ & 0.025 & -0.003 & & -0.520 & -0.417 \\
\hline 28 & -0.524 & $* * *$ & 0.022 & -0.056 & $* * *$ & -0.570 & -0.479 \\
\hline cohort & $\checkmark$ & & & & & & \\
\hline cons & $\checkmark$ & & & & & & \\
\hline \multicolumn{8}{|c|}{ Number of Obs $=301$} \\
\hline
\end{tabular}

Figure 3-4 shows the above findings in a line with the 95 percent confidence interval. The spikes of the $10^{\text {th }}$ and $20^{\text {th }}$ year cohort size are significant as shown in Table 3-3. Also notice the cohort size in years ending with 5 are all increasing but none of them are substantial relative to the $10^{\text {th }}$ year. The goal of this article is to shed some light about what are the reasons behind the 10-year puzzle and discuss 
whether it is appropriate to combine multiple years of the ACS data to study immigration cohorts.

Figure 3-4 Estimated Year Since Migration Fixed Effect with Confidence Interval YSM Fixed Effect

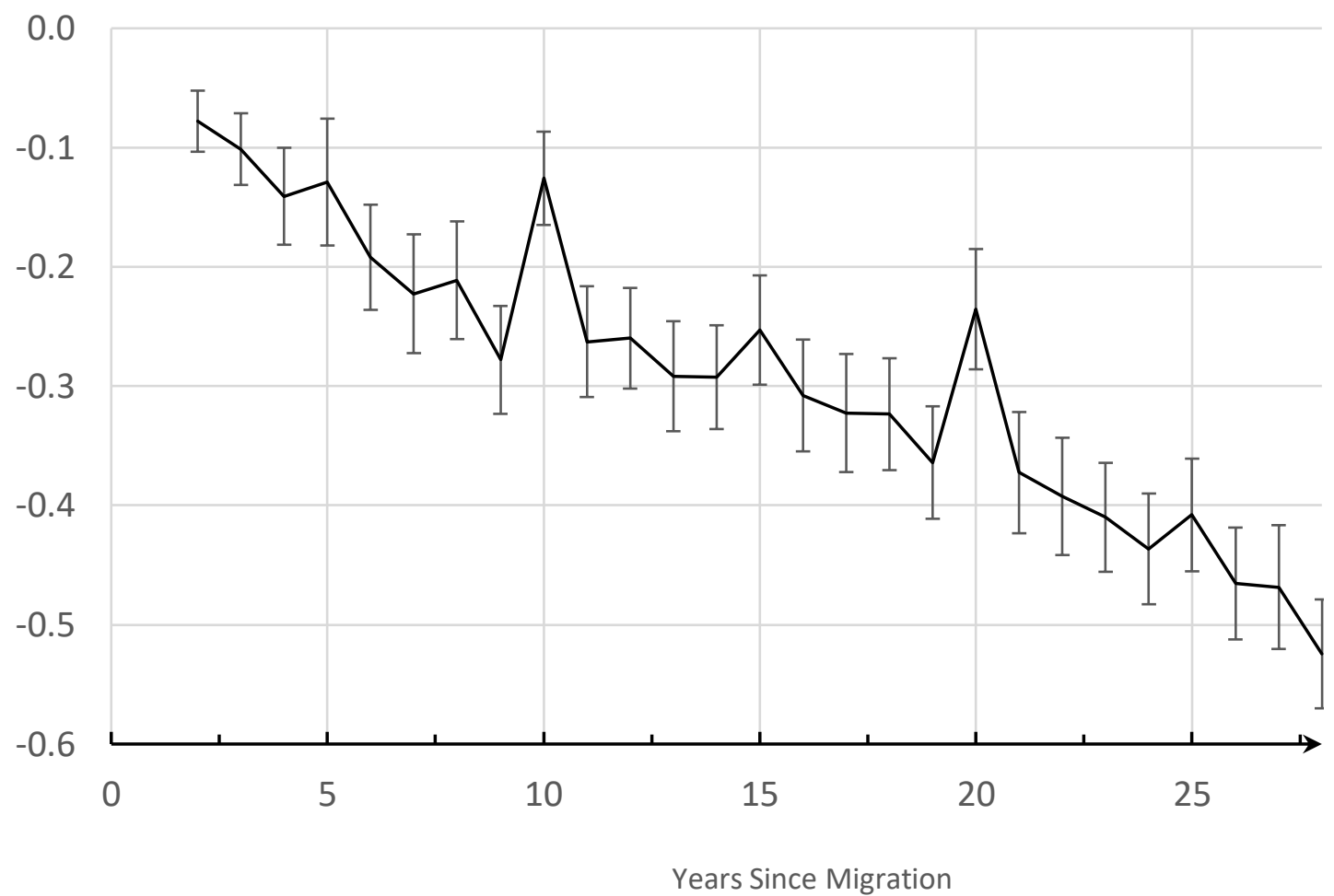

The 10-year puzzle has not been noticed by ACS users. In short, the 10-year puzzle may cause unexpected positive shock in the number of immigrant when cohort population is the independent variable. When used as the dependent variable, the 10-year puzzle creates a discontinuity in the cohort population. In next section, we are going to propose a few hypotheses regarding the cause of the 10-year puzzle with corresponding tests.

\subsection{Testing Hypotheses Behind the 10-year Puzzle}

The first hypothesis is that the 10-year puzzle is a result of difference in the country of origin. Immigrants from different countries bring vary culture and habits to the U.S. The first hypothesis may help to find if any group by itself is behind the 
puzzle. In that case, we can further identify the unique characteristic which causes the 10-year puzzle.

\subsubsection{Country of Origin}

Figure 3-5 shows the decision tree of determining which immigrant cohorts an immigrant belongs to. Unlike all the other races, immigrants from Asia are not subject to the same decision rule regarding length of stay. The cutoff point is 5 years instead of 10. All immigrants from other countries are separated into an "old immigrant" group of those who have stayed more than 10 years, and a "new immigrant" group who arrived more recently. The detailed group criteria is cited below:

"We calculate emigration rates for seven mutually exclusive groups: 1) Mexican-born males who entered the United States within the past 10 years, 2) Mexican-born females who entered within the past 10 years, 3) Mexican born who entered more than 10 years ago, 4) Canadian and European born who entered within the past 10 years, 5) Asian born who entered within the past 5 years, 6) All other foreign born who entered within the past 10 years, and 7) Asian born who entered more than 5 years ago and non-Mexican born who entered more than 10 years ago. We calculate separate rates under the assumption that each group exhibits different propensities to emigrate, as well as different demographic compositions and geographic distributions." 
Outmigration of immigrants (referred as foreign-born emigration in the above PEP technique document is estimated by the immigrant cohort. As a result, immigrants from most countries are subject to a structural change at the $10^{\text {th }}$ year. Outmigration is faster in the first ten years of stay. ${ }^{22}$ In general, the outmigration rate is decreasing over time. As a result, the outmigration rate of the $9^{\text {th }}$ year immigrants is over-estimated as the other immigrants migrated more recently. At the same time, the outmigration rate of the $10^{\text {th }}$ year immigrants is underestimated given that the outmigration rate is taken to be an average that includes of immigrants who have been in the country for decades.

Figure 3-5 Population Estimates Program Immigrants Group for Emigration Estimation

\section{The Immigrant Category Decision Tree}

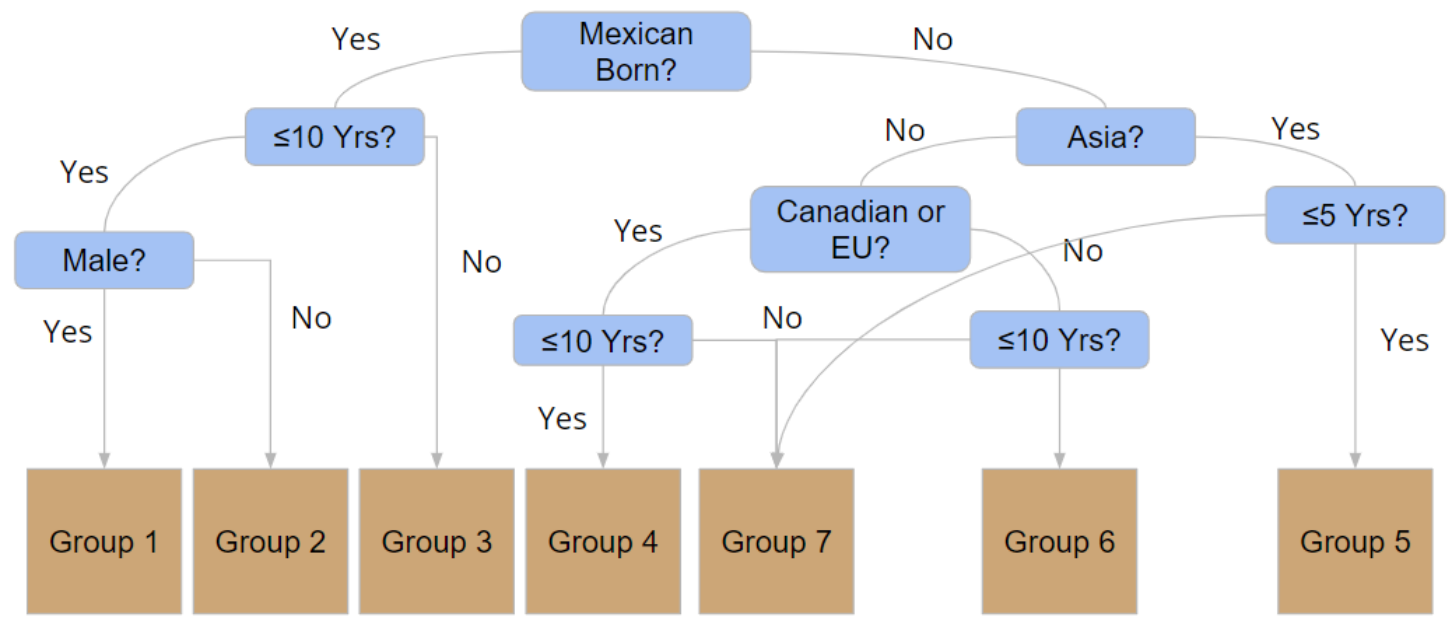

${ }^{22}$ See Ahmed and Robinson (1994), Beaujot and Rappak (1989), Borjas and Bratsberg (1994), Dustmann, Fadlon, and Weiss (2011), and Edin, LaLonde, and Aslund (2000) 
To test whether the arbitrarily chosen group causes the 10 -year puzzle, we exploit the fact that Asian immigrants are using a five-year threshold when estimating the outmigration rate while others use ten. If the discontinuity in outmigration estimation is the cause of the 10-year puzzle, Asian immigrants should have their "5-year puzzle". We can run regressions by country of birth group. Since the interest is to compare Asian with non-Asian, we divided immigrants into four categories - Asian, Hispanic and Latino, European and Oceanian, and African and others.

Table 3-4 shows the result of regression by birthplace group. The top half shows the regression result for Asian, and Hispanic and Latino immigrants. The bottom half displays the result for Europeans and Oceanians, and Africans and others. For each ethnic group, the first column shows the estimated coefficient for the year since migration fixed effect. The reference group is immigrants who had arrived at least one year earlier but less than two years earlier. The second column shows the difference between the fixed effect in a particular year and the one in the previous year.

All four groups show significant increases in cohort population in the $10^{\text {th }}$ year. Only the Hispanic and Latino group shows consistent positive shocks in years ending in five. Asian immigrants, in contrast, have slightly decreasing cohort populations in the $5^{\text {th }}$ and $15^{\text {th }}$ year. The possibility that the 10 -year puzzle is caused by the biased estimation of outmigration rate is not supported by these comparisons. The findings are depicted in Figure 3-6. 
Table 3-4 Cohort Size by Ethnicity

\begin{tabular}{|c|c|c|c|c|c|c|c|c|}
\hline \multirow{3}{*}{$\begin{array}{c}\text { In(Pop) } \\
\text { ysm } \\
2\end{array}$} & \multicolumn{4}{|c|}{ Asian } & \multicolumn{4}{|c|}{ His./Lat. } \\
\hline & \multicolumn{2}{|c|}{$\begin{array}{l}\text { coefficient } \\
\text { (1) }\end{array}$} & \multicolumn{2}{|c|}{$\begin{array}{l}\text { difference } \\
\text { (2) }\end{array}$} & \multicolumn{2}{|c|}{$\begin{array}{c}\text { coefficient } \\
\text { (3) }\end{array}$} & \multicolumn{2}{|c|}{$\begin{array}{l}\text { difference } \\
\text { (4) }\end{array}$} \\
\hline & -0.132 & $* * *$ & -0.132 & & 0.026 & & 0.026 & \\
\hline 3 & -0.182 & $* * *$ & -0.050 & & 0.037 & $*$ & 0.011 & \\
\hline 4 & -0.210 & $* * *$ & -0.028 & & -0.011 & & -0.047 & \\
\hline 5 & -0.224 & $* * *$ & -0.013 & & 0.042 & $*$ & 0.052 & $* * *$ \\
\hline 6 & -0.288 & $* * *$ & -0.064 & & -0.029 & & -0.071 & \\
\hline 7 & -0.315 & $* * *$ & -0.028 & & -0.058 & $* *$ & -0.029 & \\
\hline 8 & -0.307 & $* * *$ & 0.008 & & -0.048 & $*$ & 0.010 & \\
\hline 9 & -0.351 & $* * *$ & -0.044 & & -0.133 & $* * *$ & -0.085 & \\
\hline 10 & -0.264 & $* * *$ & 0.087 & $* * *$ & 0.071 & $* * *$ & 0.203 & $* * *$ \\
\hline 11 & -0.322 & $* * *$ & -0.057 & & -0.121 & $* * *$ & -0.191 & \\
\hline 12 & -0.331 & $* * *$ & -0.009 & & -0.108 & $* * *$ & 0.012 & \\
\hline 13 & -0.355 & $* * *$ & -0.024 & & -0.147 & $* * *$ & -0.038 & \\
\hline 14 & -0.343 & $* * *$ & 0.012 & & -0.149 & $* * *$ & -0.002 & \\
\hline 15 & -0.344 & $* * *$ & -0.001 & & -0.085 & $* * *$ & 0.064 & $* * *$ \\
\hline 16 & -0.365 & $* * *$ & -0.021 & & -0.159 & $* * *$ & -0.075 & \\
\hline 17 & -0.384 & $* * *$ & -0.018 & & -0.173 & $* * *$ & -0.014 & \\
\hline 18 & -0.368 & $* * *$ & 0.016 & $* *$ & -0.178 & $* * *$ & -0.005 & \\
\hline 19 & -0.400 & $* * *$ & -0.032 & & -0.222 & $* * *$ & -0.044 & \\
\hline 20 & -0.355 & $* * *$ & 0.045 & $* * *$ & -0.036 & & 0.186 & $* * *$ \\
\hline 21 & -0.404 & $* * *$ & -0.049 & & -0.234 & $* * *$ & -0.198 & \\
\hline 22 & -0.412 & $* * *$ & -0.008 & & -0.256 & $* * *$ & -0.022 & \\
\hline 23 & -0.441 & $* * *$ & -0.029 & & -0.268 & $* * *$ & -0.012 & \\
\hline 24 & -0.484 & $* * *$ & -0.043 & & -0.290 & $* * *$ & -0.022 & \\
\hline 25 & -0.447 & $* * *$ & 0.037 & $* *$ & -0.260 & $* * *$ & 0.030 & $* * *$ \\
\hline 26 & -0.462 & $* * *$ & -0.015 & & -0.356 & $* * *$ & -0.097 & \\
\hline 27 & -0.510 & $* * *$ & -0.048 & & -0.341 & $* * *$ & 0.016 & \\
\hline 28 & -0.547 & $* * *$ & -0.037 & & -0.406 & $* * *$ & -0.065 & \\
\hline
\end{tabular}

Note: The null hypothesis for column (2) and (4) are the difference is greater than 0.

$* * * p<0.01$

$* * p<0.05$

$* p<0.1$ 
Table 3-4 Cohort Size by Ethnicity (Continue)

\begin{tabular}{|c|c|c|c|c|c|c|c|c|}
\hline \multirow{3}{*}{$\begin{array}{c}\text { In(Pop) } \\
\text { ysm } \\
2\end{array}$} & \multicolumn{4}{|c|}{ EU/OC } & \multicolumn{4}{|c|}{ Other } \\
\hline & \multicolumn{2}{|c|}{$\begin{array}{l}\text { coefficient } \\
\text { (1) }\end{array}$} & \multicolumn{2}{|c|}{$\begin{array}{l}\text { difference } \\
\text { (2) }\end{array}$} & \multicolumn{2}{|c|}{$\begin{array}{l}\text { coefficient } \\
\text { (3) }\end{array}$} & \multicolumn{2}{|c|}{$\begin{array}{c}\text { difference } \\
\text { (4) }\end{array}$} \\
\hline & -0.243 & $* * *$ & -0.243 & & -0.049 & & -0.049 & \\
\hline 3 & -0.328 & $* * *$ & -0.085 & & -0.060 & & -0.011 & \\
\hline 4 & -0.405 & $* * *$ & -0.077 & & -0.036 & & 0.024 & \\
\hline 5 & -0.451 & $* * *$ & -0.047 & & -0.088 & $* *$ & -0.051 & \\
\hline 6 & -0.495 & $* * *$ & -0.044 & & -0.108 & $* * *$ & -0.020 & \\
\hline 7 & -0.547 & $* * *$ & -0.052 & & -0.124 & $* * *$ & -0.016 & \\
\hline 8 & -0.545 & $* * *$ & 0.002 & & -0.093 & $* * *$ & 0.031 & \\
\hline 9 & -0.587 & $* * *$ & -0.042 & & -0.146 & $* * *$ & -0.053 & \\
\hline 10 & -0.507 & $* * *$ & 0.080 & $* * *$ & -0.046 & & 0.100 & $* * *$ \\
\hline 11 & -0.598 & $* * *$ & -0.090 & & -0.147 & $* * *$ & -0.101 & \\
\hline 12 & -0.609 & $* * *$ & -0.012 & & -0.135 & $* * *$ & 0.012 & \\
\hline 13 & -0.639 & $* * *$ & -0.030 & & -0.138 & $* * *$ & -0.003 & \\
\hline 14 & -0.653 & $* * *$ & -0.014 & & -0.155 & $* * *$ & -0.017 & \\
\hline 15 & -0.616 & $* * *$ & 0.037 & $* *$ & -0.148 & $* * *$ & 0.007 & \\
\hline 16 & -0.664 & $* * *$ & -0.048 & & -0.173 & $* * *$ & -0.025 & \\
\hline 17 & -0.693 & $* * *$ & -0.029 & & -0.151 & $* * *$ & 0.022 & \\
\hline 18 & -0.698 & $* * *$ & -0.005 & & -0.180 & $* * *$ & -0.029 & \\
\hline 19 & -0.733 & $* * *$ & -0.035 & & -0.235 & $* * *$ & -0.055 & \\
\hline 20 & -0.671 & $* * *$ & 0.062 & $* * *$ & -0.143 & $* * *$ & 0.092 & $* * *$ \\
\hline 21 & -0.756 & $* * *$ & -0.085 & & -0.196 & $* * *$ & -0.054 & \\
\hline 22 & -0.788 & $* * *$ & -0.031 & & -0.255 & $* * *$ & -0.058 & \\
\hline 23 & -0.803 & $* * *$ & -0.015 & & -0.256 & $* * *$ & -0.002 & \\
\hline 24 & -0.817 & $* * *$ & -0.014 & & -0.273 & $* * *$ & -0.016 & \\
\hline 25 & -0.818 & $* * *$ & -0.001 & & -0.223 & $* * *$ & 0.050 & \\
\hline 26 & -0.822 & $* * *$ & -0.004 & & -0.295 & $* * *$ & -0.073 & \\
\hline 27 & -0.835 & $* * *$ & -0.013 & & -0.155 & $* *$ & 0.140 & $* *$ \\
\hline 28 & -0.908 & $* * *$ & -0.073 & & -0.195 & $* * *$ & -0.040 & \\
\hline $\begin{array}{l}\text { Note: The } r \\
\text { than } 0 . \\
* * * p<0.01 \\
* * p<0.05 \\
* p<0.1\end{array}$ & \multicolumn{7}{|c|}{$\begin{array}{l}\text { Note: The null hypothesis for column (2) and (4) are the difference is greater } \\
\text { than } 0 \text {. }\end{array}$} & ter \\
\hline
\end{tabular}


Figure 3-6 Year Since Migration Fixed Effect by Race Group

Year Since Migration Fixed Effect

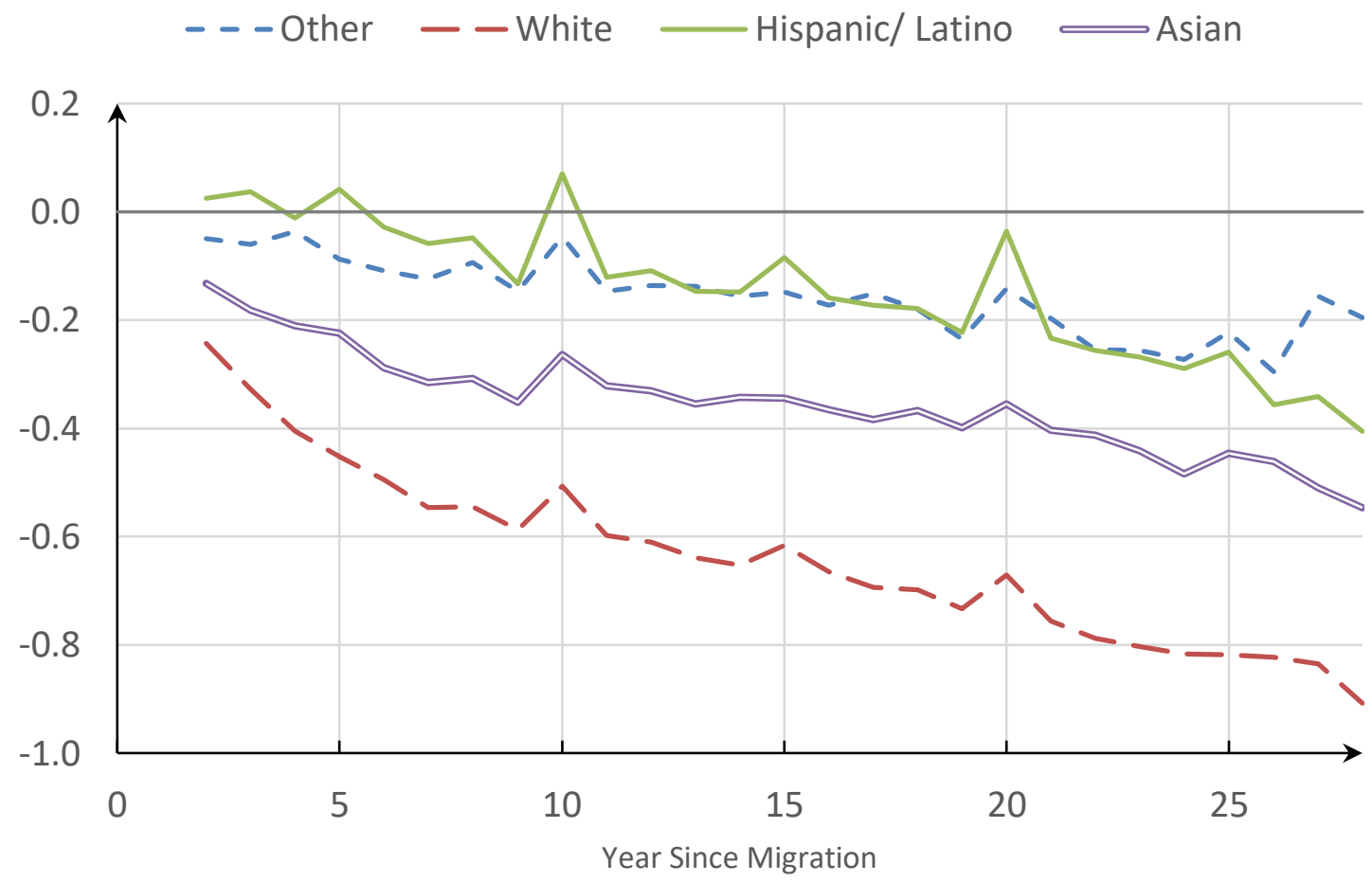

Hispanic and Latino immigrants show greater spikes in the $10^{\text {th }}$ year compared to immigrants from other places. They are also the largest source of immigrants. The decomposition of the observation increases by Hispanic origin in the $10^{\text {th }}$ year is in Table $3-5$. Only cohorts with both the $9^{\text {th }}$ year and $10^{\text {th }}$ year observed are included. The first two columns show the total population in the $9^{\text {th }}$ and $10^{\text {th }}$ year since the arrival across observed years. The third column lists the difference between the $9^{\text {th }}$ and $10^{\text {th }}$ year. The fourth column shows the increase in percentage using year 9 as the base. The last column shows the fraction of the increase of a single ethnic group to the total increase.

Both Hispanic and non-Hispanic immigrants are larger in year 10. With thirteen cohorts included, the total increase is 2.4 million, over 185,000 increase per cohort. Hispanic and Latino counts for 48 percent to 52 percent of observations, 
while 72 percent of increase is due to Hispanic and Latino. On average, nonHispanic immigrants increased by almost 9 percent between year 9 and year 10 . Hispanic and Latino immigrants increase by almost 24 percent. That is, the Hispanic and Latino groups increased by almost 3 folds compares to non-Hispanic group.

Table 3-5 The 10-Year Puzzle by Hispanic Group

\begin{tabular}{r|cc|ccc}
\hline $\begin{array}{r}\text { Estimated } \\
\text { Population }\end{array}$ & Year 9 & Year 10 & Increase & $\begin{array}{c}\text { Fraction } \\
\text { Increase }\end{array}$ & $\begin{array}{c}\text { Fraction } \\
\text { to Total } \\
\text { Change }\end{array}$ \\
\hline $\begin{array}{r}\text { Not Hispanic } \\
\text { Hispanic/Latino }\end{array}$ & $7,597,228$ & $8,270,644$ & 673,416 & $8.9 \%$ & $28.0 \%$ \\
Mexican & $4,462,972$ & $5,639,730$ & $1,176,758$ & $26.4 \%$ & $48.9 \%$ \\
Puerto Rican & 19,053 & 26,179 & 7,126 & $37.4 \%$ & $0.3 \%$ \\
Cuban & 356,014 & 415,027 & 59,013 & $16.6 \%$ & $2.5 \%$ \\
Other & $2,440,285$ & $2,930,006$ & 489,721 & $20.1 \%$ & $20.4 \%$ \\
\cline { 2 - 6 } HL Total & $7,278,324$ & $9,010,942$ & $1,732,618$ & $23.8 \%$ & $72.0 \%$ \\
\hline Total & $14,875,552$ & $17,281,586$ & $2,406,034$ & $16.2 \%$ & \\
HL Share & $48.9 \%$ & $52.1 \%$ & $72.0 \%$ & & \\
\hline
\end{tabular}

\subsubsection{Legal Status}

From the last section, immigrants from Hispanic and Latino countries have bigger spikes at the 10th year. The question is what difference across ethnic groups can explain the 10-year puzzle?

Immigrants from countries to the south of the U.S-Mexico border count for the biggest share of new immigrants to the U.S. More than 60 percent of this group are Mexican immigrants. A report from MPI shows that immigrants from Mexico count for 24 percent of the 45 million U.S. immigrant population (Israel and Batalova 2020). At the same time, a report from Pew Research Center shows that legal immigrants from Mexico have the lowest naturalization rate. As a result, there 
are relatively more Hispanic and Latino legal permanent residents than for any other group.

Legal permanent residents (LPR), also referred as green card holders, are aliens who have been granted "the status of having been lawfully accorded the privilege of residing permanently in the United States as an immigrant in accordance with the immigration laws, such status not having changed." Compared to non-LPRs, an LPR has two essential rights - the right to work in the U.S. and the right to become a U.S. citizen after meeting certain criteria.

LPRs can travel without restrictions as can U.S. citizens but with two requirements. First, they must meet the "continuous residence" requirement. This requirement means that a green card holder keeps the U.S. as the main home, which requires spending more nights in the U.S. in a year than abroad. Violation of this rule is not sufficient for immediate loss of the green card but will be sufficient for scrutiny by a U.S. Customs and Border Protection (CBP) officer. Second, the card cannot be expired upon arrival. Even though the LPR status does not expire with the green card, attempt to re-enter with an expired card may lead to refused entry, and at a minimum usually requires a potentially expensive and time-consuming renewal process.

The renewal cycle of green cards is ten years, coinciding with the 10-year puzzle. However, only immigrants who initially arrived in the U.S. as LPRs will cause the 10-year puzzle. Some of green card holders, for example students, arrived with non-immigration visas and get green cards later. For them, the green card issuance year is later than the initial migration year. As a result, their renewal year will be more than 10 years after arrival. 
Considering the relationship between the 10-year puzzle and the green card renewal has two reasons. First, the decomposition in section III shows that the majority of increase in population estimate at 10 -year intervals is due to increases in the number of observations. Green card renewal gives LPRs incentives to be present in the U.S., increasing the number of observations captured by the ACS. Second, as shown in Figure 3-7, the average number of immigrants who arrived in the U.S. with newly issued green cards is higher than 400,000 per cohort. The red bar shows the size of the 10-year puzzle for cohorts arriving in years 1997 to 2009 . The median time a naturalized immigrant spent in LPR status is 8 years ${ }^{23}$. It is plausible that roughly 200,000 LPRs need to renew their green cards in the $10^{\text {th }}$ year. Obviously, not all green card holders travel so frequently abroad that they can only be captured when they are back to renew their green cards. Many of them will spend most of time in U.S., meaning this scenario cannot explain the 10-year puzzle by itself. We provide an estimate of how much this scenario contributes to the puzzle.

Testing whether LPRs contribute to the 10-year puzzle requires the identification of immigration status, which is not offered by the ACS. This paper uses Borjas' (2017) method to identify legal immigrants. Immigrants who meet any of the following criteria are estimated to be legal immigrants:

a) that person arrived before 1980;

b) that person is a citizen;

c) that person receives Social Security benefits, SSI, Medicaid, Medicare, or Military Insurance;

\footnotetext{
${ }^{23}$ See Annual Flow Report: U.S. Naturalizations https://www.dhs.gov/immigrationstatistics/naturalizations
} 
d) that person is a veteran, or is currently in the Armed Forces;

e) that person works in the government sector;

f) that person resides in public housing or receives rental subsidies, or that person is a spouse of someone who resides in public housing or receives rental subsidies;

g) that person was born in Cuba (as practically all Cuban immigrants are granted refugee status);

h) that person's occupation requires some form of licensing (such as physicians, registered nurses, air traffic controllers, or lawyers);

i) that person's spouse is a legal immigrant or citizen.

\section{- $\quad$ List from Borjas (2017), Page 9}

Criteria (f) cannot be identified in our analysis as the public use microdata sample (PUMS) cannot be linked with the U.S. Department of Housing and Urban Development (HUD) administrative data. ${ }^{24}$ Borjas applied this method using the CPS data. Immigrants who meet none of above criteria are categorized as "undocumented immigrants." In this paper, we referred to the Borjas' "undocumented" group as "potential" undocumented immigrants, reflecting the fact that the measure is only a proxy. In the analysis that follows, data from ACS 2006 and 2007 are dropped as insurance data used for item (c) above are not available for those years. Legal immigrants who met the criteria are separated into two groups

\footnotetext{
${ }^{24}$ For more information about how to identify subsidized housing units with the ACS, see Molfino (Molfino n.d.)
} 
based on their self-reported naturalization status in the ACS - naturalized immigrant and non-naturalized legal immigrant.

Figure 3-7 The $10^{\text {th }}$ Year Population Growth with Population Arrived with Green Cards by Year of Arrival

\section{Cohort Initial New Arrivals Legal Permanent Residents} With 10-Year Puzzle Size

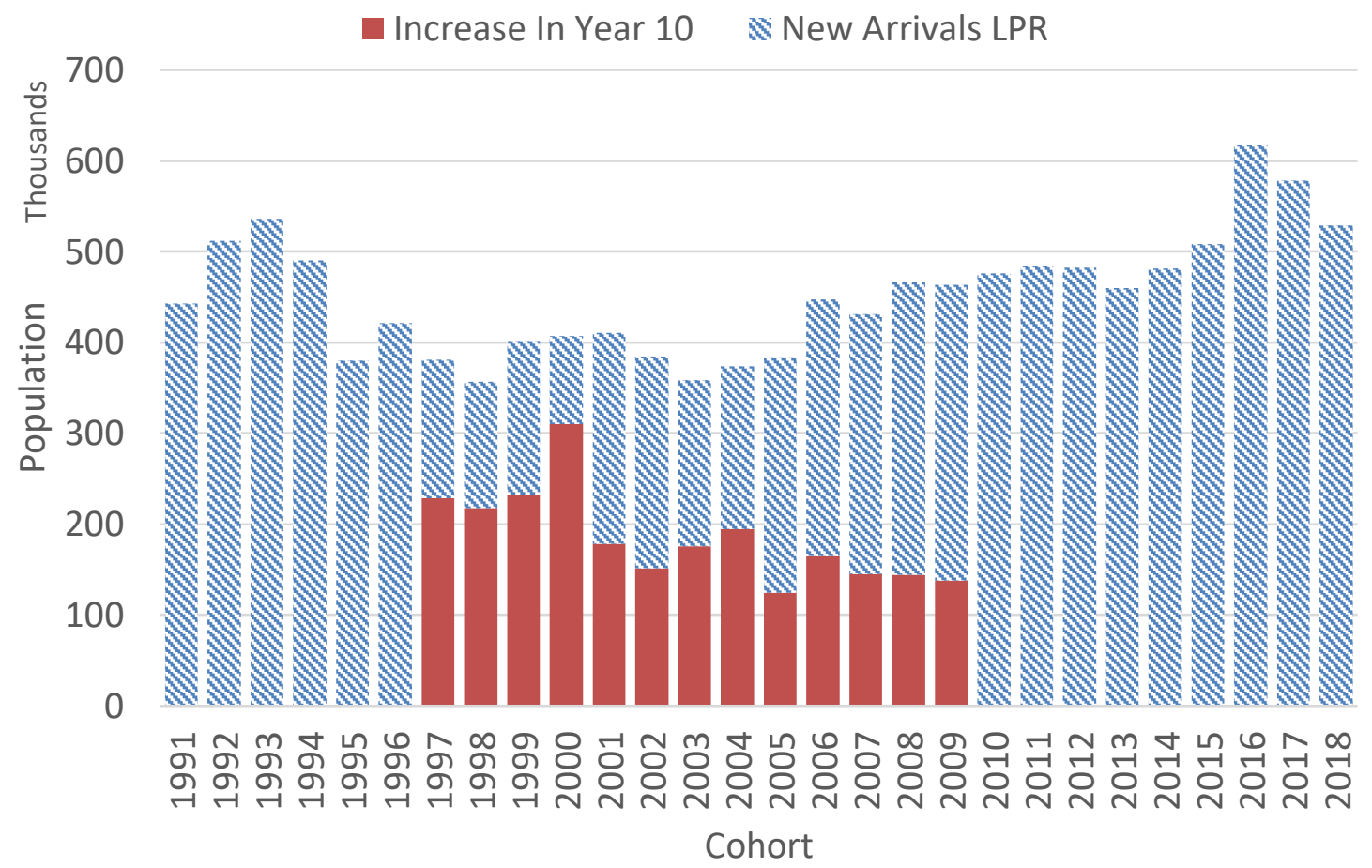

Table 3-4 shows the regression result for the potential undocumented group and the non-naturalized legal immigrant group. Columns 1 and 3 show the estimated coefficients. Columns 2 and 4 show the difference between a coefficient and the previous one. The asterisks in columns 2 and 4 represent statistical significance of the difference. Both groups are decreasing by years since migration. The 10-year puzzle exists for both groups. If Borjas' method does not leave too many LPRs in the undocumented category, the findings do not support the argument that the 10year puzzle is caused by LPRs. 
Table 3-6 Cohort Size by Immigration Status

\begin{tabular}{|c|c|c|c|c|c|c|c|c|}
\hline \multirow{3}{*}{$\frac{\text { In(Pop) }}{\text { years_in_us }}$} & \multicolumn{4}{|c|}{ Potential Undocumented } & \multicolumn{4}{|c|}{ Legal, Not Naturalized } \\
\hline & \multicolumn{2}{|c|}{ Coefficient } & \multicolumn{2}{|c|}{ Difference } & \multicolumn{2}{|c|}{ Coefficient } & \multicolumn{2}{|c|}{ Difference } \\
\hline & -0.161 & $* * *$ & -0.161 & & -0.036 & $* *$ & -0.036 & \\
\hline 3 & -0.236 & $* * *$ & -0.075 & & -0.028 & & 0.009 & \\
\hline 4 & -0.328 & $* * *$ & -0.092 & & -0.049 & & -0.021 & \\
\hline 5 & -0.372 & $* * *$ & -0.044 & & -0.051 & $*$ & -0.002 & \\
\hline 6 & -0.539 & $* * *$ & -0.168 & & -0.167 & $* * *$ & -0.116 & \\
\hline 7 & -0.675 & $* * *$ & -0.136 & & -0.264 & $* * *$ & -0.097 & \\
\hline 8 & -0.747 & $* * *$ & -0.072 & & -0.284 & $* * *$ & -0.020 & \\
\hline 9 & -0.886 & $* * *$ & -0.139 & & -0.377 & $* * *$ & -0.093 & \\
\hline 10 & -0.772 & $* * *$ & 0.113 & $* * *$ & -0.239 & $* * *$ & 0.138 & $* * *$ \\
\hline 11 & -0.996 & $* * *$ & -0.224 & & -0.384 & $* * *$ & -0.146 & \\
\hline 12 & -1.041 & $* * *$ & -0.045 & & -0.391 & $* * *$ & -0.007 & \\
\hline 13 & -1.143 & $* * *$ & -0.101 & & -0.437 & $* * *$ & -0.046 & \\
\hline 14 & -1.211 & $* * *$ & -0.068 & & -0.440 & $* * *$ & -0.003 & \\
\hline 15 & -1.210 & $* * *$ & 0.001 & & -0.402 & $* * *$ & 0.038 & $*$ \\
\hline 16 & -1.343 & $* * *$ & -0.132 & & -0.467 & $* * *$ & -0.065 & \\
\hline 17 & -1.422 & $* * *$ & -0.080 & & -0.515 & $* * *$ & -0.048 & \\
\hline 18 & -1.474 & $* * *$ & -0.052 & & -0.515 & $* * *$ & 0.001 & \\
\hline 19 & -1.583 & $* * *$ & -0.108 & & -0.578 & $* * *$ & -0.063 & \\
\hline 20 & -1.446 & $* * *$ & 0.137 & $* * *$ & -0.418 & $* * *$ & 0.160 & $* * *$ \\
\hline 21 & -1.713 & $* * *$ & -0.267 & & -0.601 & $* * *$ & -0.184 & \\
\hline 22 & -1.800 & $* * *$ & -0.087 & & -0.621 & $* * *$ & -0.019 & \\
\hline 23 & -1.907 & $* * *$ & -0.107 & & -0.617 & $* * *$ & 0.004 & \\
\hline 24 & -1.982 & $* * *$ & -0.075 & & -0.651 & $* * *$ & -0.034 & \\
\hline 25 & -2.025 & $* * *$ & -0.043 & & -0.632 & $* * *$ & 0.018 & $*$ \\
\hline 26 & -2.157 & $* * *$ & -0.132 & & -0.741 & $* * *$ & -0.109 & \\
\hline 27 & -2.230 & $* * *$ & -0.073 & & -0.739 & $* * *$ & 0.002 & \\
\hline 28 & -2.405 & $* * *$ & -0.176 & & -0.828 & $* * *$ & -0.089 & \\
\hline
\end{tabular}

Table 3-7 shows the regression results for naturalized immigrants. Unlike the other two groups, the years since migration fixed effect is increasing as more immigrants naturalize. At the same time, the increasing speed decreases as most immigrants will naturalize after 10 to 15 years in the U.S. To identify the abnormal increase in an increasing trend, this analysis uses three different tests. Test 1 linearly extrapolates backward using estimated coefficients in the following two years. Test 2 examines if the coefficient in the following year is smaller than the current one. Test 3 reverses the extrapolation in test 1 using estimates from the previous two years. The null hypothesis is that the current year fixed effect is lower than that for 
the comparison group. The asterisks in the table show whether we can reject the null hypothesis and at what level. When the population is increasing and concave down, both test 1 and test 2 are more strict than test 3 .

The 10 -year puzzle, especially for the $20^{\text {th }}$ year, is still obvious for naturalized group. A naturalized citizen has no incentive to be in the U.S. in the $10^{\text {th }}$ year than in the prior or subsequent year. 
Table 3-7 Cohort Size of Naturalized Immigrants

\begin{tabular}{|c|c|c|c|c|c|c|}
\hline \multirow{3}{*}{$\frac{\text { In(Pop) }}{\text { years_in_us }}$} & \multicolumn{6}{|c|}{ Naturalized } \\
\hline & \multicolumn{2}{|c|}{ Coefficient } & \multirow{2}{*}{$\begin{array}{l}\text { Diff. } \\
0.559\end{array}$} & \multirow[t]{3}{*}{ Test 1} & \multirow[t]{3}{*}{ Test 2} & \multirow{2}{*}{$\begin{array}{l}\text { Test } 3 \\
-\end{array}$} \\
\hline & 0.559 & $* * *$ & & & & \\
\hline 3 & 0.651 & $* * *$ & 0.092 & & & - \\
\hline 4 & 0.860 & $* * *$ & 0.209 & $*$ & & \\
\hline 5 & 1.175 & $* * *$ & 0.315 & & & \\
\hline 6 & 1.618 & $* * *$ & 0.443 & & & $*$ \\
\hline 7 & 1.853 & $* * *$ & 0.234 & & & \\
\hline 8 & 2.046 & $* * *$ & 0.194 & $* * *$ & & \\
\hline 9 & 2.144 & $* * *$ & 0.097 & & & \\
\hline 10 & 2.347 & $* * *$ & 0.204 & $* *$ & & $* * *$ \\
\hline 11 & 2.387 & $* * *$ & 0.039 & & & \\
\hline 12 & 2.465 & $* * *$ & 0.078 & & & $* *$ \\
\hline 13 & 2.529 & $* * *$ & 0.064 & & & \\
\hline 14 & 2.599 & $* * *$ & 0.070 & & & \\
\hline 15 & 2.686 & $* * *$ & 0.087 & $*$ & & \\
\hline 16 & 2.710 & $* * *$ & 0.024 & & & \\
\hline 17 & 2.758 & $* * *$ & 0.048 & & & $*$ \\
\hline 18 & 2.789 & $* * *$ & 0.031 & $* * *$ & & \\
\hline 19 & 2.799 & $* * *$ & 0.010 & & & \\
\hline 20 & 2.906 & $* * *$ & 0.107 & $* * *$ & $* * *$ & $* * *$ \\
\hline 21 & 2.848 & $* * *$ & -0.058 & & & \\
\hline 22 & 2.856 & $* * *$ & 0.008 & & & $* * *$ \\
\hline 23 & 2.871 & $* * *$ & 0.015 & $* *$ & & \\
\hline 24 & 2.866 & $* * *$ & -0.005 & & & \\
\hline 25 & 2.920 & $* * *$ & 0.054 & $* *$ & $* * *$ & $* *$ \\
\hline 26 & 2.896 & $* * *$ & -0.024 & & & \\
\hline 27 & 2.910 & $* * *$ & 0.014 & - & $*$ & $* *$ \\
\hline 28 & 2.887 & $* * *$ & -0.023 & - & - & \\
\hline
\end{tabular}

Test $1 \mathrm{HO}: \mathrm{YO}<2 * \mathrm{Y} 1-\mathrm{Y} 2$

Test $2 \mathrm{HO}: \mathrm{YO}<\mathrm{Y} 1$

Test 3 HO: $Y 0<2 * Y(-1)-Y(-2)$

$*$ rejected at 0.1

** rejected at 0.05

$* * *$ rejected at 0.1

\subsection{Conclusion}

This paper finds unexplained spikes in immigrant cohort populations based on combining ACS in successive survey years. We have ruled out some explanations such as differences in the birthplace or legal status for the 10-year puzzle. Without proper explanation and adjustment, the ACS cannot provide an 
accurate estimate for the population of a single cohort. The existence of the 10-year puzzle indicates that a structural change in the survey or weights may alter the estimate in the $10^{\text {th }}$ year. Unfortunately, this paper does not pin down what the structural change is.

At the same time, this paper put together some evidence regarding the structural break. First, the number of observations for the same cohort increases between the $9^{\text {th }}$ and the $10^{\text {th }}$ year and Hispanic immigrants count for almost three quarters of the increase. Second, characteristics other than birthplace and immigration status are responsible to the increase. 


\section{Bibliography}

Abadie, Alberto, Alexis Diamond, and Jens Hainmueller. 2010. "Synthetic control methods for comparative case studies: Estimating the effect of California's tobacco control program." Journal of the American statistical Association 105 (490): 493505 .

Abramitzky, Ran, and Leah Boustan. 2017. "Immigration in American Economic History." Journal of Economic Literature 55 (4): 1311-45.

Abramitzky, Ran, Leah Platt Boustan, and Katherine Eriksson. 2014. "A Nation of Immigrants: Assimilation and Economic Outcomes in the Age of Mass Migration." Journal of Political Economy 122 (3): 467-506.

Ahmed, Bashir, and Gregory J. Robinson. 1994. "Estimates of Emigration of the Foreign-Born Population: 1980-1990." U.S. Bureau of the Census Population Division Working Paper 9.

Altonji, Joseph, and David Card. 1989. "The Effects of Immigration on the Labor Market Outcomes of Natives." National Bureau of Economic Research (No. w3123).

Angrist, Joshua D., and Jorn-Steffen Pischke. 2009. Mostly harmless econometrics. New Jersey: Princeton Universtiy Press.

Ayres, Ian, and John J. Donohue III. 2002. "Shooting down the more guns, less crime hypothesis." National Bureau of Economic Research (No. w9336).

Ayres, Ian, and John J. Donohue III. 2003. "The latest misfires in support of the" more guns, less crime" hypothesis." Stanford Law Review 1371-1398.

Beaujot, Roderic, and Peter J. Rappak. 1989. "The Link Between Immigration and Emigration in Canada, 1945-1986." Canadian Studies in Population 16 (2): 201216.

Berkowitz, Bonnie, and Chris Alcantara. 2020. The terrible numbers that grow with each mass shooting. March 15. https://www.washingtonpost.com /graphics/2018/national/mass-shootings-in-america/.

Black, Dan A., and Daniel S. Nagin. 1998. "Do right-to-carry laws deter violent crime?" The Journal of Legal Studies 27 (1): 209-219.

Bleakley, Hoyt, and Aimee Chin. 2010. "Age at Arrival, English Proficiency, and Social Assimilation among U.S. Immigrants." American Economic Journal: Applied Economics 2 (1): 165-92.

Borjas, George J. 1985. "Assimilation, Changes in Cohort Quality, and the Earnings of Immigrants." Journal of Labor Economics 3 (4): 463-89.

Borjas, George J. 2017. "The earnings of undocumented immigrants." National Bureau of Economic Research (No. w23236).

Borjas, George J., and Bernt Bratsberg. 1994. "Who leaves? The outmigration of the foreign-born." National Bureau of Economic Research No. w4913. 
Borjas, George J., and Bernt Bratsberg. 1994. "Who leaves? The outmigration of the foreign-born." National Bureau of Economic Research (No. w4913).

Borjas, George J., and Bernt Bratsberg. 1996. "Who Leaves? The Outmigration of the Foreign-Born." The Review of Economics and Statistics 78 (1): 165-76.

Borjas, J. George. 1987. "Self-Selection and the Earnings of Immigrants." American Economic Review 77: 531-553.

Card, David. 2001. "Immigrant Inflows, Native Outflows, and the Local Market Impacts of Higher Immigration." Journal of Labor Economics 19 (1): 22-64.

Cheung, Benjamin Y., Maciej Chudek, and Steven J. Heine. 2011. "Evidence for a Sensitive Period for Acculturation: Younger Immigrants Report Acculturating at a Faster Rate." Psychological Science 22 (2): 147-52.

Chiquiar, Daniel, and Gordon H. Hanson. 2005. "International Migration, Selfselection, and the Distribution of Wages: Evidence from Mexico and the United States." Journal of Political Economy 113 (2): 239-281.

Chiswick, Barry R. 1978. "The Effect of Americanization on the Earnings of Foreign-Born Men." Journal of Political Economy 86 (5): 897-921.

Chiswick, Barry R., and Paul W. Miller. 2004. "Where Immigrants Settle In the United States." Journal of Comparative Policy Analysis: Research and Practice (6.2): 185-197.

Constant, Amelie, and Douglas S. Massey. 2003. "Self-Selection, Earnings, and Out-Migration: A Longitudinal Study of Immigrants to Germany." Journal of Population Economics 16 (4): 631-53.

Cook, Philip J., and James A. Leitzel. 1996. "Perversity, Futility, Jeopardy: An Economic Analysis fo the Attack on Gun Control." Law \& Contemp. Probs (59): 91.

Cook, Philip J., and Jens Ludwig. 2000. Gun violence: The real costs. Oxford University Press on Demand.

-. 1997. Guns in America: national survey on private ownership and use of firearms. US Department of Justice, Office of Justice Programs, National Institute of Justice.

Cook, Philip J., and Jens Ludwig. 2006. "The social costs of gun ownership." Journal of Public Economics 90 (1-2): 379-391.

Cook, Philip J., Stephanie Molliconi, and Thomas B. Cole. 1995. "Regulating gun markets." J. Crim. L. \& Criminology 86 (59).

Cunha, Flavio, James Heckman, and Salvador Navarro. 2005. "Separating uncertainty from heterogeneity in life cycle earnings." oxford Economic papers 57 (2): 191-261. 
Doudchenko, Nikolay, and Guido W. Imbens. 2016. "Balancing, regression, difference-in-differences and synthetic control methods: A synthesis." National Bureau of Economic Research (No. w22791).

Duggan, Mark. 2001. "More guns, more crime." Journal of political Economy 109 (5): 1086-1114.

Duleep, Harriet Orcutt, and Daniel J. Dowhan. 2002. "Insights from Longitudinal Data on the Earnings Growth of U.S. Foreign-Born Men." Demography 39 (3): 485506.

Dustmann, Christian, Itzhak Fadlon, and Yoram Weiss. 2011. "Return Migration, Human Capital Accumulation and the Brain Drain." Journal of Development Economics 95 (1): 58-67.

Edin, Per-Anders, Peter Fredriksson, and Olof Aslund. 2003. "Ethnic Enclaves and the Economic Success of Immigrants Evidence from a Natural Experiment." Quarterly Journal of Economics 118 (1): 329-57.

Edin, Per-Anders, Robert J. LaLonde, and Olof Aslund. 2000. "Emigration of Immigrants and Measures of Immigrant Assimilation: Evidence from Sweden." Working Paper.

Feliciano, Cynthia. 2005. "Educational Selectivity in U.S. Immigration: How Do Immigrants Compare to Those Left Behind?" Demography 42 (1): 131-152.

Gonzalex-Barrera, Ana. 2017. Mexican Lawful Immigrants Among the Least Likely to Become U.S. Citizens. Pew Research Center. Accessed June.

Harlow, Caroline Wolf. 2002. Firearm use by offenders. US Department of Justice, Office of Justice Programs, Bureau of Justice Statistics.

Hess, Ursula, Sylvie Blairy, and Robert E. Kleck. 1997. "The intensity of emotional facial expressions and decoding accuracy." Journal of Nonverbal Behavior 21 (4): 241-257.

$\mathrm{Hu}$, Wei-Yin. 2000. "Immigrant Earnings Assimilation: Estimates from Longitudinal Data." American Economic Review 368-372.

Israel, Emma, and Jeanne Batalova. 2020. "Mexican Immigrants in the United States." Migration Policy Institute. November 5. Accessed March 23, 2021. https://www.migrationpolicy.org/article/mexican-immigrants-united-states-2019.

Kalesan, Bindu, Marcos D. Villarreal, Katherine M. Keyes, and Sandro Galea. 2016. "Gun ownership and social gun culture." Injury prevention." Injury prevention 22 (3): $216-220$.

Kim, Seik. 2009. "Economic Assimilation of Foreign Born Workers in the United States: An Overlapping Rotating Panel Analysis." No. UWEC-2008-19.

Knight, Brian. 2013. "State gun policy and cross-state externalities: Evidence from crime gun tracing." American Economic Journal: Economic Policy 5 (4): 200-229. 
Lenneberg, Eric H. 1967. The Biological Foundations of Language. Vol. 2. 12 vols. Hospital Practice.

Lott, John R. 1998. More guns, less crime. University of Chicago Press.

Lubotsky, Darren. 2007. "Chutes and Ladders? A Longitudinal Analysis of Immigrant Earnings." Journal of Political Economy 115 (5): 820-67.

Lubotsky, Darren. 2011. "The Effect of Changes in the U.S. Wage Structure on Recent Immigrants' Earnings." The Review of Economics and Statistics 93 (1): 5971.

Ludwig, Jens, and Philip J. Cook. 2001. "The benefits of reducing gun violence: Evidence from contingent-valuation survey data." Journal of risk and Uncertainty 22 (3): 207-226.

Mincer, Jacob. 1958. "Investment in Human Capital and Personal Income Distribution." Journal of Political Economy 66 (4): 281-302.

Molfino, Emily. n.d. "Identifying Subsidized Housing Units Within the American Community Survey Through Administrative Record Linkage: A Technical Report."

National Research Council. 2005. Firearms and violence: a critical review. National Academies Press.

Noe-Bustamante, Luis, Antonio Flores, and Sono Shah. 2019. Facts on Hispanics of Mexican origin in the United States, 2017. September 16. https://www.pewresearch.org/hispanic/fact-sheet/u-s-hispanics-facts-on-mexicanorigin-latinos/.

Passel, Jeffrey S. 2019. "Measuring illegal immigration: How Pew Research Center counts unauthorized immigrants in the U.S." Pew Research Center. Accessed 0401 , 2021. https://www.pewresearch.org/fact-tank/2019/07/12/how-pew-researchcenter-counts-unauthorized-immigrants-in-us/.

Plassmann, Florenz, and John Whitley. 2003. "Confirming" more guns, less crime"." Stanford Law Review 1313-1369.

Plassmann, Florenz, and T. Nicolaus Tideman. 2001. "Does the right to carry concealed handguns deter countable crimes? Only a count analysis can say." The Journal of Law and Economics 44 (S2): 771-798.

Qian, Zhenchao, and Daniel Lichter. 2007. "Social Boundaries and Marital Assimilation: Interpreting Trends in Racial and Ethnic Intermarriage." American Sociological Review 72 (1): 68-94.

Raissian, Kerri M. 2016. "Hold your fire: Did the 1996 Federal Gun Control Act expansion reduce domestic homicides?" Journal of Policy Analysis and Management 35 (1): 67-93.

Roy, Andrew Donald. 1951. "Some Thoughts on the Distribution of Earnings." Oxford Economic Papers 3 (2): 135-146. 
Ruggles, Steven, Sarah Flood, Ronald Goeken, Josiah Grover, Erin Meyer, Jose Pacas, and Mattew Sobek. n.d. IPUMS USA: Version 9.0[dataset]. Minneapolis, MN: IPUMS, 2019. Accessed 2019. https://doi.org/10.18128/D010.V9.0.

U.S. Census Bureau. 2020. "Methodology for the United States Population Estimates: Vintage 2019." March. Accessed March 30, 2021. https://www2.census.gov/programs-surveys/popest/technicaldocumentation/methodology/2010-2019/natstcopr-methv2.pdf.

U.S. Census Bureau. n.d. "U.S. Census Bureau Strategic Plan." Accessed 03 31, 2021. https://www.census.gov/about/budget.html.

United States Census Bureau. 2020. "Design and Methodology Report." July 2. Accessed Jan 18, 2021. https://www.census.gov/programssurveys/acs/methodology/design-and-methodology.html.

—. 2020. "Methodology." United States Census Bureau. December 22. Accessed January 18, 2021. https://www.census.gov/programs-surveys/popest/technicaldocumentation/methodology.html.

Waters, Mary C, and Tomas R Jimenez. 2005. "Assessing Immigrant Assimilation: New Empirical and Theoretical Challenges." Annual Review of Sociology 31 (1): 105-125. doi:10.1146/annurev.soc.29.010202.100026.

Zimring, Franklin E. 1968. "Games with guns and statistics." Wis. L. Rev. 1113.

Zimring, Franklin E. 1972. "The medium is the message: Firearm caliber as a determinant of death from assault." The Journal of Legal Studies 1 (1): 97-123. 


\section{VITA}

Zhiyang You was born in Beijing, China, on April 25, 1990. He is currently a Ph.D. candidate at the University of Missouri-Columbia. Zhiyang wants to be a person who has a net positive effect on this wonderful world.

Zhiyang's parents, Zhoumi You and Jing Yang, are both college professors teaching Computer Science. Along with his grandparents, Zhendong You and Chaofan Zhou, who are also scholars, Zhiyang was raised in the China University of Geosciences, Beijing. He enjoyed riding his small red bicycle to play basketball on the campus. He went to the elementary school and middle school attached to the university. Zhiyang also received his English name, David, since the pronunciation of "David" in Mandarin is the same as "big stomach," indicating how delightful food was to Zhiyang as a kid.

In middle school, Zhiyang met with his favorite teacher, Ms. Yaohong Jia. She was the most responsible and hard-working educator he has ever met. Zhiyang graduated second place in his grade with the help and guidance of Ms. Jia and her fellow teachers. He also started playing billiard, taekwondo, basketball, and many other sports.

Zhiyang went to the 2nd High School Attached to Beijing Normal University from 2005 to 2008 . He was the bottom student in the class. He observed that people smarter than him also worked harder than him. Zhiyang tried to catch up with his outstanding classmates but never succeed. He learned to be optimistic and learned many significant characteristics. He became a self-taught opera singer who practiced daily on the balcony. He wants to apologize to his old neighbors. 
Zhiyang went to the University of North Alabama with the greatest support from his parents. He started with Physics and Management and ended with Economics and Accounting. He met with Mr. David Black, who believed Zhiyang was a "thinker" and guided him into the great field of Economics. Zhiyang enjoyed his life in Florence, Alabama. He made many friends by playing computer games, kayaking, and many other activities. Zhiyang went to California for one year and worked for multiple companies and individuals with little success.

Zhiyang went to the University of Missouri-Columbia to study Economics in graduate school. He struggled with the coursework and caught up slowly with the help of Simon and Yang. Zhiyang barely passed the qualify and comprehensive exams. He was lucky to find the best advisor, Dr. Peter Mueser, who patiently guided Zhiyang to conduct research and learn new knowledge. Zhiyang had a hard time focusing on a single subject. There are many interesting topics in the world of Economics. He wrote three papers when searching for his best interest and ended up with labor economics.

Zhiyang met his amazing wife, Jingqi, in 2018 and had his first baby boy, Lucas, in 2019. Zhiyang is thankful for his wife's contribution and support. 